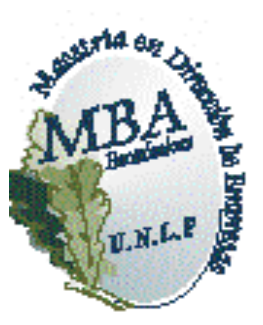

Universidad Nacional de La Plata

Facultad de Ciencias Económicas

MBA - Maestría en Dirección de Empresas

\title{
Análisis de eficiencia municipal: La Municipalidad de La Plata
}

Trabajo final para optar al título de Magister

Autor: Cra. Analía Viviana Bellido

Director:Dr. Daniel Alberto Lauría

\section{La Plata}

Octubre 2013 


\section{Indice}

1. Planteo del Problema

2. Objetivos de la Investigación

3. Evaluación del problema 5

4. Alcance de la investigación 7

5. Marco Teórico de Referencia 9

5.1. Características del régimen municipal de la provincia de Buenos Aires 9

5.2. Presupuesto de recursos y gastos 12

5.3. La eficacia y eficiencia 16

5.4. Calidad 22

6. Metodología 24

6.1. Población y muestra 24

6.2. Tipo de investigación 26

6.3. Técnicas de Recolección de Datos 26

6.4. Técnicas de Análisis 27

7. Resultados de la Investigación 29

7.1. Análisis de la Evolución municipal de los recursos por el período 2007- 2011. 29

7.2 Análisis de la evolución municipal de los gastos por el período 2007-2011. 34

7.3 Análisis Regional: La Plata y la Región LP,B y E. 42

7.3.1 Consolidación del Presupuesto de Gastos Totales de la Región 43

7.3.2 Consolidación del Presupuesto de Ingresos Totales de la Región 48

7.3.3 Transferencias realizadas por el gobierno de la provincia de Buenos Aires a la Región 53

7.3.4 Detalle de la composición de la Transferencia por descentralización realizada por el gobierno de la provincia de Buenos Aires a la Región. 53

7.3.5 Comparación de los Gastos en personal de la región con el municipio de La Plata 54

7.4 Comparación Internacional de Gastos Municipales 55 


\section{Planteo del Problema}

En la actualidad existe un interés creciente por la evaluación de la gestión del sector público en general, que se ve impulsado de lograr competitividad, dada la influencia directa que causa su accionar en la actividad económica del sector privado.

En particular, los municipios, concebidos como el sector público más cercano a la población, en su rol de prestador de servicios públicos, creador de obras que demanda el progreso local y ordenador del desarrollo en su territorio, están siendo objeto de una mayor exigencia de información por el sector privado.

Así, cabe señalar al respecto, que si bien dicho interés puede considerarse común a todas las épocas, dado el contacto diario del vecino con las cosas que dependen de su administración y el muy probable conocimiento directo de los responsables de la misma, no puede ignorarse que, desde dicha base, el mencionado interés se ha visto incrementado notablemente en los últimos tiempos.

Sin entrar al análisis de las causas de dicho fenómeno -lo que resultaría ajeno al objeto de la presente- no puede dejar de mencionarse la existencia de dos circunstancias que, indudablemente, concurren a despertar una mayor atención del ciudadano por la cosa pública municipal: Por un lado el afianzamiento de la práctica democrática, con la elección periódica de las autoridades del municipio, que obliga al ciudadano a evaluar la gestión al emitir su voto y, por el otro, el notable desarrollo de los medios de comunicación, donde a los medios tradicionales, como diarios locales, semanarios o radios de circuito cerrado, se han sumado -de modo notable- innumerables radios de frecuencia modulada y sitios de Internet que, por el propio interés que despierta en su público, dedican gran parte de su espacio al comentario o análisis de la gestión municipal. 
Es factible aseverar que los municipios se enfrentan a un nuevo modelo de gestión, con ciudadanos más informados de sus derechos y deberes, como así también, de empresas que exigen saber más acerca de la administración municipal y sus finanzas.

En este contexto, es necesario mencionar que, resultando el contralor de la administración del erario público y la publicidad de los actos de gobierno, elementos imprescindibles del sistema republicano, existen, en los distintos niveles de gobierno, diversos organismos de control externo, como por ejemplo, la Sindicatura General de la Nación, el Consejo Federal de Responsabilidad Fiscal, el Honorable Tribunal de Cuentas de la provincia de Buenos Aires, etc., con un fin de control de la administración y gestión de los recursos públicos.

Así por ejemplo, respecto al control de las cuentas municipales, es función del Honorable Tribunal de Cuentas de la provincia de Buenos Aires: 1) Examinar las cuentas de percepción e inversión de las rentas públicas, tanto provinciales como municipales, aprobarlas o desaprobarlas y en este último caso, indicar el funcionario o funcionarios responsables, como así también el monto y la causa de los alcances respectivos. 2) Inspeccionar las oficinas públicas provinciales o municipales que administren fondos públicos y tomar las medidas necesarias para prevenir cualquier irregularidad en la forma y con arreglo al procedimiento que determine la Ley.

También se encuentra el Consejo Federal de Responsabilidad Fiscal, creado a través de la ley "Régimen Federal de Responsabilidad Fiscal" No 25.917, en la cual se establece que el gobierno nacional, y los gobiernos provinciales y de la Ciudad de Buenos Aires, tomarán las medidas necesarias para calcular parámetros e indicadores homogéneos de gestión pública, que midan la eficiencia y eficacia en materia de recaudación y eficiencia en materia de gasto público, e indica que los gobiernos provinciales invitarán a los municipios a adherir a dicha ley(1).

(1) Articulo 8ㅇ - Los gobiernos provinciales, de la Ciudad Autónoma de Buenos Aires y el Gobierno nacional, tomarán las medidas necesarias para calcular parámetros e indicadores homogéneos de gestión pública que midan la eficiencia y eficacia en materia de recaudación y eficiencia en materia de gasto público, a los efectos de que permitan realizar 
Particularmente, debe destacarse que el presupuesto municipal expresa la previsión de los ingresos y gastos, en función de las orientaciones, objetivos y políticas contenidos en los planes de desarrollo integrales formulados en cada municipalidad.

En tal sentido puede decirse que dichos planes integrales de desarrollo no podrían llevarse adelante si no se planifican a través de actividades concretas y con la estimación de los costos de cada una de ellas.

Es por ello que los objetivos, planteados por los encargados de la administración, en respuesta a las necesidades y demandas de los ciudadanos, deberían quedar expresados en el presupuesto. Ello, como garantía mínima de su ejecución y a fin de permitir la oportuna verificación de su cumplimiento.

Según Duverger(2) los estados tienen una actividad planificada y generalmente obligatoria y el presupuesto es un acto de gobierno mediante el cual se prevén los ingresos y gastos, autorizando los últimos para un período futuro. El presupuesto establece una limitación a la libertad financiera de los gobiernos y de los administradores y debe cumplirse.

También debe señalarse al respecto que, el hecho de que todos los gastos y recursos del estado se reúnan en un solo presupuesto, permite un debido control presupuestario dificultando la posibilidad de disimular economías u ocultar gastos.

Por su parte la publicidad del presupuesto implica la posibilidad de conocimiento, por parte de la población, del plan de recursos y gastos del Estado, sometiéndolo así a la opinión pública y permitiendo que el sector

comparaciones interjurisdiccionales, a cuyos fines se solicitarán propuestas metodológicas al Foro Permanente de Direcciones de Presupuesto y Finanzas de la República Argentina. La propuesta deberá ser elaborada dentro de los ciento ochenta (180) días de la entrada en vigencia de la presente ley y su medición deberá ser publicada conforme lo establecido en el artículo $7^{0}$ de la misma.

Articulo 33. - Los gobiernos provinciales invitarán a sus Municipios a adherir a la presente norma, propondrán la aplicación en el ámbito de tales gobiernos de principios similares a los aquí establecidos y coordinarán la difusión de la información de los mismos. 
privado ajuste sus propias actividades en función de la economía del sector público. Es por ello que el presupuesto debe ser claro y preciso, tanto en lo referente a gastos como al cálculo de los recursos.

Asimismo, y siendo el presupuesto básicamente un instrumento para la aplicación de recursos económicos que son de todos los ciudadanos, resulta deseable que, desde su propia formulación, exprese racionalidad en sus objetivos, equidad en la recaudación de los recursos y asignación de los gastos, y la necesaria eficacia y eficiencia en el modo de su ejecución, asegurando la legalidad, la participación y la transparencia.

Sin embargo, la realidad de la cuestión ofrece diversas aristas que merecen ser analizadas. A ello se dedica el presente trabajo. Así por ejemplo, y siguiendo lo sostenido por Alberto Porto(3), los municipios de la Argentina, generan, en promedio, algo más del $50 \%$ de sus recursos totales; siendo la principal fuente de recursos propios la tasa de alumbrado barrido y limpieza y, en segundo lugar, la tasa de inspección seguridad e higiene. En cuanto a los gastos, indica que casi la totalidad se destinan a gastos corrientes.

Se desprende de esto que a los municipios les quedan escasos recursos para destinar, a erogaciones de inversión, entendiendo que éstas son las que transforman realmente al mismo y permiten, muchas veces, resolver en forma eficaz situaciones de indigencia y pobreza, ya sea en forma directa, construyendo desagües cloacales y llevando agua potable o creando centros de salud o bien en forma indirecta creando por ejemplo parques industriales o mejorando las vías de acceso para favorecer la radicación de industrias y crear fuentes de trabajo genuino.

Por el contrario una parte muy importante del presupuesto se consume en gastos corrientes, dejando poco margen para las inversiones. Ello, resultaría un indicativo de ineficiencia.

(3) Alberto Porto - Finanzas Públicas Locales en la Argentina -Documento de Trabajo Nro. 57 octubre 2004 publicación realizada en la página web .www.depeco.econo.unlp.edu.ar/doctrab/doc57.pdf 
Finalmente y teniendo en cuenta que en la eficiencia o no de la administración estatal se halla comprometido básicamente el interés del ciudadano, ya sea como contribuyente o bien como demandante o destinatario de las obras o servicios responsabilidad del municipio, debe tenerse presente que si bien existe información presupuestaria y es pública, en general dicha información es compleja.

Resulta difícil saber con qué nivel de eficiencia se gasta lo recaudado. Los documentos publicados por los organismos municipales suelen ser de difícil comprensión, dada su abundancia en datos y números, en los que no es fácil delimitar las actividades realizadas, a fin de poder evaluar la eficiencia de la administración. Se observa más bien la escasez de datos e información clara e integrada, que permita evaluar concretamente la eficiencia de la utilización de los recursos públicos y sus aplicaciones, permitiendo así que el sector privado ajuste sus propias actividades en función de la economía del sector público.

\section{Objetivos de la Investigación}

- Determinar parámetros de eficiencia de la administración municipal del partido de La Plata.

- Determinar parámetros de eficiencia de la región La Plata, Berisso y Ensenada.

- Comparar dichos parámetros de eficiencia con la experiencia internacional a través de municipios testigos que abarquen Mercosur, Europa y América del Norte.

\section{Evaluación del problema}

La Economía es la ciencia que estudia la aplicación de los recursos escasos a necesidades ilimitadas, y he aquí el basamento de la necesidad de la eficiencia en términos generales. Desde el punto de vista de la sociedad en 
su conjunto, una asignación eficiente de recursos hace a una mayor satisfacción de sus necesidades.

Como expresan los Magister en Dirección y Gestión Pública Local, Elsa Versino y Pascual Torga: "Es principio fundamental del Estado que su accionar tenga por objeto el logro del bien común, es decir que la gestión debe centrarse en satisfacer las necesidades colectivas con una producción pública que resulte efectiva, eficiente y oportuna pero además y fundamentalmente que el análisis de demanda previo y la oferta resulten de una evaluación correcta, sincera, real y ética buscando equidad y justicia por cuanto ello genera la paz social" (4).

A su vez, la sociedad moderna, ha elevado las exigencias sobre los estándares de servicios públicos aceptados, tanto en el ámbito privado como estatal.

Por tal motivo, toda organización tiene la necesidad de mejorar los mecanismos administrativos y burocráticos para facilitar y agilizar los procesos en los cuales está implicado el ciudadano.

Asimismo el contribuyente, esperaría de la administración municipal la meditada asignación de los recursos materiales y humanos para los cuales contribuye.

En otras palabras el contribuyente desea una administración municipal eficiente.

Los ingresos y gastos del sector público se integran constituyendo el presupuesto. A través de esta herramienta brinda una descripción de su plan

(4) 19 Encuentro Nacional de investigadores universitarios del área contable 9o Simposio regional de investigación contable : El mecanismo de seguimiento de implementación de la convención interamericana contra la corrupción (MESESIC)- AUTORES: Elsa Irene Versino-Contador Público, Licenciado en Economía, Mag. Dirección y Gestión Pública Local y Pascual Alberto Torga-Contador Público, Licenciado en Economía, Mag. Dirección y Gestión Pública Local- La Plata - Buenos Aires.2013. 
de gasto y de su financiamiento, en aras de alcanzar sus objetivos de progreso económico y social del municipio y de la satisfacción de las necesidades de los habitantes mediante la prestación de servicios públicos.

Al respecto expresa el doctor Gordillo Agustín(5) “Un manejo más honesto, eficiente, público, honorable, adecuado, etc. de los fondos públicos puede significar una mejor atención de algunas de las funciones sociales que el Estado a veces cumple y también le libera fondos para atender sus clásicas funciones básicas de seguridad y justicia. El acceso a la justicia, un derecho humano básico, se desgrana cuando los fondos del Estado se desvían hacia donde no deben“.

En términos generales, para todos los sectores de la economía, es de suma importancia conocer el nivel de eficiencia con el que se producen los servicios públicos, ya que cuanto más eficiente sea, mayor ahorro de recursos conseguirá y por lo tanto, menores gastos serán los necesarios para garantizar una cantidad determinada de servicios públicos, que satisfaga las necesidades de la sociedad con la menor presión tributaria.

Cuando la relación Gasto/PBI da indicio de presión tributaria, ello tiene impacto directo en el poder adquisitivo del contribuyente, siendo que mayores niveles de presión tributaria sólo son razonables en tanto y en cuanto ello implique sustanciales mejoras en los servicios e infraestructura que coadyuven a una mejora en la actividad productiva del sector privado. Caso contrario, son ineficiencias que financia el contribuyente a través de una disminución de su poder adquisitivo con consiguiente impacto en el flujo circular de la economía.

\section{Alcance de la investigación}

(5) www.agustingordillo.com/cv/ -Artículos de interés y/o actualidad no incluidos en otros libros del Autor "Un corte transversal al derecho administrativo: la Convención Interamericana Contra la Corrupción”, LL, 1997-E, 1091.

Reproducido, con modificaciones, en la conferencia "La contratación administrativa en la Convención Interamericana contra la Corrupción", en V Encuentro de Asesores Letrados Bonaerenses, La Plata, Asesoría General de Gobierno, 1998, pp. 101 a 119. 
El presente trabajo se realiza para el municipio de La Plata y en el marco de un proyecto de investigación de la Maestría en Dirección de Empresas cuyo título es "La competitividad empresarial y su impacto regional", acreditado en el Programa de Incentivos de la Secretaría de Ciencia y Técnica de la UNLP, con un tronco común cuyo objeto es la Región de La Plata, Berisso y Ensenada (Región LP, B y E), de donde se han tomado los datos de las otras dos localidades de sendas investigaciones.

Para el cálculo de los parámetros de eficiencia se utilizan datos de las ejecuciones presupuestarias a fecha 31 de diciembre que abarca el período comprendido entre los años 2007 a 2011.

Dado que para La Plata solamente se cuenta con el Valor Bruto de Producción (VBP) y no su Producto Bruto Geográfico (PBG), se tomó el primero como una medida aproximada, aunque claramente superior al PBG.

Salvo el análisis de evolución, para el resto de lo analizado corresponde al año 2011.

Ante las dificultades presentadas para la obtención de los datos necesarios para llevar a cabo la comparación internacional, el criterio empleado para la determinación de los municipios extranjeros que se utilizan en el presente trabajo, se vio limitado al de la accesibilidad de la información requerida(6) (PBG, habitantes, cantidad de personal y ejecuciones presupuestarias correspondientes al año 2011, en las cuales debían figurar el gasto total y gasto en personal anual). Cabe destacar que se puso especial énfasis en la búsqueda de ciudades situadas en países del Mercosur, Europa y América del Norte.

Asimismo, y a los fines de la comparación internacional, todos los cálculos realizados, fueron llevados a pesos argentinos, según la cotización del Banco Central de la República Argentina al 31 de diciembre de 2011, y 
calculados cada uno de los parámetros por unidad (como por ejemplo gasto municipal por habitante).

\section{Marco Teórico de Referencia}

\subsection{Características del régimen municipal de la provincia de Buenos Aires}

Desde un enfoque geográfico, el sistema de organización que predomina en la provincia de Buenos Aires es el de municipio-partido. A través del mencionado sistema, la totalidad del territorio provincial se divide en partidos, correspondiendo cada espacio territorial a un municipio.

Cada municipio o municipalidad cuenta con una ciudad principal o cabecera, lugar de asentamiento de las autoridades municipales, y otros centros de población, donde funcionan delegaciones municipales, las cuales son meras descentralizaciones administrativas del gobierno municipal.

La Constitución Nacional (CN) trata sobre el régimen municipal, garantizando su existencia y obligando a las Provincias a asegurar en sus constituciones el ejercicio de esta institución (7).

En la Provincia de Buenos Aires los lineamientos del Régimen Municipal están contenidos en la Constitución Provincial, mientras que la norma que especifica los aspectos particulares es la Ley Orgánica Municipal.

Respecto de la organización de los municipios, ocupan un papel muy importante las reglamentaciones de la Ley Orgánica, ya sean las disposiciones referidas al control de las cuentas públicas municipales (ejercido por los Tribunales de Cuentas) como así también las leyes de participación de impuestos a municipios que determinan un aspecto relevante de las relaciones financieras con el gobierno provincial.

(7) Articulo $5^{\circ}$.- Cada provincia dictará para sí una Constitución bajo el sistema representativo republicano, de acuerdo con los principios, declaraciones y garantías de la Constitución nacional; y que asegure su administración de justicia, su régimen municipal, y la educación primaria. Bajo estas condiciones el gobierno federal, garante a cada provincia el goce y ejercicio de sus instituciones. 
A partir de la reforma de la CN de 1994 y con la incorporación del artículo 123(8) se reafirman, el carácter constitucional del municipio y el principio de la autonomía, ya que explícitamente se citan en él los elementos componentes de la autonomía.

\section{- Funciones de los municipios}

Según la Constitución de la Provincia de Buenos Aires (9) es incumbencia de la municipalidad la administración de los intereses y servicios locales en la Capital y cada uno de los partidos que formen la Provincia.

Tiene a su cargo el ornato y salubridad, los establecimientos de beneficencia que no estén a cargo de sociedades particulares, asilos de inmigrantes que sostenga la Provincia, las cárceles locales de detenidos y la vialidad pública.

(8) Articulo $123^{\circ}$.- Cada provincia dicta su propia constitución, conforme a lo dispuesto por el Artículo $5^{\circ}$ asegurando la autonomía municipal y reglando su alcance y contenido en el orden institucional, político, administrativo, económico y financiero.

(9) Artículo 190 ․- La administración de los intereses y servicios locales en la Capital y cada uno de los partidos que formen la Provincia, estará a cargo de una municipalidad, compuesta de un departamento ejecutivo unipersonal y un departamento deliberativo, cuyos miembros, que no podrán ser menos de seis ni más de veinticuatro, durarán cuatro años en sus funciones, renovándose cada dos años por mitad y serán elegidos en el mismo acto que se elijan los senadores y diputados, en la forma que determine la ley. Artículo 192\%.- Son atribuciones inherentes al régimen municipal, las siguientes:

1. Convocar a los electores del distrito para elegir municipales y consejeros escolares, con quince días de anticipación por lo menos, cuando el Poder Ejecutivo dejare transcurrir los términos legales sin hacerlo; 2 . Proponer al Poder Ejecutivo, en la época que corresponda, las ternas para nombramientos de jueces de Paz y suplentes.

3. Nombrar los funcionarios municipales; 4. Tener a su cargo el ornato y salubridad, los establecimientos de beneficencia que no estén a cargo de sociedades particulares, asilos de inmigrantes que sostenga la Provincia, las cárceles locales de detenidos y la vialidad pública; 5. Votar anualmente su presupuesto y los recursos para costearlo; administrar los bienes raíces municipales, con facultad de enajenar tanto éstos como los diversos ramos de las rentas del año corriente; examinar y resolver sobre cuentas del año vencido, remitiéndolas enseguida al Tribunal de Cuentas. Vencido el ejercicio administrativo sin que el Concejo Deliberante sancione el presupuesto de gastos, el intendente deberá regirse por el sancionado para el año anterior. Las ordenanzas impositivas mantendrán su vigencia hasta que sean modificadas o derogadas por otras. El presupuesto será proyectado por el departamento ejecutivo y el deliberativo no está facultado para aumentar su monto total. Si aquél no lo remitiera antes del 31 de octubre, el Concejo Deliberante podrá proyectarlo y sancionarlo, pero su monto no podrá exceder del total de la recaudación habida en el año inmediato anterior. En caso de veto total o parcial, si el Concejo Deliberante insistiera por dos tercios de votos, el intendente estará obligado a promulgarlo. Toda ordenanza especial que autorice gastos no previstos en el presupuesto, deberá establecer los recursos con que han de ser cubiertos; 6 . Dictar ordenanzas y reglamentos dentro de estas atribuciones; 7. Recaudar, distribuir y oblar en la Tesorería del Estado las contribuciones que la Legislatura imponga al distrito para las necesidades generales, sin perjuicio de que el Poder Ejecutivo nombre funcionarios especiales para este objeto, si lo cree más conveniente; 8 . Constituir consorcios de municipalidades y cooperativas de vecinos a los fines de la creación de superusinas generadoras de energía eléctrica. 
En la Ley Orgánica de la Municipalidades (10) se establece en el artículo 52 las funciones que corresponden al Consejo sujetas a la coordinación provincial, como disponer la prestación de los servicios públicos de barrido, riego, limpieza, alumbrado, provisión de agua, obras sanitarias y desagües pluviales, inspecciones, registro de guías, transporte y todo otro tendiente a satisfacer necesidades colectivas de carácter local.

\section{- Fuentes de Financiamiento: Recursos municipales}

En términos generales, el gasto municipal reconoce tres fuentes de financiamiento:

A) Recursos propios: según la Ley Orgánica de las Municipalidades constituyen recursos municipales ciertos impuestos, tasas, derechos, licencias, contribuciones, retribuciones de servicios y renta que especifica en el artículo 226.

Los principales recursos propios que recaudan los municipios son: la tasas de Alumbrado, Barrido y Limpieza, de Inspección de Seguridad e Higiene, de Inspección Veterinaria; Derechos de oficina, de Construcción; Control de Marcas y Señales, Tasa de Red Vial, Derechos de Cementerio, Tasa por Servicios Asistenciales, Contribuciones de Mejoras, Tasa por Servicios Sanitarios y Reparación y conservación de pavimentos, calles y caminos.

B) Endeudamiento: los municipios bonaerenses cuentan con escasas alternativas para financiar sus erogaciones en el largo plazo y la mayoría de ellas se concentran en su totalidad en organismos del sector público.

C) Ingresos de otras jurisdicciones: Los recursos municipales que provienen de otras jurisdicciones son los que resultan de:

(10) Decreto/ley №6.769/58 y modificatorias. 
- el régimen de coparticipación municipal,

- las transferencias por descentralización del cobro de impuestos provinciales,

- los aportes no reintegrables derivados de convenios con otros niveles de gobierno, y

- los subsidios recibidos del gobierno provincial y nacional.

\section{Régimen de coparticipación municipal}

Una de las fuentes de financiamiento de los municipios de la Provincia de Buenos Aires es la referida a las transferencias del régimen de coparticipación municipal.

El esquema de coparticipación municipal vigente en la Provincia de Buenos Aires es la consecuencia de una serie de modificaciones que se iniciaron en la década del '70 y culminaron con la ley 10.559 y sus modificatorias a fines de los ' 80 . El objetivo que tuvo en el momento de su diseño fue el de "fortalecer el régimen municipal". Se trató de dotar de mayor cantidad de recursos a los gobiernos municipales bajo el supuesto implícito de que las responsabilidades de gasto no pueden ser financiadas con recursos propios y que son necesarias transferencias compensatorias desde un nivel superior de gobierno, en este caso la provincia.

\subsection{Presupuesto de recursos y gastos}

El presupuesto es un elemento clave para una gestión municipal ordenada, planificada, racional y transparente. Su elaboración debe ser una tarea en la que participen autoridades, funcionarios y ciudadanos.

El presupuesto constituye a un cálculo de ingresos y gastos, su preparación requiere de un conjunto de conocimientos, habilidades, información y definición de objetivos, metas y actividades. Es un elemento central en la gestión municipal. 
Los presupuestos se estructuran en base a las partidas de ingresos 0 recursos y las partidas de gastos.

Entre los componentes de las partidas de recursos o ingresos se encuentran las siguientes:

- Recursos corrientes: corresponden a los ingresos que en forma permanente percibe el municipio por concepto de tasas, derechos, multas y contribuciones autorizados por ley, coparticipación de impuestos nacionales y provinciales entre otros. Se clasifican en Ingresos tributarios, Ingresos no tributarios y Otros recursos corrientes.

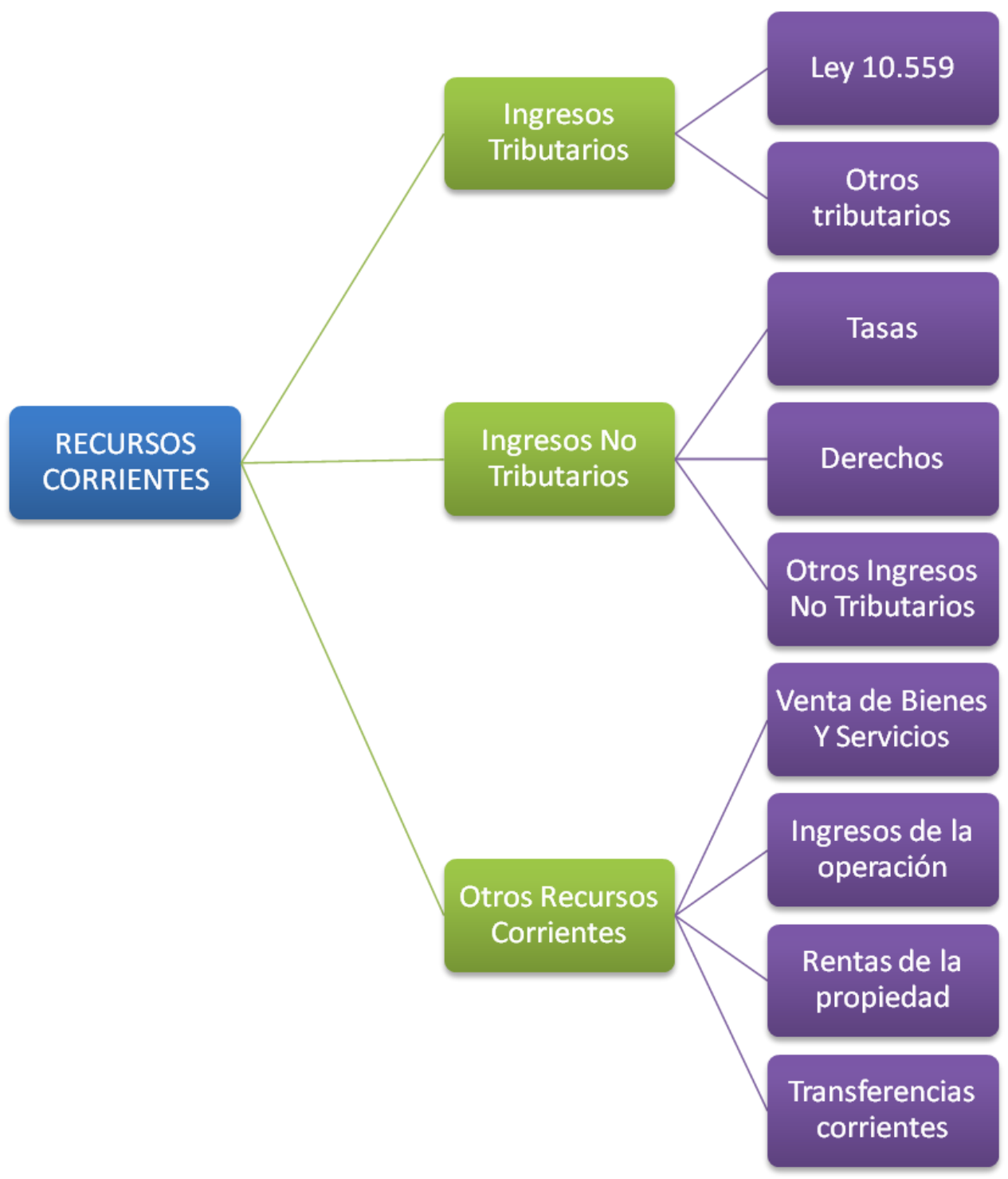


- Recursos de capital: A diferencia de los recursos corrientes que tienen un carácter regular, éstos tienen un carácter eventual. Son el resultado de la venta de activos municipales incluidos los préstamos obtenidos y/o recuperados, es decir todo ingreso originado en una modificación en el patrimonio municipal.Se clasifican en Recursos propios de capital y Otros recursos de capital.

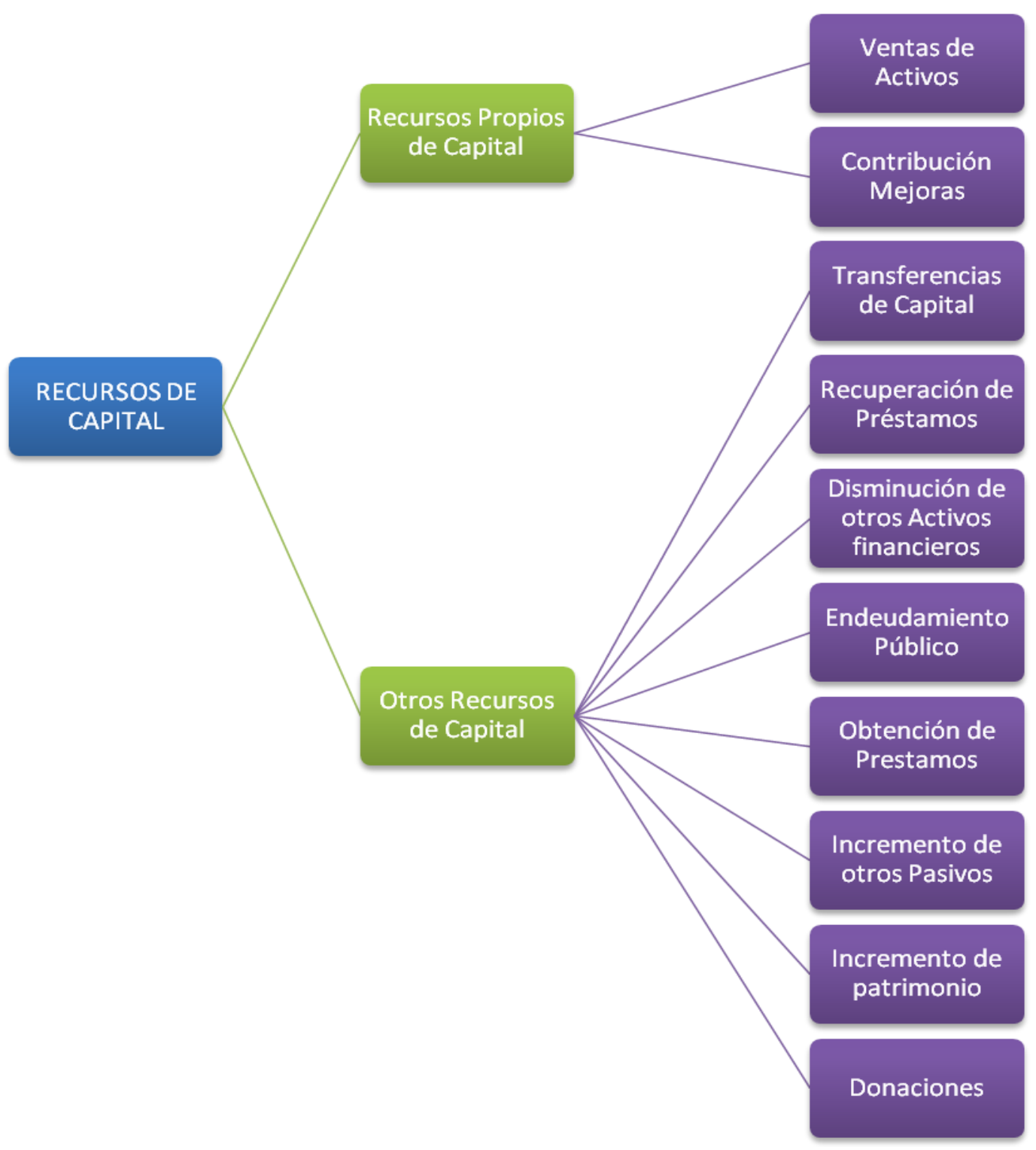


Transferencias de capital: son recursos financieros no reembolsables que el gobierno central transfiere a las municipalidades. Otros ingresos por transferencias son los que se reciben para la ejecución de los programas asistenciales como el vaso de leche y los comedores populares.

Donaciones: son los ingresos que provienen de otros gobiernos 0 de instituciones internacionales o nacionales, públicas o privadas recibidos a título gratuito.

Ingresos por endeudamiento: se originan en los créditos obtenidos de organismos nacionales, internacionales 0 extranjeros, públicos 0 privados. Se destinan exclusivamente a servicios públicos y a obras 0 proyectos de inversión.

Las partidas de gastos se clasifican en:

- Gastos corrientes: son los gastos que se realizan para el mantenimiento u operación de los servicios que presta la municipalidad. son pagos que efectúan las municipalidades por la adquisición de bienes y servicios, las remuneraciones del personal activo y cesante, y otros. Estos gastos se caracterizan por no ser recuperables. Se componen de:

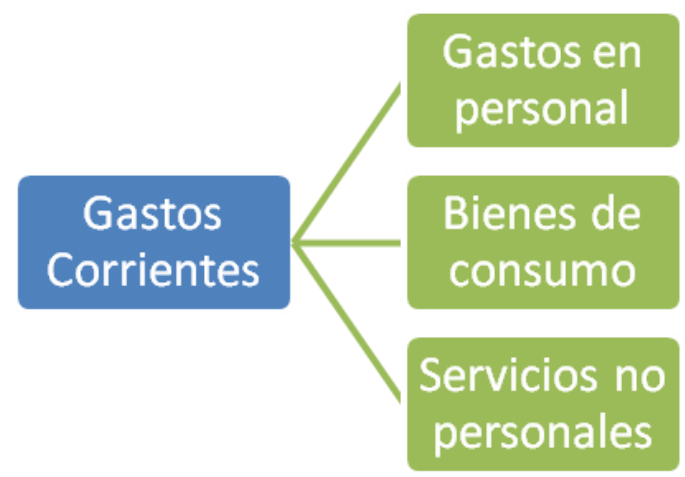

- Gastos de capital: son gastos de inversión en infraestructura para el mejoramiento de los servicios que presta la municipalidad o para la promoción del desarrollo local. son los destinados a la adquisición, instalación y acondicionamiento de bienes duraderos tales como la 
construcción de caminos, asfalto, centros asistenciales, mercados de abastos, entre otros. Se componen de:

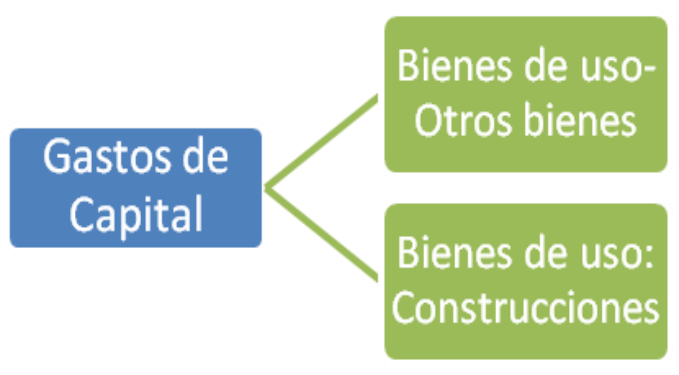

- Gastos Financieros: Servicio de la deuda se refiere al pago de la amortización y de los intereses de las deudas contraídas. Se componen de:

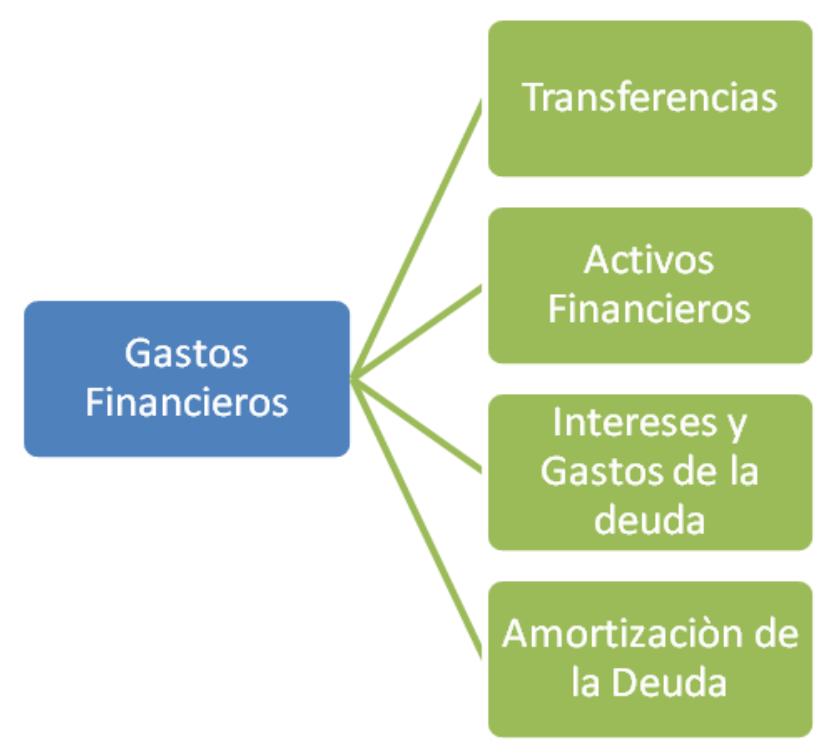

El presupuesto municipal es un estimativo de los ingresos fiscales y una autorización de los gastos públicos que efectúa el Municipio cada año, en ejercicio del control político que en materia fiscal le corresponde. Asimismo incluye la definición de las disposiciones necesarias que garanticen una ejecución eficiente de los recursos.

\subsection{La eficacia y eficiencia}

Desde la aparición de la globalización, se han provocado profundos cambios en todo el mundo y en todas las organizaciones, generando 
particularmente un gran impacto en las estructuras políticas y administrativas del Estado, que le exigen modernizaciones y significativos progresos en materia de comunicación, transparencia, eficiencia y coordinación.

Asimismo el impacto de la globalización en el ámbito público ha ejercido sobre el ciudadano un cambio de actitud, observando a los gobiernos con renovada visión y demandando de ellos servicios eficientes y responsables, reducción del déficit y control del gasto público.

El objetivo básico y prioritario de la Administración Pública, ya sea en el ámbito local, provincial o nacional, debe ser la prestación de sus servicios a la ciudadanía con la máxima eficacia y eficiencia.

Por ello se expresa que la eficacia hace referencia a la capacidad de conseguir un objetivo deseado; mientras la eficiencia es la capacidad de conseguir este objetivo con el mínimo de recursos posibles y disponibles.

En cuanto al término eficiencia se lo puede definir también como la relación entre los resultados obtenidos y los recursos utilizados, y en este sentido, la Administración Pública debe cuidar muy bien que los recursos guarden el equilibrio de una fiscalidad justa.

Los ciudadanos muestran un interés constante en conocer la cantidad de servicios públicos que reciben y que se financian mediante el pago de sus impuestos. En términos generales, cuanto mayor es dicha cantidad (permaneciendo constante la calidad de los servicios), mayor grado de satisfacción manifiestan respecto de la actuación del sector público correspondiente. En efecto, es bastante frecuente que se reclame que se aumente la cantidad y cobertura de servicio públicos, como educación, salud, seguridad y justicia.

Sin embargo, no debe perderse de vista que, para ofrecer dichos servicios el sector público incurre en un gasto público que no es ilimitado. Es decir, si el sector público incrementa su gasto para satisfacer estas demandas 
sociales deberá disponer de unos ingresos superiores. En caso contrario, al igual que ocurre en una familia o una empresa, deberá solicitar financiación para ese exceso de gasto y, por consiguiente, endeudarse.

Se considera que a los ciudadanos no sólo les interesa conocer la oferta de servicios públicos de la que pueden disponer, sino también la relación que existe entre ésta y el gasto público que la genera. En este sentido, es de crucial importancia para que esa relación sea la adecuada y, por lo tanto, que el gasto público sea sostenible en el tiempo, que el sector público no incurra en gastos superfluos, que ahorre cuando sea posible y que, en definitiva, el gasto se efectúe de un modo racional, evitando el derroche de recursos o la mala gestión de los mismos. Precisamente, la eficiencia es el término que permite calcular dicha relación, es decir, es el concepto que posibilita medir cómo utiliza el sector público los recursos o gastos que tiene asignados para cumplir con la prestación de servicios a la sociedad.

El sector público utiliza un conjunto de factores productivos, fundamentalmente trabajo y capital, con los que, dado un nivel tecnológico, produce un conjunto de servicios públicos. Con servicios, tales como los de salud, educación, justicia, asistencia social, etc. se pretende incrementar el bienestar social.

Ante la abundante literatura sobre la definición de eficiencia proveniente desde distintos campos del saber, se hace la siguiente selección:

\section{- Desde la economía}

En líneas generales, el concepto de eficiencia puede aplicarse a distintas aspectos de la economía. En el ámbito de la producción de bienes y servicios, la idea general contenida en el concepto de eficiencia es que no exista despilfarro en la utilización de los recursos; es decir, la eficiencia exige obtener el máximo de producción a partir de una cantidad dada de recursos, o a la inversa, minimizar los recursos consumidos para obtener una determinada 
producción. Según esta doble definición se puede hablar de eficiencia en términos de output, en el primer caso, y en el segundo, en términos de input.

La eficiencia económica consiste básicamente en producir la mayor cantidad al menor costo, o lograr los resultados esperados usando la menor cantidad posible de recursos. Es posible hablar de diversos tipos de eficiencia económica. Por ejemplo se hace referencia a una eficiencia de costos, eficiencia de ingresos o eficiencia en beneficios.

La eficiencia de costos se refiere en conseguir el menor precio o costo para la mayor cantidad de producción posible. Para que se reduzcan los costos en la fabricación de un producto en una empresa determinada, ésta última debe cumplir con las siguientes condiciones: ocupar al mayor rendimiento de los factores y de esta manera se utiliza la menor cantidad posible, es decir, cumplir con una eficiencia técnica. Por último y en segundo lugar, los factores productivos deben trabajar en proporción a lo que dictan los precios, en otras palabras, se trata de hacer una selección muy detallada del proceso productivo más indicado, lo que significa lograr una eficiencia asignativa. Si la empresa es capaz de combinar ambas eficiencias, la técnica por una lado y la asignativa por el otro, es capaz de ser eficiente en lo que se refiere a los costos de producción.

La eficiencia por ingresos consiste en obtener el máximo ingreso considerando el costo de los factores y el precio total del producto para ser posteriormente vendido. Para obtener una máxima en los ingresos es necesario que la producción del bien se cumpla con eficiencia técnica (que los factores obtengan la mayor producción alcanzable), pero también se debe tener en cuenta que el precio que se le adjudicará al producto final debe tener una relación con los del resto de los productos ofrecidos en el mercado, de tal manera que los ingresos alcanzados sean significativos, a esto se le llama eficiencia asignativa en las producciones. Con ambas eficiencias anteriormente mencionadas la empresa es capaz de lograr una eficiencia en los ingresos.

En tercer y último lugar, en lo que se refiere a la eficiencia en beneficios se intenta alcanzar la máxima en los beneficios, lo que implica el máximo de 
ingreso al mínimo costo. Para esto se requiere la existencia de una eficiencia en ingresos y eficiencia en costos. En otras palabras es necesaria una eficiencia técnica, factores adecuados según sus precios y combinar adecuadamente los productos en función de los precios.

Los indicadores de eficiencia se enfocan en el control de los recursos o las entradas del sistema, evalúan la relación entre los recursos y su grado de aprovechamiento por parte de los procesos o actividades. Consiste en el examen de costos en que incurren las entidades públicas encargadas de la producción de bienes y/o la prestación de servicios, para alcanzar sus objetivos y resultados. Por lo tanto, se entiende por eficiencia el costo (costo mínimo) con el cual la entidad cumple sus objetivos (hacer más con menos recursos).

La eficiencia está dada como una medida del manejo de los recursos o de las variables existentes en el proceso. Los recursos o variables que están presentes en el proceso son: Talento humano, presupuesto, equipos tecnológicos, logísticos y metodológicos. En resumen, la eficiencia está relacionada con las respuestas que se den al interrogante de cómo se hizo. Este tipo de indicadores mide la forma de cómo se utilizaron los recursos durante el proceso de generación del producto y/o servicio.

Ejemplos: Costo unitario del insumo, Tiempo promedio de atención, Tiempo promedio de respuesta a una necesidad o solicitud, Productividad total, promedio o per cápita, Utilización de medios electrónicos, Nivel de sistematización y automatización de procesos, entre otros.

- Desde la administración

El autor BennoSander(11) cuando define al término eficiencia se refiere al criterio económico que revela la capacidad administrativa de producir el máximo de resultados con el mínimo de recursos, energía y tiempo.

(11) BennoSander,es un reconocido especialista en temas de administración y organización de la educación en toda América Latina. Consultor Internacional en Educación y Cs. Sociales. 
Algunos expertos como Koontz y Weihrich, aseguran que "la eficiencia consiste en el logro de aquellas metas que se ha propuesto una empresa utilizando para ello la menor cantidad de posible de recursos"(12).

De considerar a Iván Thompson(13) la eficiencia es un logro de un objetivo al menor costo posible, buscar un uso óptimo de los recursos disponibles para lograr los objetivos deseados.

La eficiencia debe diferenciarse de la eficacia, concepto con el que suele confundirse. La eficacia es un término que mide el grado de cumplimiento de un objetivo propuesto por una entidad. Si se ha alcanzado plenamente el objetivo planteado inicialmente, se dice que se ha actuado con eficacia.

Debe tenerse presente que una actuación eficaz no implica eficiencia en la consecución de los objetivos planteados. A la inversa, se puede dar el caso de una entidad que minimice el consumo de factores productivos (actuación eficiente) pero que no cumpla los objetivos preestablecidos (actuación ineficaz). Sin embargo, en el ámbito de actuación de una entidad pública es frecuente que el cumplimiento de los objetivos previstos (eficacia) se anteponga a la asignación racional de los recursos (en términos de eficiencia), cuando los bienes y servicios producidos o provistos por dicha unidad son imprescindibles para satisfacer las necesidades básicas personales y colectivas de los ciudadanos.

Entre los tipos de ineficiencia y a modo de ejemplo, se destaca la denominada ineficiencia que se genera por razones imputables a los individuos que intervienen en el proceso productivo. En efecto, los individuos pueden limitar su esfuerzo y maximizar su utilidad consumiendo más recursos (por ejemplo, tiempo de trabajo) de los necesarios para un output determinado. Este tipo de ineficiencia suele aparecer cuando no existen controles suficientes dentro de la propia entidad para que no se desperdicien los recursos, por lo

(12) Koontz Harold y Weihrich Heinz «Administración Un Perspectiva Global», 12a. Edición, McGraw-Hill Interamericana, 2004, Págs. 6 y 14.

(13) Iván Thompson, Definición de eficiencia [en línea] [Consultado Agosto de 2012]. Disponible en internet: http://www.promonegocios.net/administracion/definicioneficiencia.html 
que en el sector público es muy común que se de esta clase de ineficiencias, debido a la falta de incentivos en la que generalmente se desarrollan las actividades.

El estado en su rol de proveedor de servicios, debe cuidar que cada costo sea correspondido con su valor agregado, teniendo en cuenta que las ineficiencias o incumplimientos, generan mayores costos en el servicio, y que en definitiva dicho servicio podría prestarse invirtiendo menores recursos.

Es factible deducir entonces que un proceso es eficiente cuando poco costo genera mucho valor.

\subsection{Calidad}

Gestionar enfocado en la calidad es válido para cualquier organización; aún en aquellas sin fines de lucro. Por sus características de mejora continua y eficiencia en la gestión, sería fundamental aplicar este enfoque a la administración pública.

La eficiencia es otro elemento básico en la "calidad total". Resolver la organización de recursos disponibles: capital, materiales, ideas y procesos para alcanzar el máximo rendimiento, es el único camino de la eficiencia.

Encaminada a la mejora continua el sistema busca corregir, en el largo plazo, desvíos que se reflejan en desperdicios, demoras innecesarias y errores, achicando los costos producidos por estas acciones. La ineficiencia se calcula en función de los "costos de no calidad". Más altos costos de no calidad, reflejan ineficiencia y por ende un precio superior del bien o servicio. Los costos producidos por ineficiencia en el gobierno municipal y la prestación del servicio incrementan los gastos públicos necesariamente financiados por los contribuyentes.

Continuando con el análisis de la Calidad Total, se puede dividir a los costos en: visibles e invisibles. 
Los costos visibles son aquellos que se registran en los libros contables del ente. Los costos invisibles, por el contrario, no son relevados por sistema alguno, por lo cual no queda historia de ellos, aunque impactan fuertemente en los resultados del ente.

Los costos invisibles suelen ser más importantes que los visibles, con el agravante de que por su intangibilidad son difíciles de identificar, reconocer, aceptar y corregir. Algunos ejemplos de costos invisibles son: Tiempo de personal, tiempo de reacción, desmotivación, falta de participación, etc.

En conclusión se deben analizar los procesos de trabajo, a fin de detectar y minimizar los costos invisibles, para mejorar la eficiencia y realizar un menor esfuerzo para cumplir con la provisión de los servicios.

Si se detecta que un producto, servicio o tarea no cumple con las especificaciones, cuando el mismo ya está elaborado, no evita los costos de un producto o servicio mal elaborado, lo correcto es prevenir, es decir advertir la posibilidad de aparición de un defecto antes de que se presente y actuar sobre el proceso corrigiéndolo.

La calidad total no busca culpables en las personas, sino busca revisar críticamente los procesos que originan que las personas se equivoquen.

Esto implica asumir que la Calidad Total no solamente está destinada a satisfacer las necesidades del cliente, sino que, Calidad Total es mucho más que eso: es reducir costos, es incrementar la productividad y es lograr una mejor calidad de vida.

En el sector público la cultura de la Calidad Total pareciera ser de dificultosa implementación toda vez que se trata de estructuras burocráticas y no resulta sencillo definir quien es el cliente final y la detección de sus requerimientos. 
Así esta creciente realidad, exige de sus gobiernos locales, fundamentalmente las municipalidades, como órgano jurídico y político más cercano al ciudadano, nuevos roles y nuevos estilos de gestión, que respondan a las demandas de comunicación, transparencia, eficiencia y coordinación, exigidas también a los gobiernos provinciales y nacionales.

Los nuevos estilos de gestión de las organizaciones municipales, requieren el uso de herramientas modernas que apoyen categóricamente el mejoramiento y el cambio que estas organizaciones demandan para asumir sus nuevos roles.

El modelo de gestión tradicional del Sector Público se caracteriza por un alto nivel de burocratización, en el cual las conductas se rigen por medio de reglas y normas de las cuales no es posible apartarse. En esta línea, entonces, el control de gestión tiende a centrarse sobre los procedimientos, a fin de asegurar que la normativa sea respetada.

Si la decisión política del gobierno municipal sería mejorar la administración pública, planteando estrategias que adapten la gestión a los tiempos actuales, el modelo gestión de calidad (Calidad total = satisfacción del cliente + eficiencia en la Organización) es una herramienta válida que bien aplicada la optimizará.

La productividad en la gestión pública, expresada en términos de satisfacción del ciudadano y la correcta orientación del gasto público, requiere de cambios, planificación y control para la mejora continua.

\section{Metodología}

\subsection{Población y muestra}

La población seleccionada se conforma por el municipio de La Plata. 
Está ubicada sobre la pampa húmeda, distante 56 kilómetros en dirección sudeste de la ciudad de Buenos Aires, capital de la República Argentina; y a 9,87 metros sobre el nivel del mar.

Con una población estimada por el último Censo Nacional (2010) en 654.324habitantes, y una superficie territorial de 940,38 kilómetros cuadrados, la densidad habitacional refleja 585,2 habitantes por kilómetro cuadrado, convirtiéndola en una de las más populosas de la Provincia.

La ciudad y sus alrededores poseen particulares características que definen su perfil socio-económico.

En primer lugar se destaca, desde el punto de vista político e institucional, por ser el centro administrativo de la Provincia y sede de casi todos los organismos y autoridades provinciales.

En segundo lugar, también es sede universitaria por excelencia ya que la Universidad Nacional de La Plata es uno de los centros universitarios más importantes del país (entre sus Facultades se encuentran la Facultad de Ciencias Económicas, Facultad de Humanidades y Ciencias de la Educación, Facultad de Derecho y Ciencias Sociales, Facultad de Ingeniería, Facultad de Ciencias Exactas, Facultad de Ciencias Naturales, Facultad de Arquitectura). Asimismo, la Universidad cuenta con importantes Centros de Investigación en cada una de las facultades, donde se desarrollan estudios referidos a distintas actividades y problemáticas de la localidad y de la región. Otras dos Universidades más se encuentran en la ciudad: Universidad Tecnológica Nacional y Universidad Católica de La Plata.

Por último, desde el punto de vista económico/productivo la región cuenta con un complejo portuario, un polo de desarrollo industrial y una zona franca. Entre sus industrias más relevantes se encuentran; una refinería de petróleo, la siderurgia, petroquímica, astilleros, empresas de envasado de carne, molinos, textiles y fábricas de maquinarias. 


\subsection{Tipo de investigación}

La presente investigación es de tipo exploratoria y de naturaleza cuantitativa.

\subsection{Técnicas de Recolección de Datos}

Para llevar a cabo la investigación, se emplearon fuentes de información secundaria.

Las fuentes de datos consultadas fueron las siguientes:

Consultas a través de páginas webs: Instituto Nacional de Estadística y Censos-www.indec.mecon.ar-consultada en fecha 22 de octubre de 2012 y Ministerio de Economía de la provincia de Buenos Aires- Subsecretaría de Coordinación Económica-consultada en fecha 16 de octubre de 2012http://www.ec.gba.gov.ar/areas/Sub_Politica_Coord_Eco/CoordMunicipal/muni cipios.

Entrevistas personales con funcionarios y personal de la Dirección Provincial de Programación y Gestión Municipal dependiente de la Subsecretaría de Asuntos Municipales del Ministerio de Gobierno de la Provincia de Buenos Aires- remitiendo posteriormente la información solicitada vía mail, y de la Municipalidad de La Plata - Área Modernización Productiva, Agencia Platense de Recaudación y Contaduría-, también en este caso remitiendo posteriormente la información solicitada vía mail.

La información referida a las cuentas municipales, si bien es pública y se encuentra disponible, es escasa y con frecuencia difiere la forma de exposición entre las distintas fuentes que fueron consultadas (Municipio, Tribunal de Cuentas o Ministerio de Gobierno, éstos dos últimos dependientes del gobierno provincial). Ante tal situación se trabajó sobre ejecuciones presupuestarias municipales brindadas por el Ministerio de Gobierno de la provincia de Buenos Aires-Subsecretaría de Asuntos Municipales- Dirección Provincial de Programación y Gestión Municipal. 
Esta tarea fue compleja, ya que en algunos casos se hizo necesario concurrir a la "Dirección Provincial de Programación y Gestión Municipal", en varias oportunidades, dado que la información requerida no estaba sistematizada, en oportunidad de su solicitud.

Para la realización de las comparaciones con países extranjeros, se tomaron como fuente de datos las publicaciones pertinentes realizadas a través de las páginas Web: www.alicante.es; mail:tesorería@alicante-ayto.es; www.ine.cl; www.ci.bothell.wa.us; www.guarulhosweb.com.br/noticia.

\subsection{Técnicas de Análisis}

El procesamiento de datos realizado fue:

- Análisis de la evolución de los recursos municipales por el período 20072011: corrientes y de capital.

- Evolución de los recursos corrientes: ingresos tributarios, ingresos no tributarios y otros recursos corrientes.

- Evolución de los recursos de capital: recursos propios de capital y otros recursos de capital.

- Análisis de la evolución de los gastos municipales por el período 20072011: corrientes, de capital, financieros y deuda flotante.

- Evolución de los gastos corrientes: en personal, en bienes y servicios y servicios no personales.

- Evolución de los gastos de capital: bienes de uso-otros bienes y bienes de uso-construcciones.

- Evolución de gastos financieros: transferencias, activos financieros, intereses y gastos de la deuda y amortización de la deuda.

- Relación Ingresos Corrientes/Gastos Corrientes. 
Respecto de la Región se analizaron los siguientes datos con la información presupuestaria del año 2011:

- Consolidación (porcentual y en pesos) del Presupuesto de Gastos Totales de Región.

- Discriminación (porcentual y en pesos) de Gastos totales consolidados para la Región y en comparación con el municipio de La Plata.

- Discriminación de los Gastos Corrientes consolidados para la Región y en comparación con el municipio de La Plata.

- Consolidación de los Gastos Totales de la Región, discriminado por tipo de gasto.

- Consolidación (porcentual y en pesos) del Presupuesto de Ingresos de la Región.

- Discriminación (porcentual y en pesos) de Ingresos Totales consolidados para la Región y en comparación con el Municipio de La Plata.

- Discriminación de Ingresos Corrientes consolidados para la región y en comparación con el Municipio de La Plata.

- Discriminación de los Ingresos de Capital para la Región y en comparación con el Municipio de La Plata.

- Transferencias realizadas por el gobierno de la provincia de Buenos Aires a la Región.

- Detalle de la composición de la Transferencia por descentralización realizada por el gobierno de la provincia de Buenos Aires a la Región. 
- Comparación de Gastos en personal de la Región con el Municipio de La Plata.

Para el análisis internacional y teniendo en cuenta que trabajar por unidad proporciona de alguna manera, una mejora en las comparaciones, las relaciones se calculan por habitante o por cada mil habitante. A tal fin de se efectúan las siguientes comparaciones relativas, en base a ejecuciones presupuestarias del año 2011.

- Gastos en Personal

- Empleados Municipales por cada 1000 habitantes

- Gasto Total municipal por habitante

- Gastos Total Municipal por habitante con relación al PBI

- Gasto en personal Municipal por habitante

- Gasto en personal Municipal por habitante con relación al PBI

Finalmente, para su mejor interpretación y obtener una visión en conjunto de los resultados de los indicadores obtenidos, se muestran a través de tablas y gráficos con el análisis correspondiente.

\section{Resultados de la Investigación}

7.1. Análisis de la Evolución municipal de los recursos por el período 20072011. 


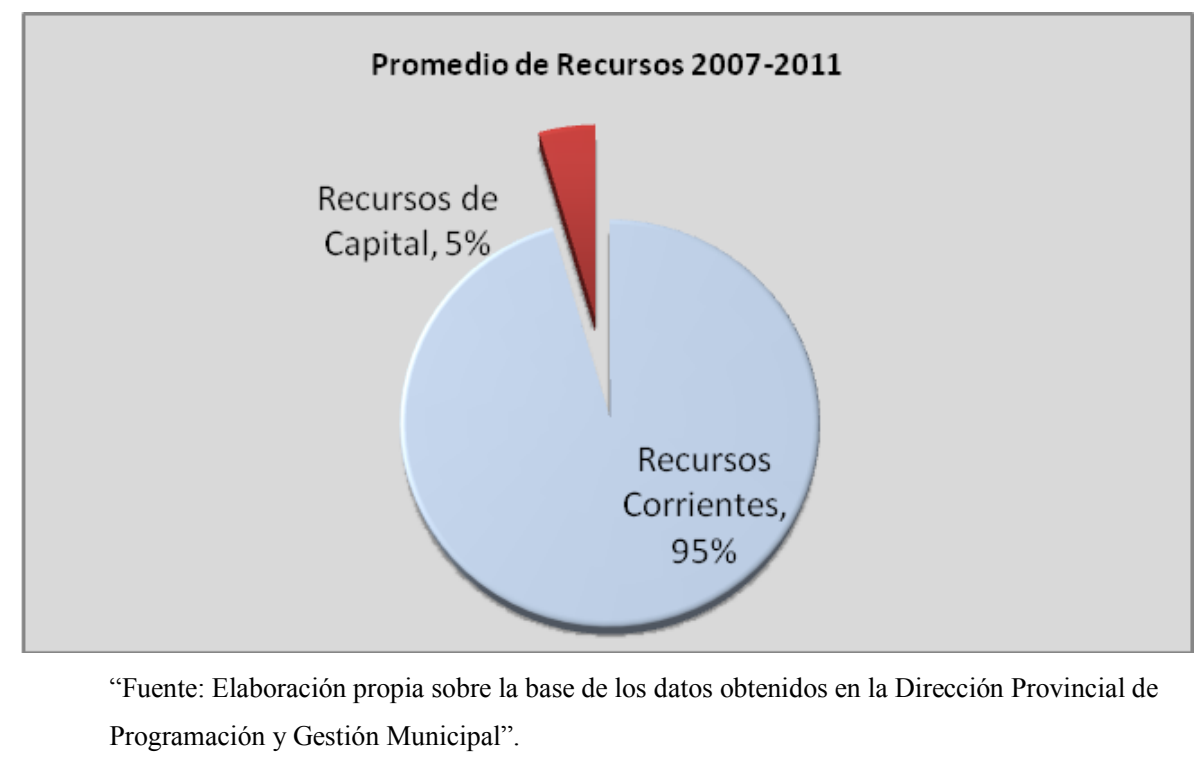

Clasificación por tipo de Recurso:

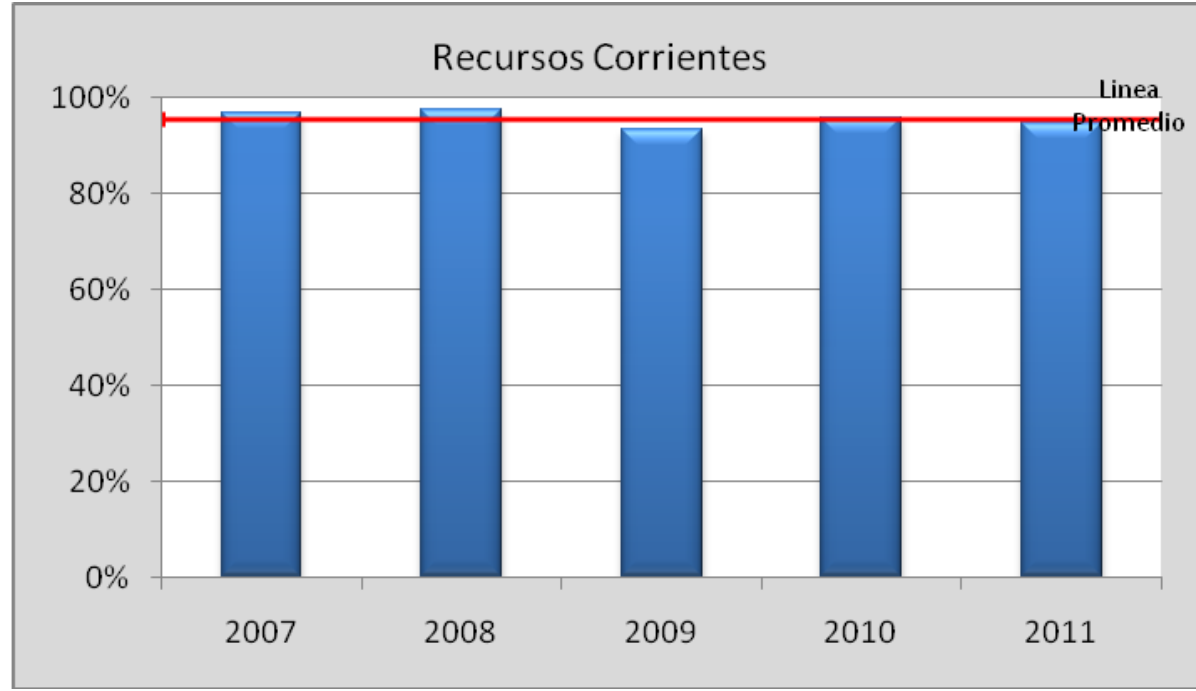

"Fuente: Elaboración propia sobre la base de los datos obtenidos en la Dirección Provincial de Programación y Gestión Municipal”.

Los Recursos Corrientes del Municipio se mantienen casi sin variaciones en los períodos analizados, su promedio es un $95 \%$ de participación en la totalidad de los recursos, aunque se pude observar que en el año 2009, esta levemente por debajo del promedio, ubicandose en un $93 \%$. 


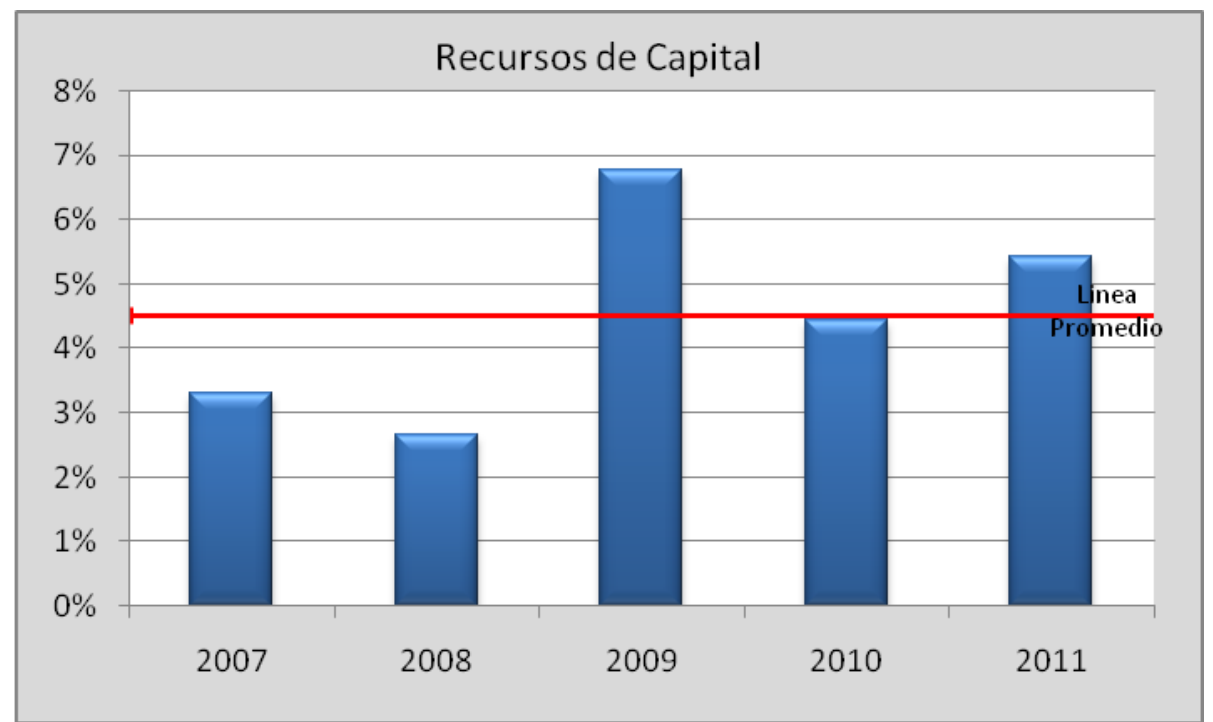

"Fuente: Elaboración propia sobre la base de los datos obtenidos en la Dirección Provincial de Programación y Gestión Municipal".

Los Recursos de Capital representan un promedio del $5 \%$ en la totalidad de los recursos, observándose que en el año 2007representan un 3,3\% y en el año 2008 cae aun más a un $2,6 \%$, el mayor valor por encima del promedio se encuentra en el año 2009 con un 6,7\%.

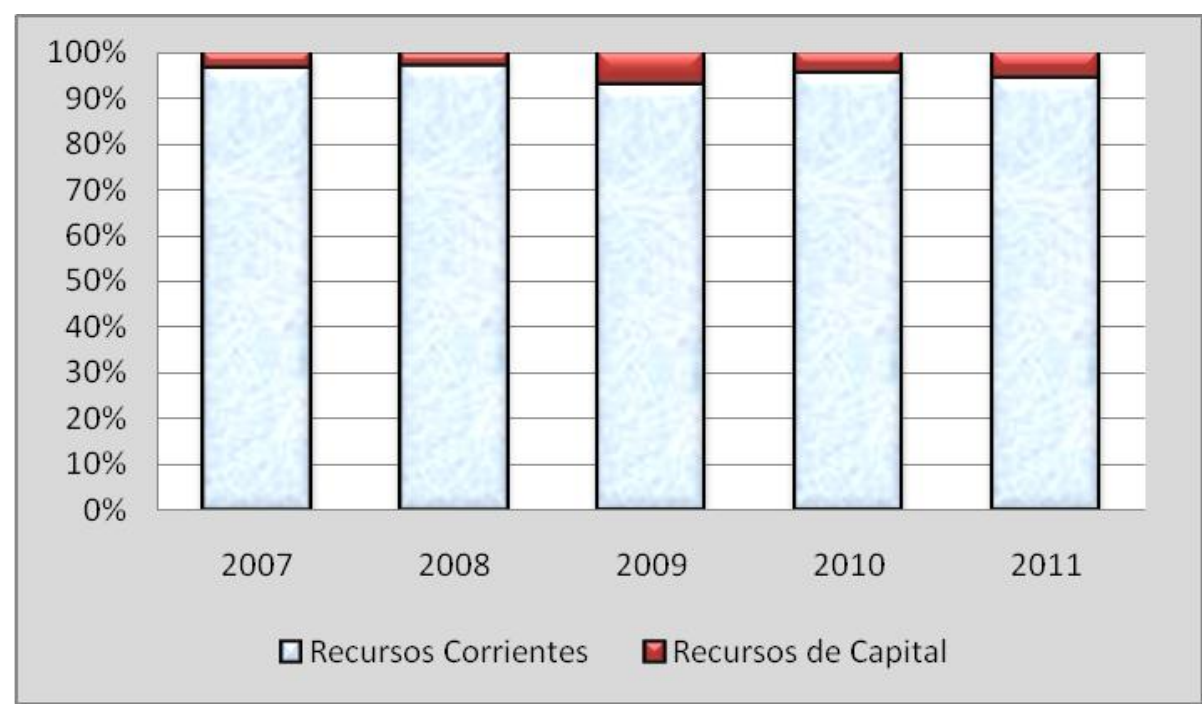

"Fuente: Elaboración propia sobre la base de los datos obtenidos de la Dirección Provincial de Programación y Gestión Municipal”.

Recursos Corrientes: 


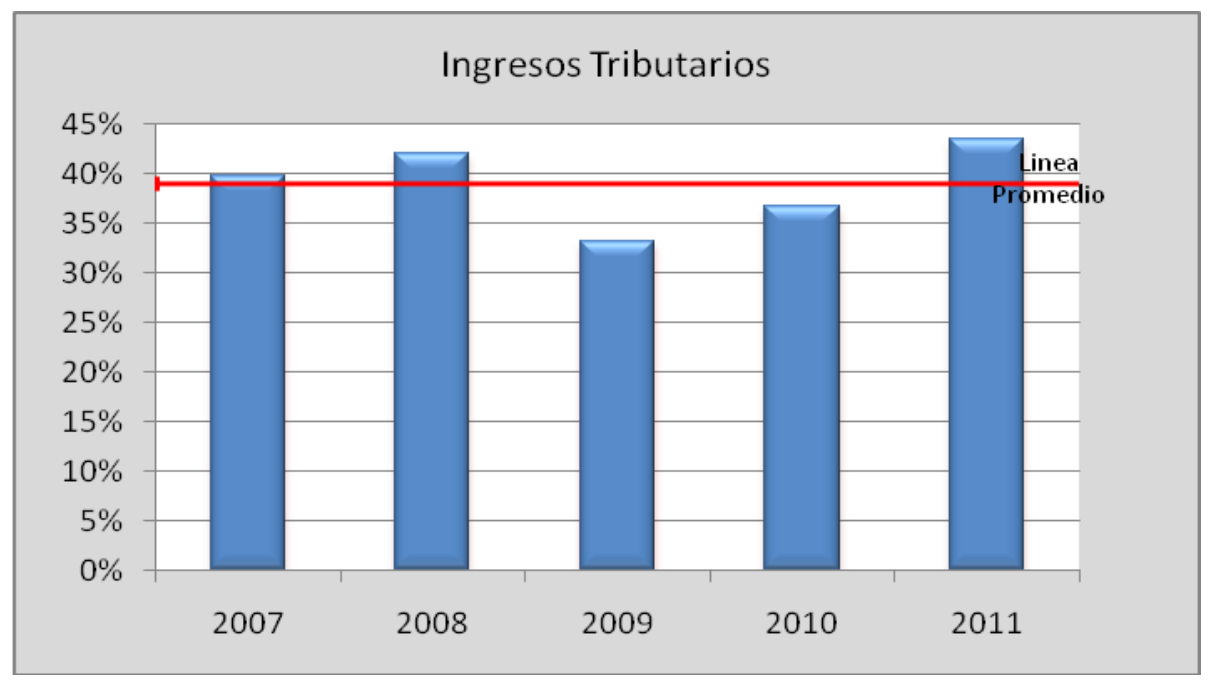

"Fuente: Elaboración propia sobre la base de los datos obtenidos de la Dirección Provincial de Programación y Gestión Municipal”.

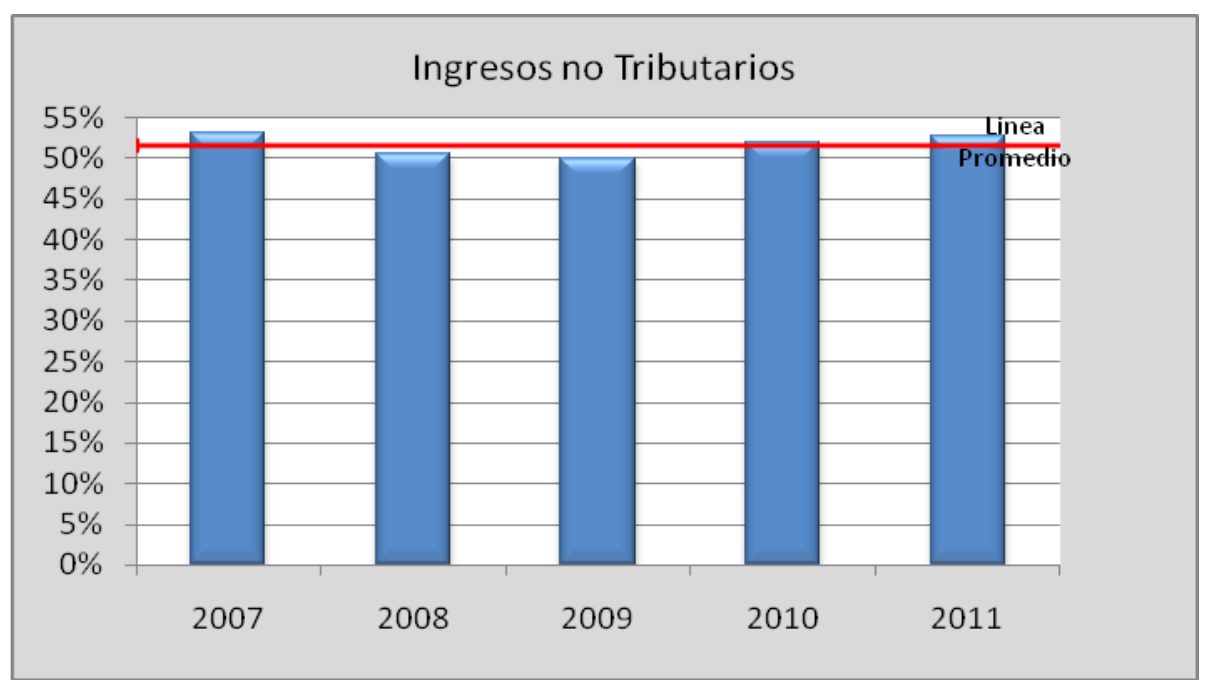

"Fuente: Elaboración propia sobre la base de los datos obtenidos de la Dirección Provincial de Programación y Gestión Municipal”.

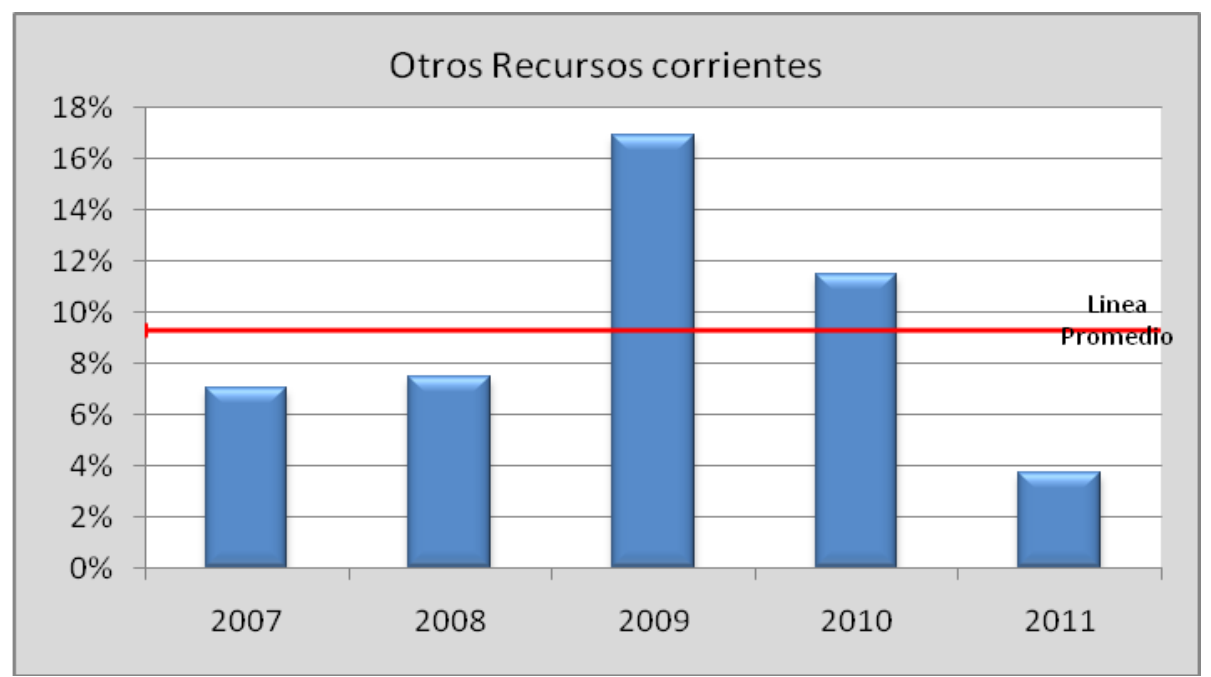

"Fuente: Elaboración propia sobre la base de los datos obtenidos de la Dirección Provincial de Programación y Gestión Municipal”. 
Del total de Recursos Corrientes, se puede observar que los Ingresos no Tributarios en promedio representan un 52\%, los Ingresos Tributarios un 39\% y 9\%corresponden a Otros Recursos corrientes.

Recursos de Capital:

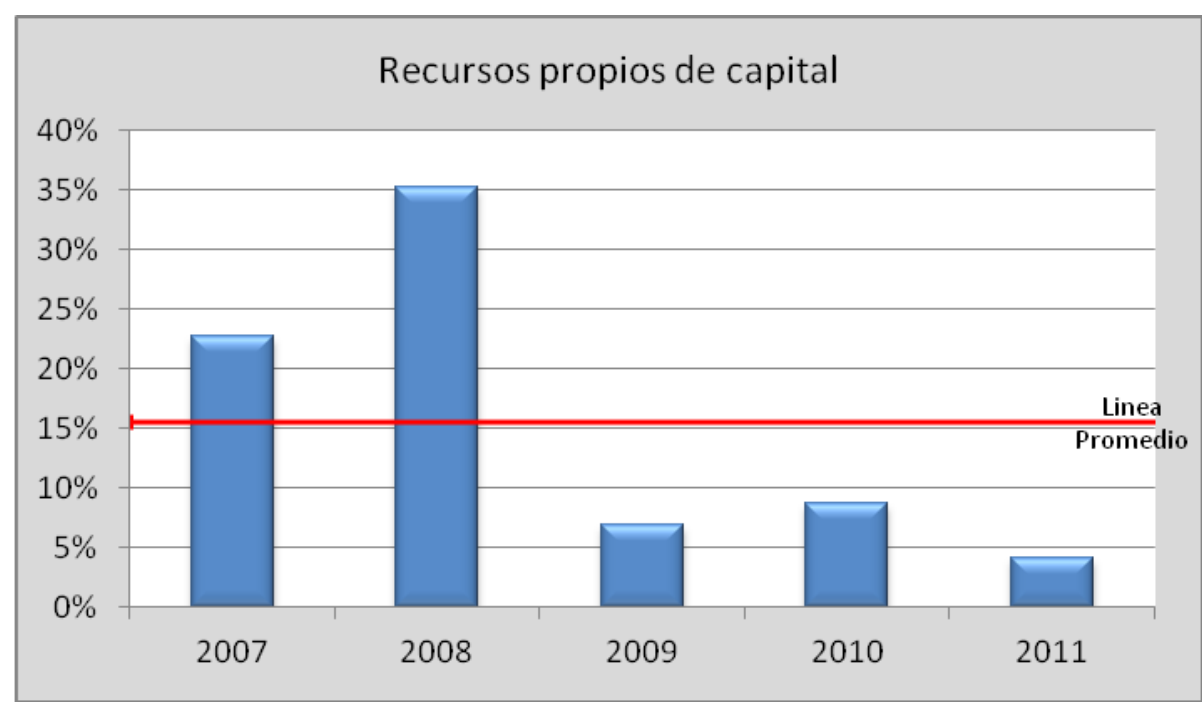

"Fuente: Elaboración propia sobre la base de los datos obtenidos de la Dirección Provincial de Programación y Gestión Municipal”.

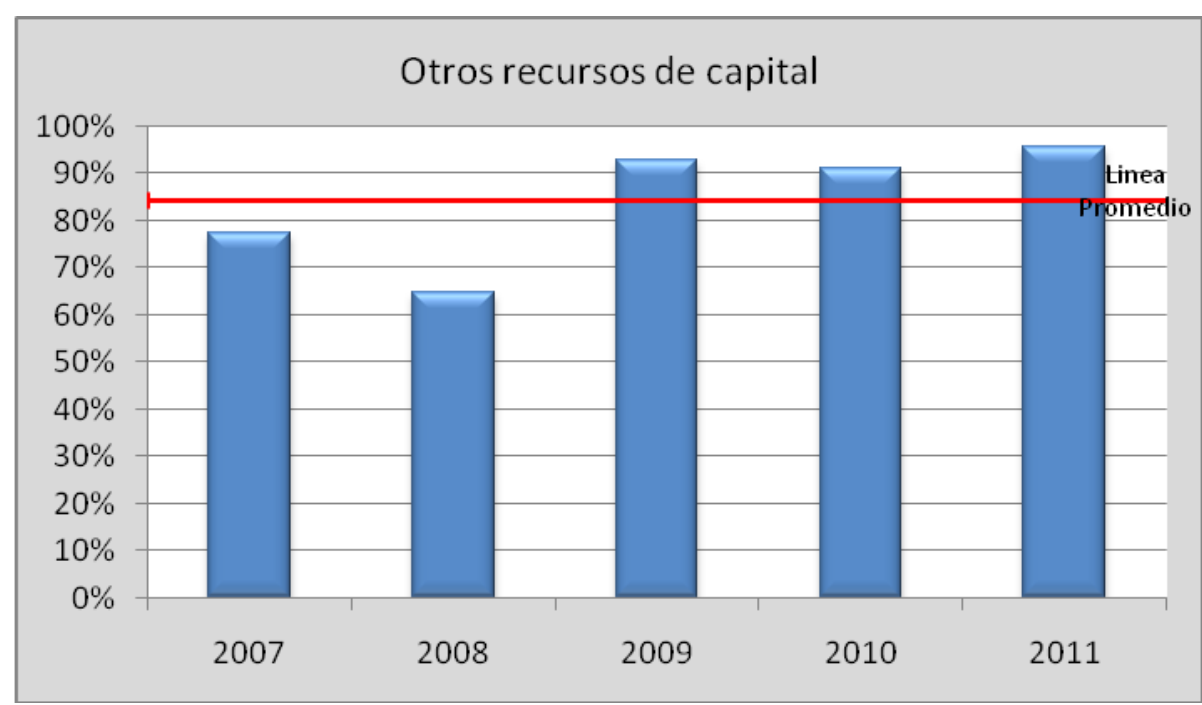

"Fuente: Elaboración propia sobre la base de los datos obtenidos de la Dirección Provincial de Programación y Gestión Municipal”. 
En relación a los Recursos de Capital se observa que en el período analizado el promedio de los Recursos propios de capital es $16 \%$ en comparación con el $84 \%$ promedio que representan Otros recursos de capital. 7.2 Análisis de la evolución municipal de los gastos por el período 2007-2011.

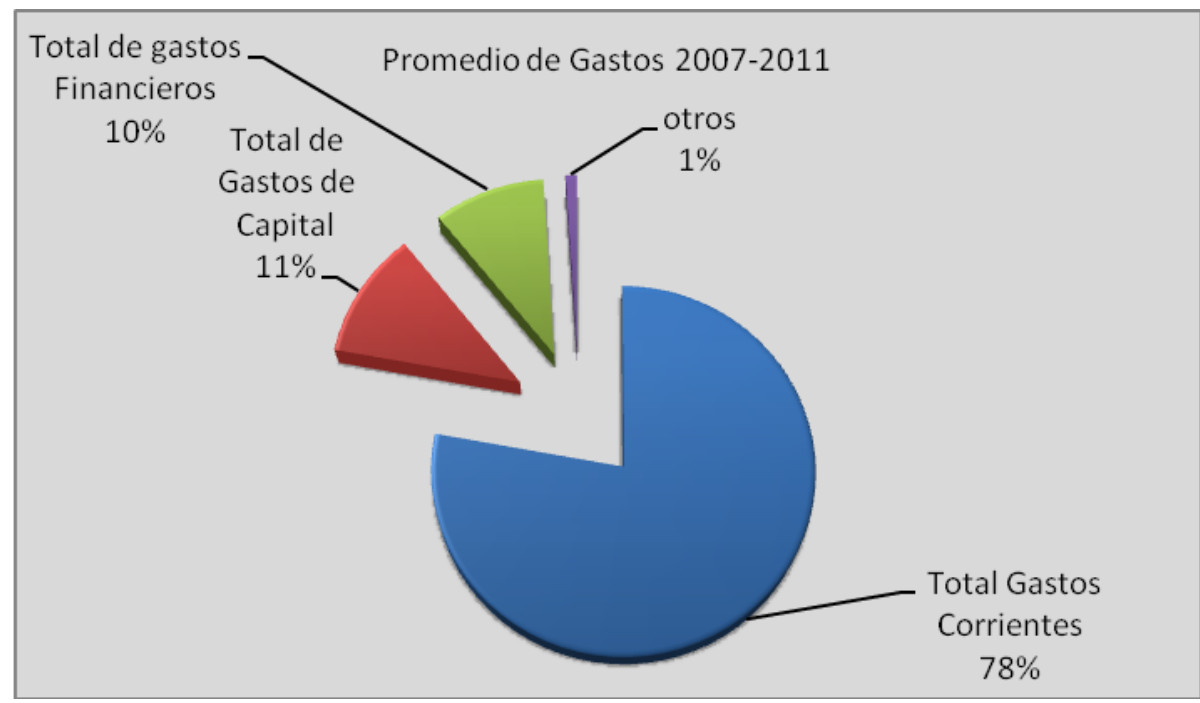

*Otros Incluye otros gastos y deuda flotante.

"Fuente: Elaboración propia sobre la base de los datos obtenidos de la Dirección Provincial de Programación y Gestión Municipal”.

Clasificación por tipo de gasto:

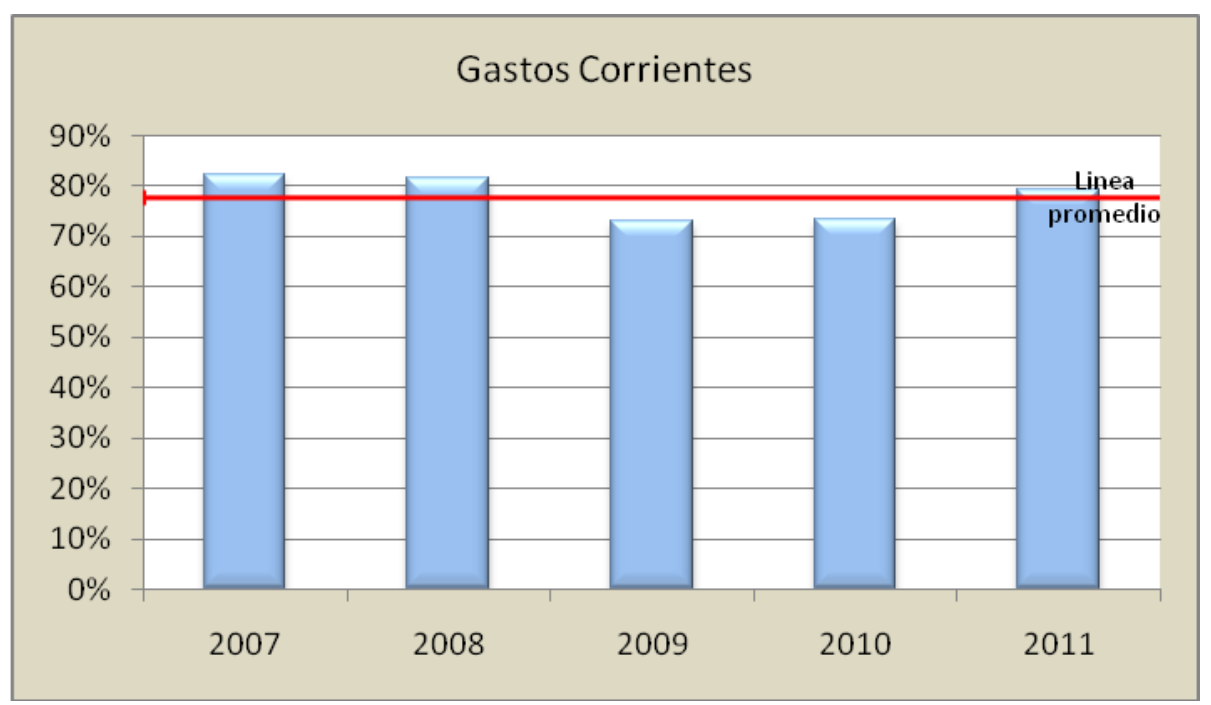

"Fuente: Elaboración propia sobre la base de los datos obtenidos de la Dirección Provincial de Programación y Gestión Municipal”. 


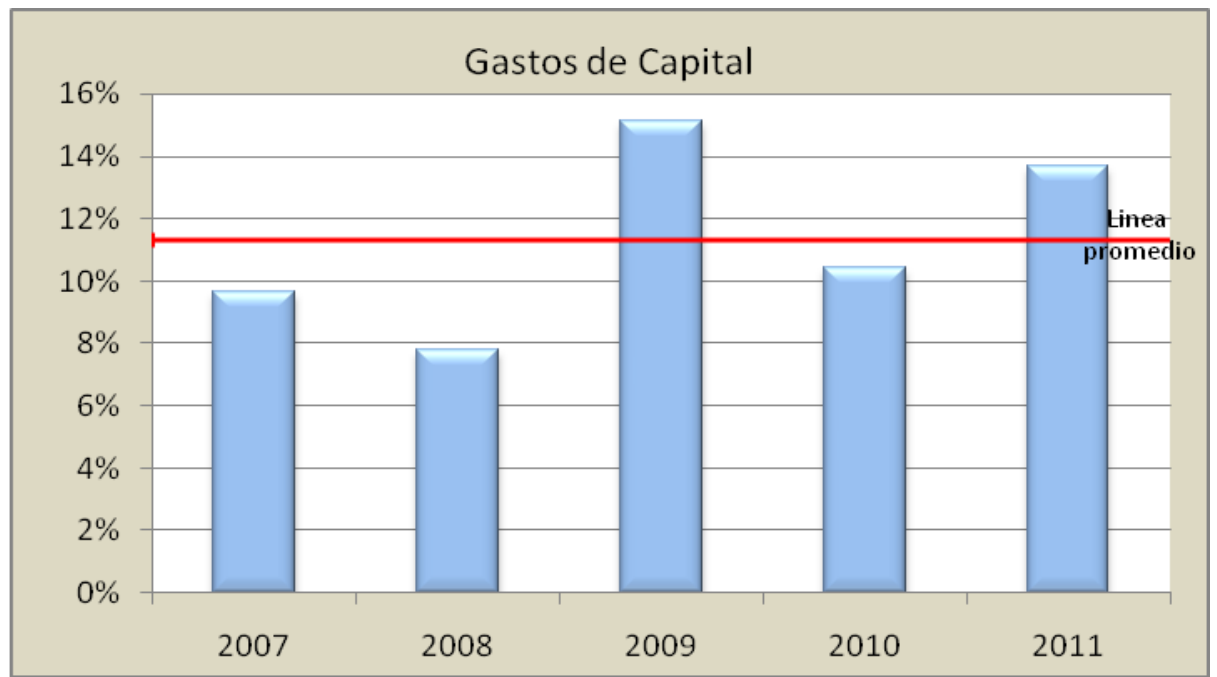

"Fuente: Elaboración propia sobre la base de los datos obtenidos de la Dirección Provincial de Programación y Gestión Municipal".

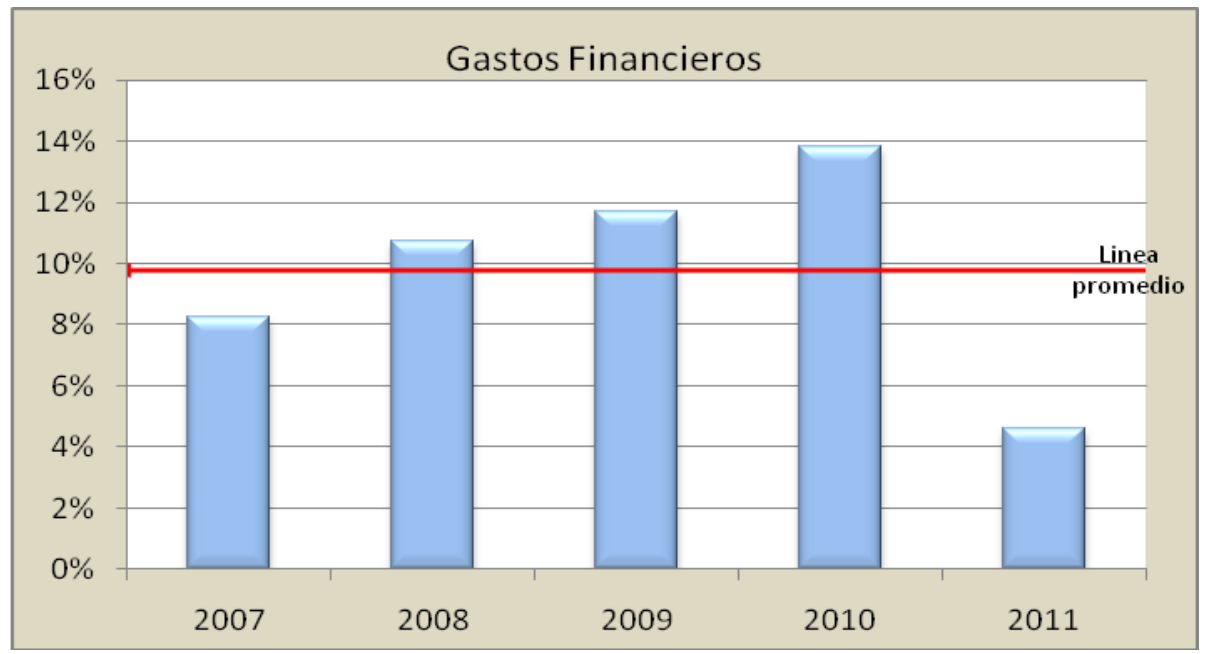

"Fuente: Elaboración propia sobre la base de los datos obtenidos de la Dirección Provincial de Programación y Gestión Municipal”.

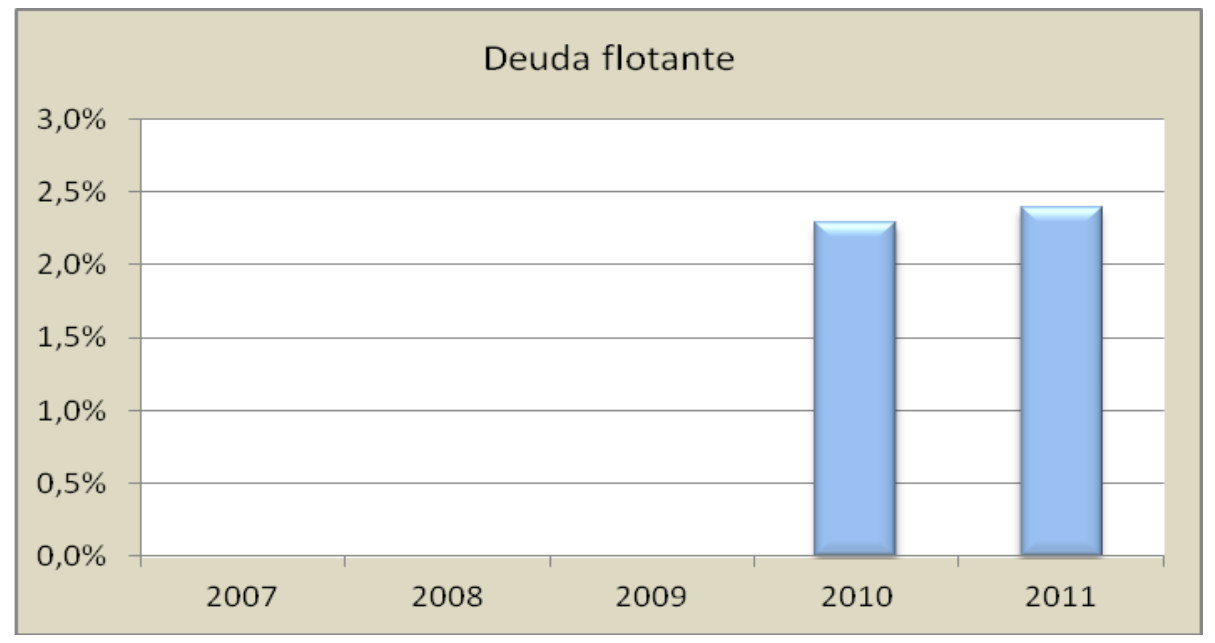

"Fuente: Elaboración propia sobre la base de los datos obtenidos de la Dirección Provincial de Programación y Gestión Municipal". 


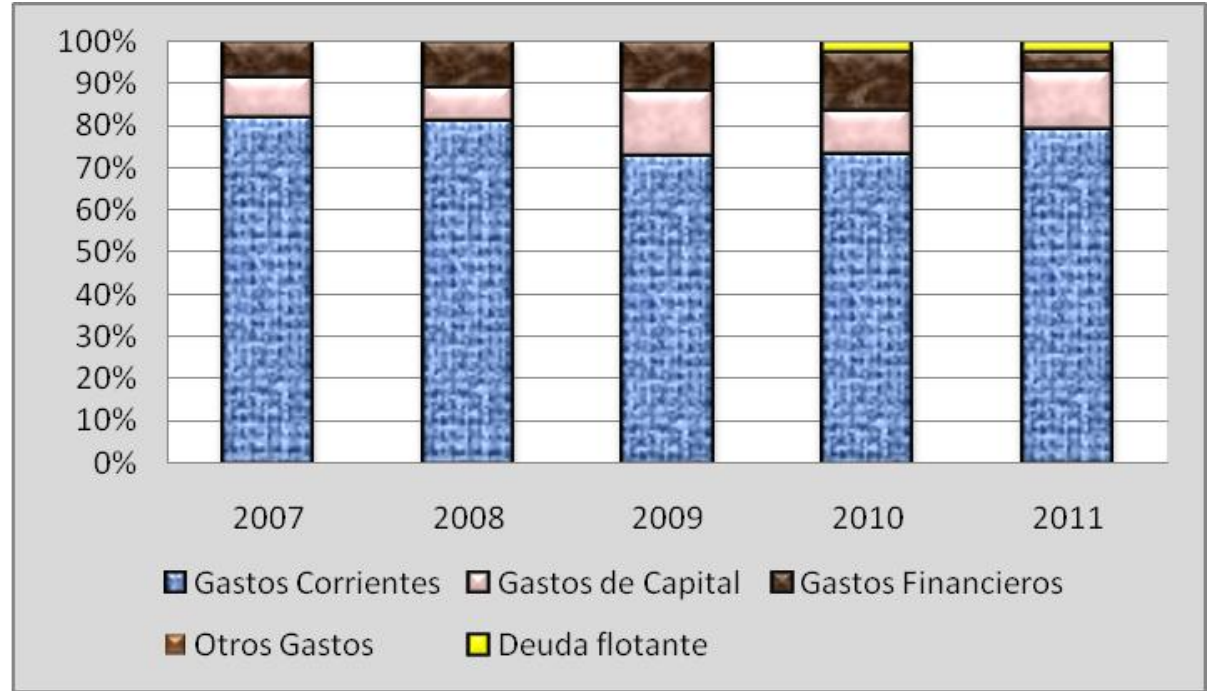

"Fuente: Elaboración propia sobre la base de los datos obtenidos de la Dirección Provincial de Programación y Gestión Municipal”.

\section{Gastos Corrientes:}

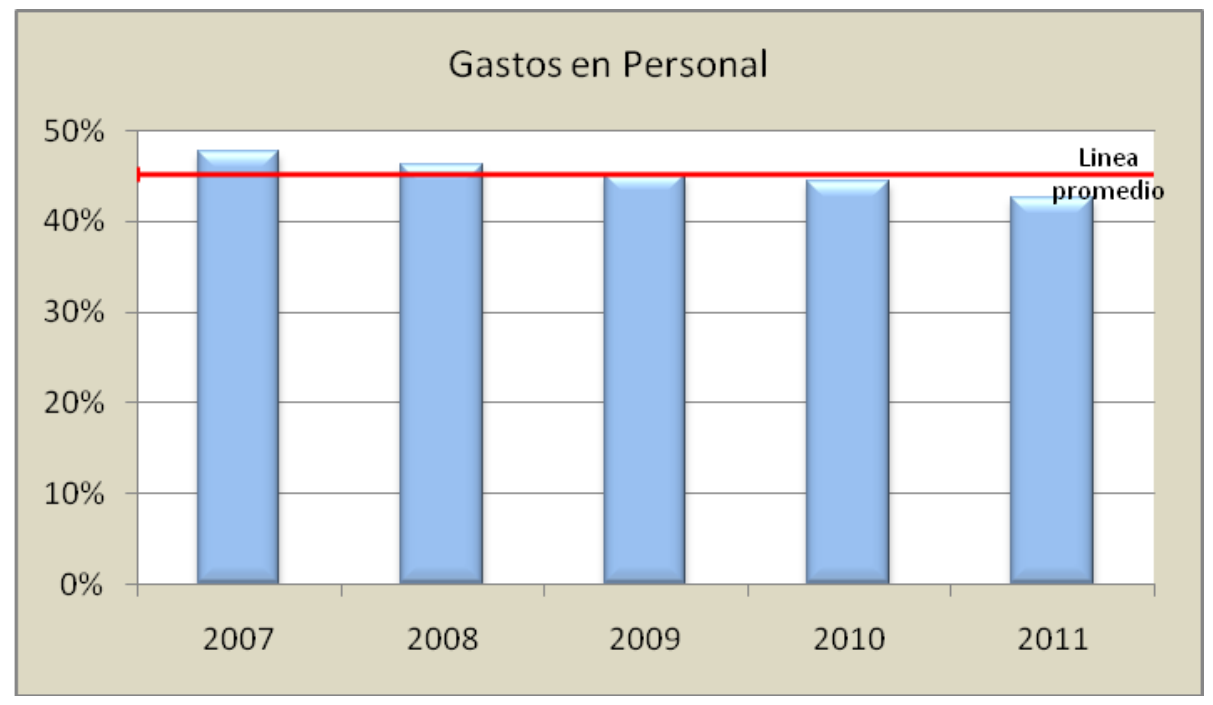

"Fuente: Elaboración propia sobre la base de los datos obtenidos de la Dirección Provincial de Programación y Gestión Municipal”. 


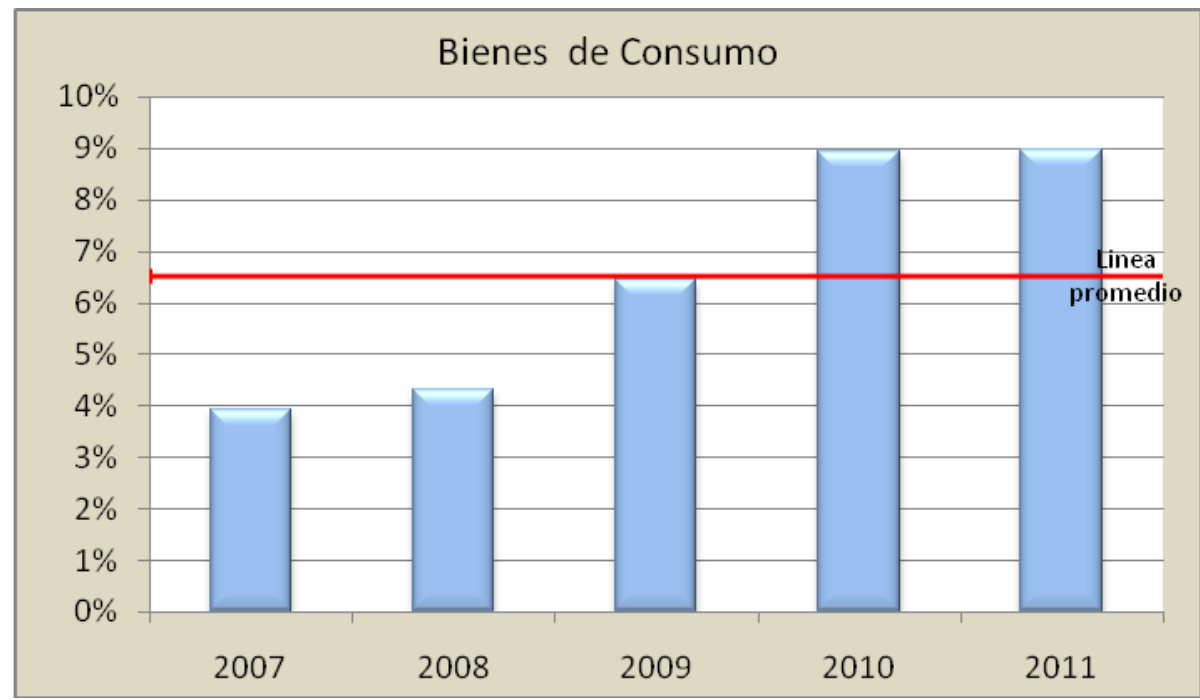

"Fuente: Elaboración propia sobre la base de los datos obtenidos de la Dirección Provincial de Programación y Gestión Municipal".

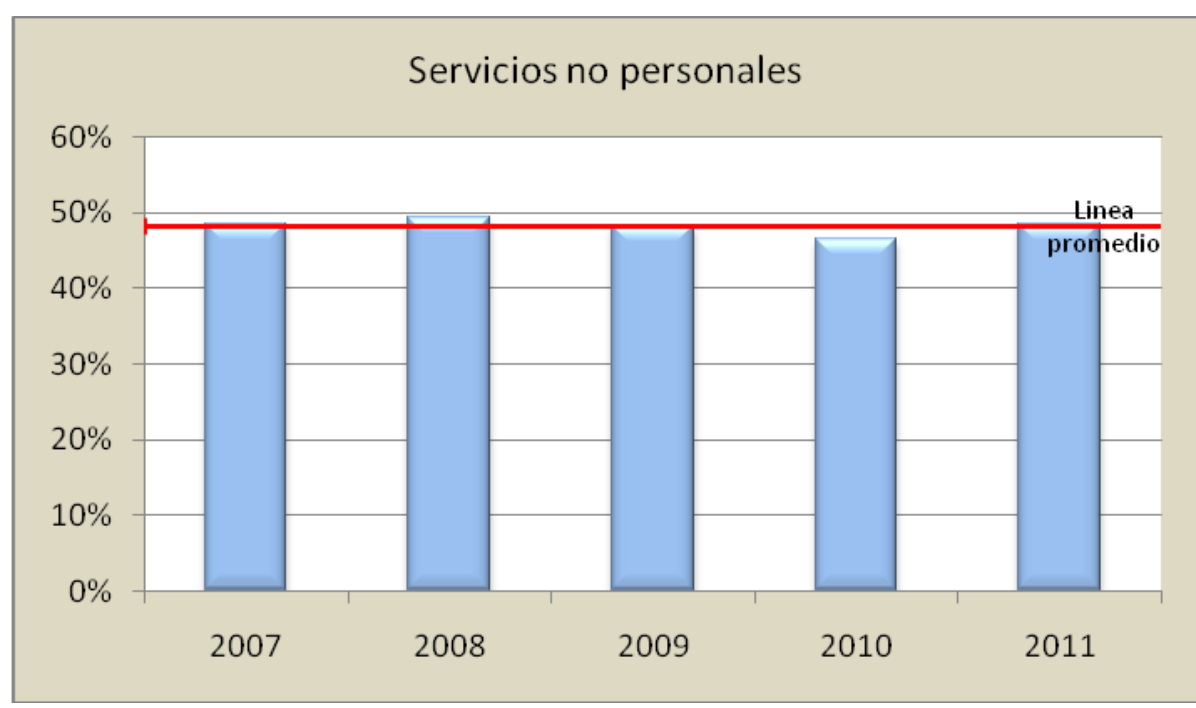

"Fuente: Elaboración propia sobre la base de los datos obtenidos de la Dirección Provincial de Programación y Gestión Municipal”.

Respecto de los Gastos Corrientes el mayor promedio se puede observar en los Servicios no personales con un $48 \%$, luego los Gastos en personal en un $45 \%$ promedio y por último los Bienes de Consumo que representan un promedio del $7 \%$.

La mayor variación a lo largo de los 5 años observados, se producen en los Bienes de Consumo,cuya aumento se da del $4 \%$ en el año 2007 al $9 \%$ en el año 2011; manteniendose contanste en los dos ùltimos años. 


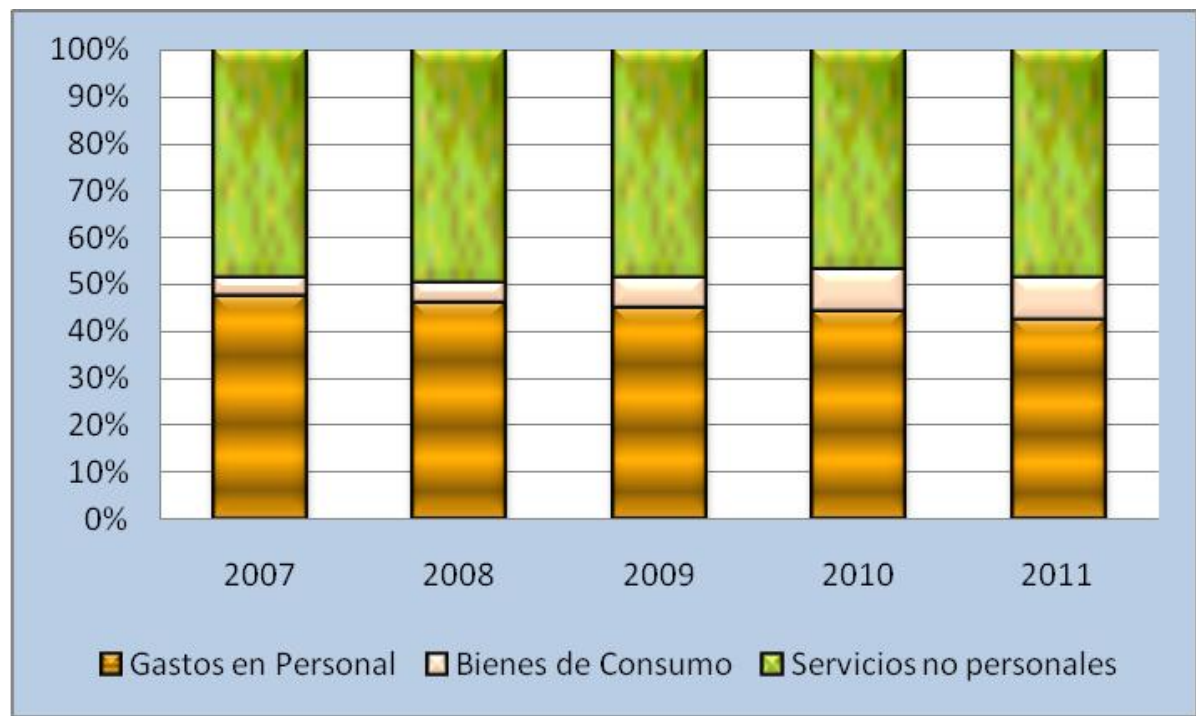

"Fuente: Elaboración propia sobre la base de los datos obtenidos de la Dirección Provincial de Programación y Gestión Municipal”.

Gastos de Capital:

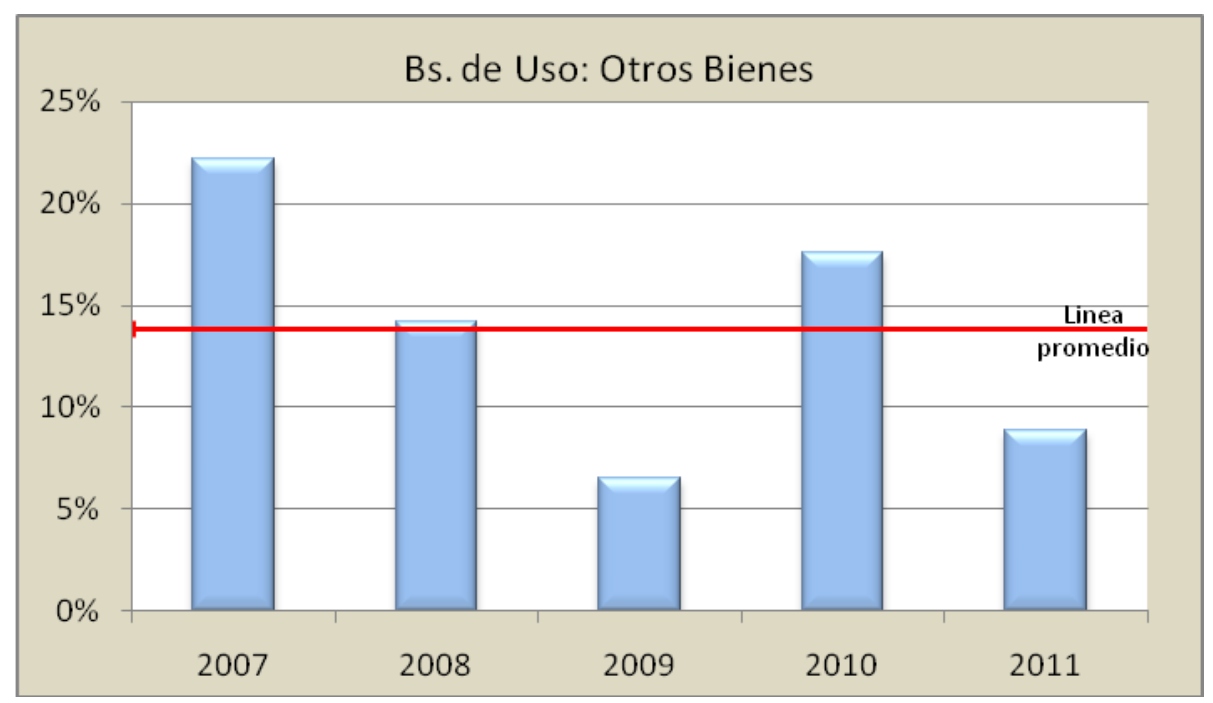

"Fuente: Elaboración propia sobre la base de los datos obtenidos de la Dirección Provincial de Programación y Gestión Municipal”. 


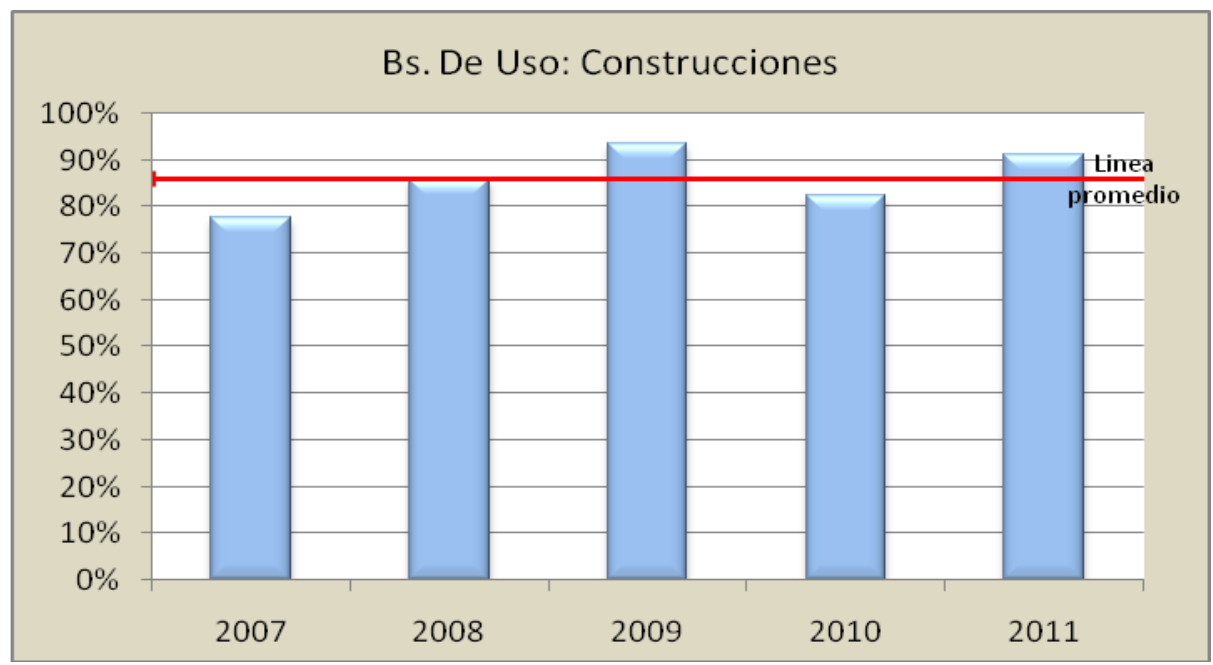

"Fuente: Elaboración propia sobre la base de los datos obtenidos de la Dirección Provincial de Programación y Gestión Municipal”.

En relación a los Gastos de Capital, Bienes de Uso -Otros Bienes, se puede observar una tendencia desde el año 2007 al año 2009, aún desciendo por debajo del promedio el cual se ubica en un 14\%. En el Rubro Construcciones se observa lo contrario, es decir, un aumento tendencial hasta el año 2009 , aùn por encima del promedio el cual se ubica en $86 \%$.

El año 2009, es el de menor participación para el rubro Otros Bienes y el de mayor participación para Construcciones, siendo sus porcentajes 7\% y $93 \%$ respectivamente.

Gastos Financieros:

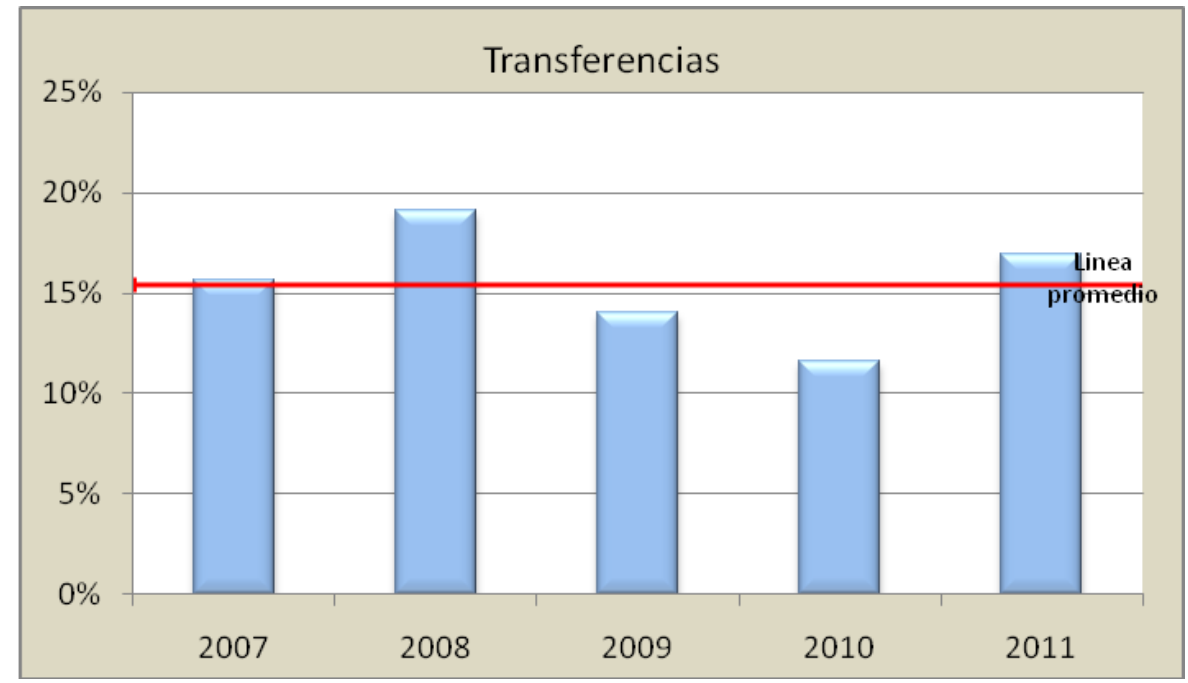

"Fuente: Elaboración propia sobre la base de los datos obtenidos de la Dirección Provincial de Programación y Gestión Municipal”. 


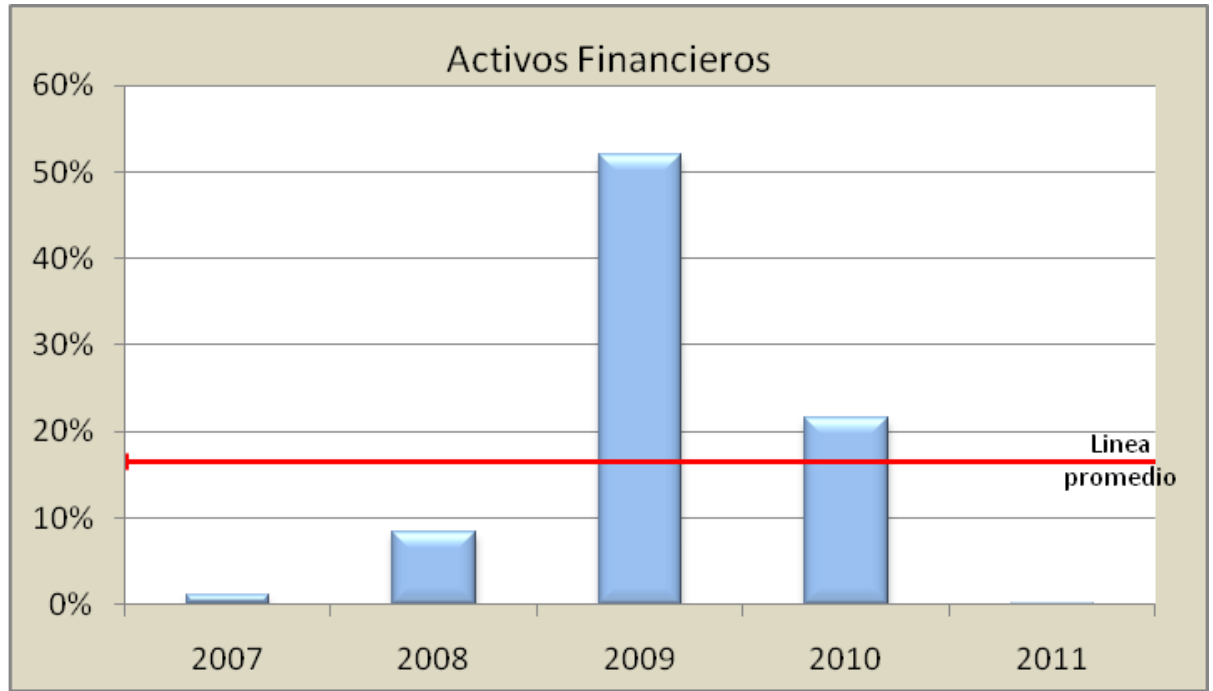

"Fuente: Elaboración propia sobre la base de los datos obtenidos de la Dirección Provincial de Programación y Gestión Municipal”.

Respecto de los Activos Financieros se puede observar que su promedio es del $17 \%$, y su mayor porcentaje de participación dentro de los gastos financieros se observa en el año 2009, (52\%).

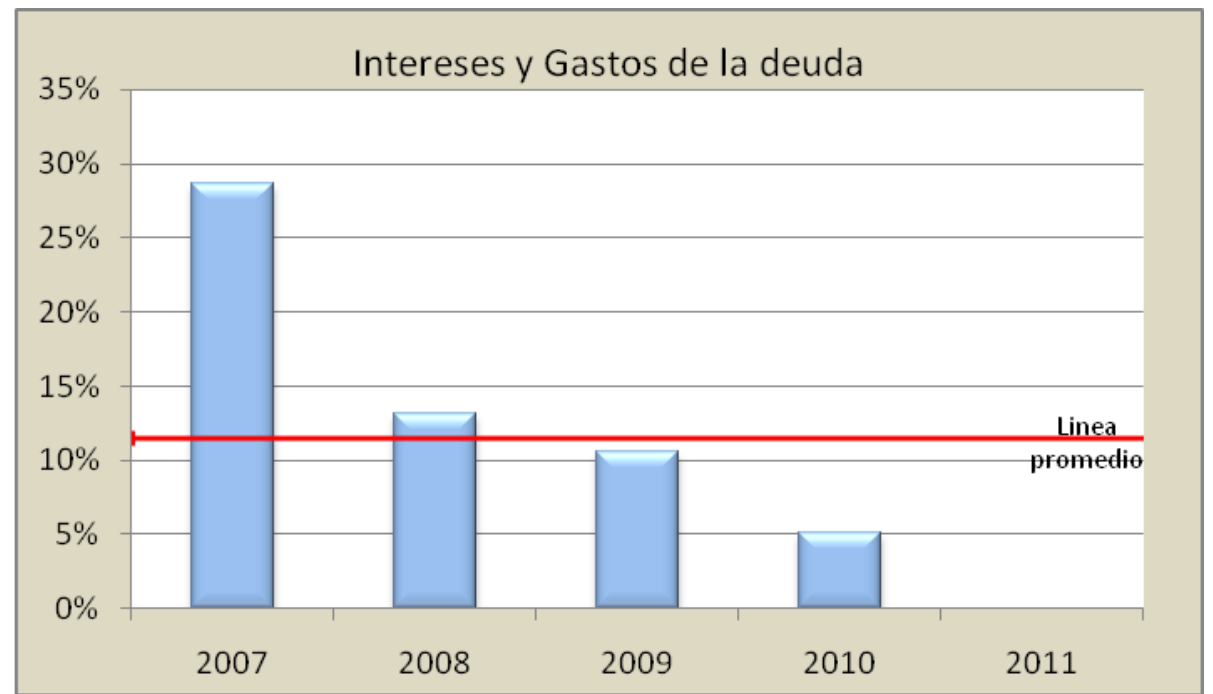

"Fuente: Elaboración propia sobre la base de los datos obtenidos de la Dirección Provincial de Programación y Gestión Municipal”.

Respecto de los Intereses y Gastos de la deuda se puede observar que la participación dentro de los Gastos Financieros ha ido disminuyendo año a año. 
En el año 2007 su participación es del 29\% y en el año 2011 no se pagaron Intereses y Gastos de deuda, siendo su promedio en el término de los cinco años del $12 \%$.

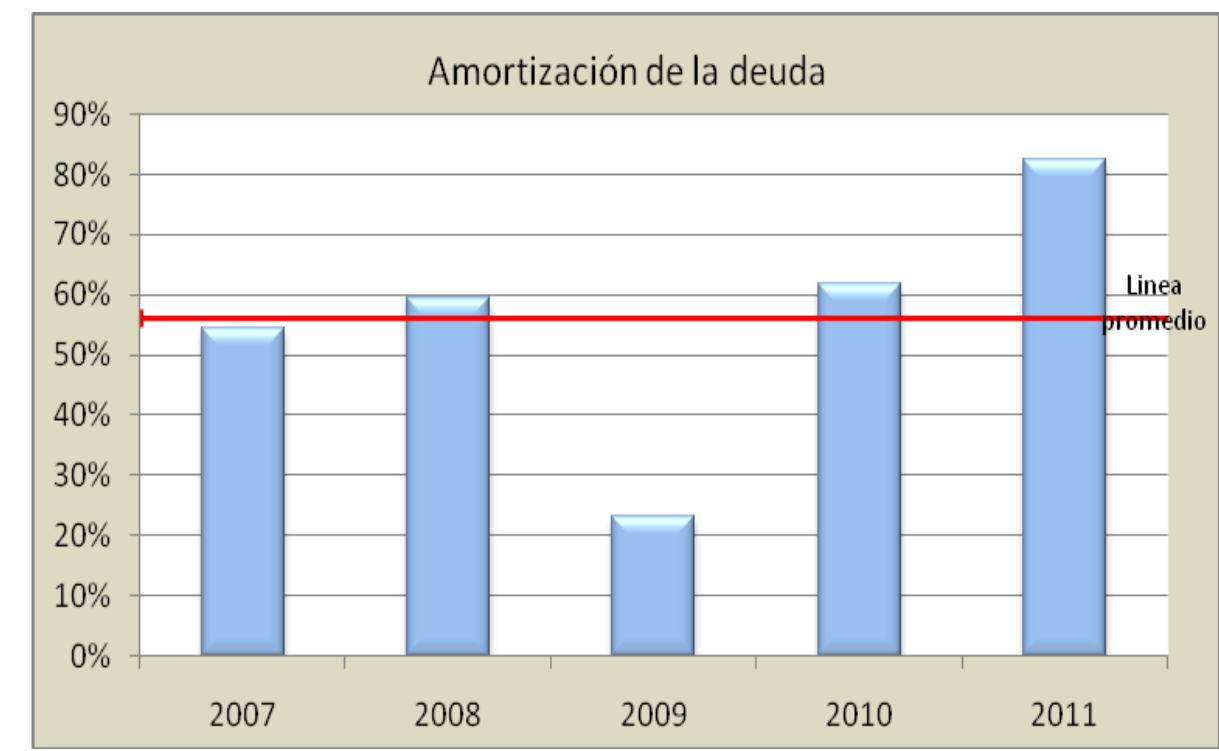

"Fuente: Elaboración propia sobre la base de los datos obtenidos de la Dirección Provincial de Programación y Gestión Municipal”.

En cuanto a la Amortización de la deuda, a partir del año 2009 se observa que existe una tendencia en aumento, colocándose levemente, en el año 2010, por encima del promedio (56\%) y en el año 2011 superando ampliamente el promedio.

Relación Ingresos Corrientes-Gastos Corrientes

\begin{tabular}{|l|r|r|r|r|r|}
\hline & $\mathbf{2 0 0 7}$ & $\mathbf{2 0 0 8}$ & \multicolumn{1}{|c|}{$\mathbf{2 0 0 9}$} & \multicolumn{1}{c|}{$\mathbf{2 0 1 0}$} & $\mathbf{2 0 1 1}$ \\
\hline $\begin{array}{l}\text { Ingresos corrientes/Gastos } \\
\text { corrientes }\end{array}$ & 1,18 & 1,20 & 1,28 & 1,25 & 1,61 \\
\hline $\begin{array}{l}\text { Ingresos corrientes -no } \\
\text { tributarios/Gastos corrientes }\end{array}$ & 0,63 & 0,61 & 0,64 & 0,65 & 0,85 \\
\hline $\begin{array}{l}\text { Ingresos no tributarios/Gasto en } \\
\text { personal }\end{array}$ & 1,32 & 1,31 & 1,42 & 1,45 & 1,91 \\
\hline
\end{tabular}




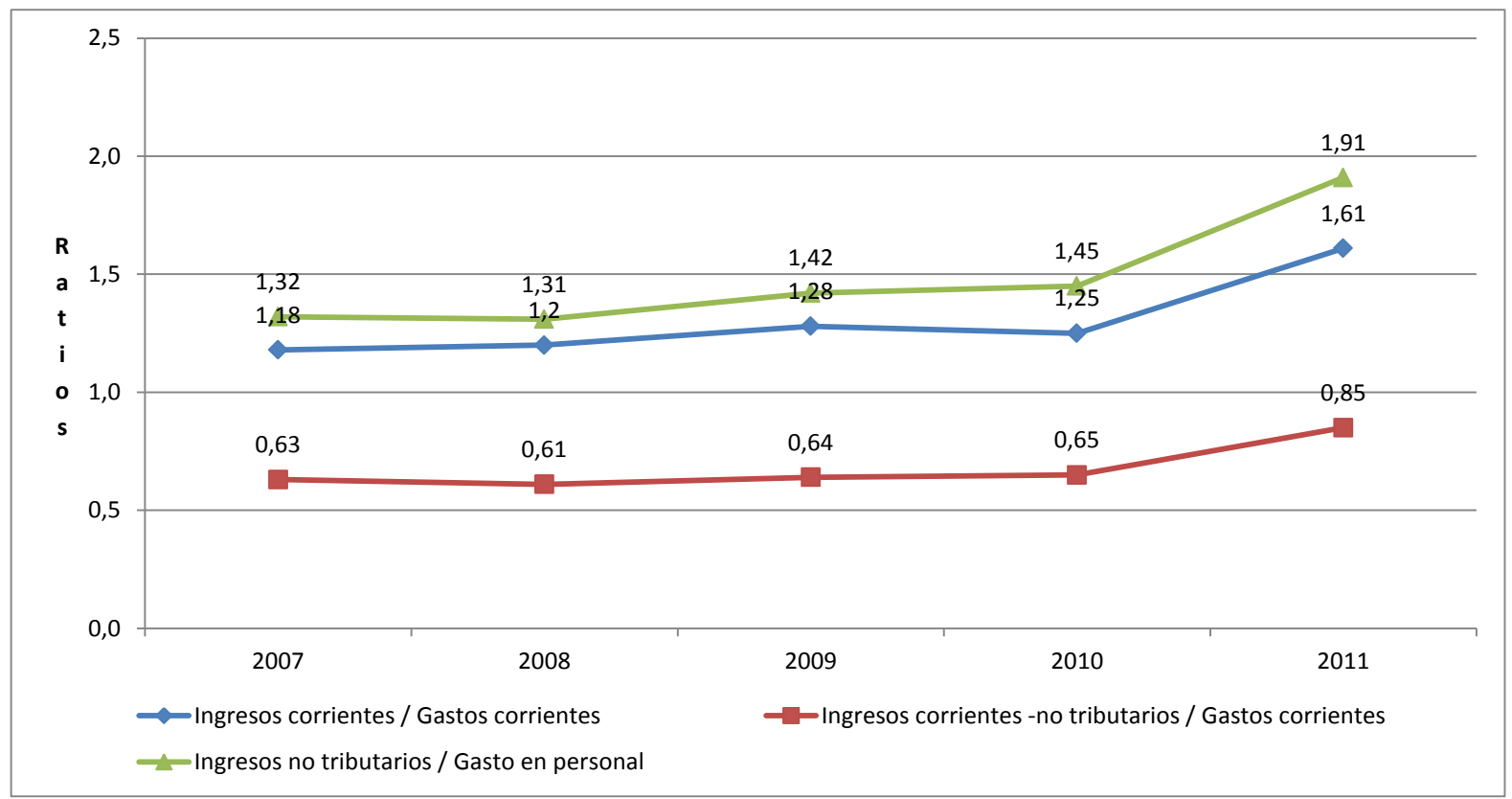

"Fuente: Elaboración propia sobre la base de los datos obtenidos de la Dirección Provincial de Programación y Gestión municipal".

En la Relación Ingresos Corrientes/Gastos Corrientes, se observa que en todos los casos los Ingresos Corrientes superan los Gastos Corrientes.

También se observa en Relación Ingresos Corrientes-Ingresos No tributarios/ Gastos Corrientes, que los recursos de origen municipal ${ }_{14}$, que se recauda a través de Tasas y Derechos, resultan insuficientes para cubrir la totalidad de los gastos corrientes, aunque se debe destacar que a medida que fueron transcurriendo los años (2007 a 2011) dicha relación ha ido aumentando, es decir, el municipio ha ido solventando un mayor porcentaje de dichos gastos corrientes.

Por otra parte la Relación Ingresos Corrientes-Ingresos No tributarios/ Gasto en Personal, muestra que los ingresos de origen municipal,cubren ampliamente los gastos en personal del municipio y,a su vez, dicha relación ha ido aumentando con el transcursos de los años analizados.

\subsection{Análisis Regional: La Plata y la Región LP,B y E.}




\subsubsection{Consolidación del Presupuesto de Gastos Totales de la Región}

\begin{tabular}{|c|c|c|}
\hline Conceptos & Región LP-B y E & La Plata \\
\hline Total de Gastos & $\$ 1.228 .976 .584$ & $\$ 872.392 .544$ \\
\hline
\end{tabular}

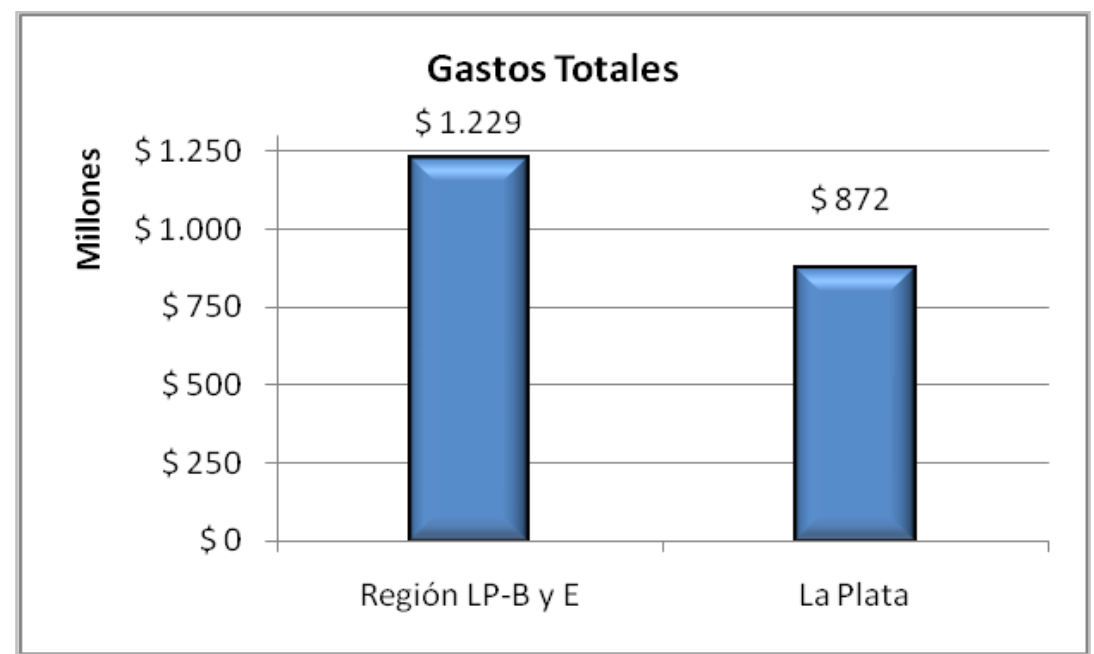

"Fuente: Elaboración propia sobre la base de los datos obtenidos de la Dirección Provincial de Programación y Gestión Municipal”.

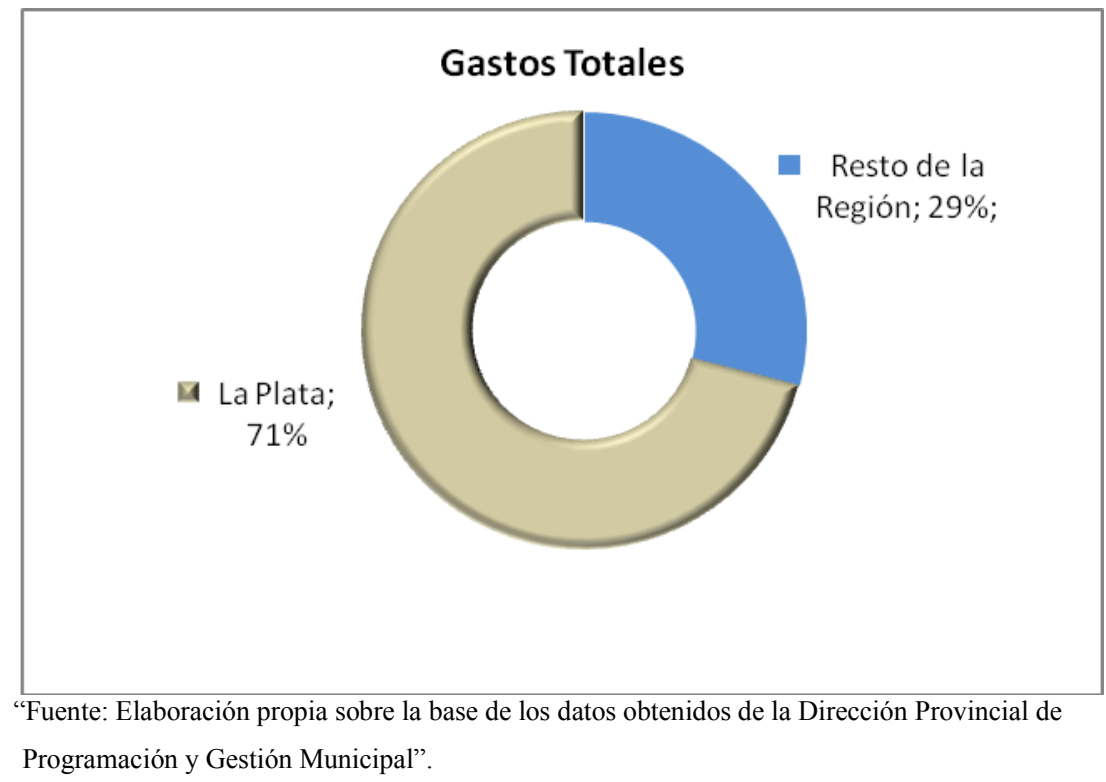


Dentro de los gastos totales de la región, el municipio de La Plata participa en un $71 \%$.

\subsubsection{Discriminación de Gastos totales consolidados para la Región y en comparación con el municipio de La Plata}

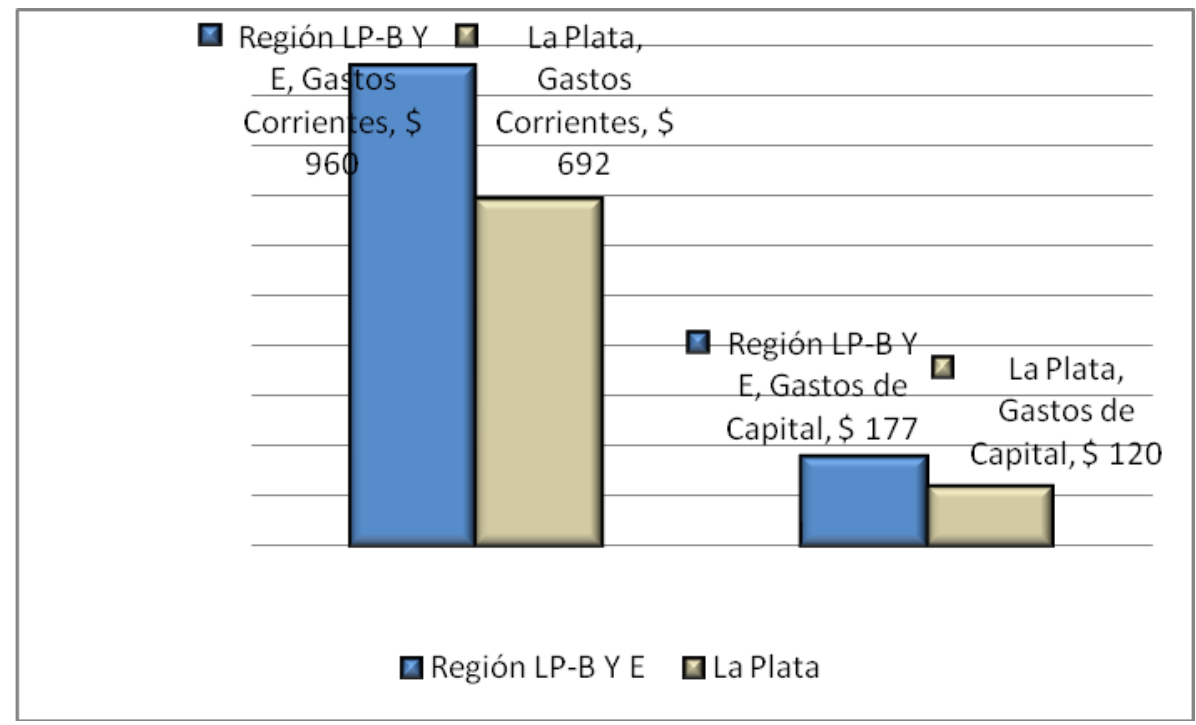

Cifras en millones de pesos

"Fuente: Elaboración propia sobre la base de los datos obtenidos de la Dirección Provincial de Programación y Gestión Municipal”.

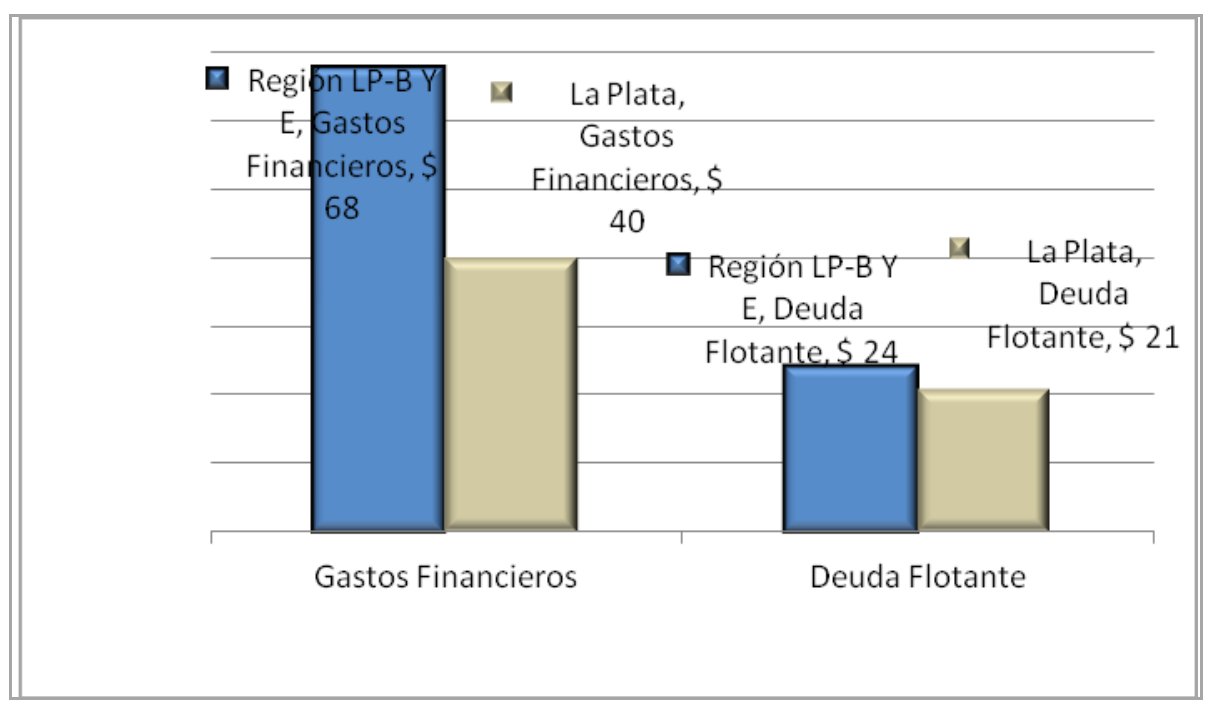

Cifras en millones de pesos

"Fuente: Elaboración propia sobre la base de los datos obtenidos de la Dirección Provincial de Programación y Gestión Municipal”. 


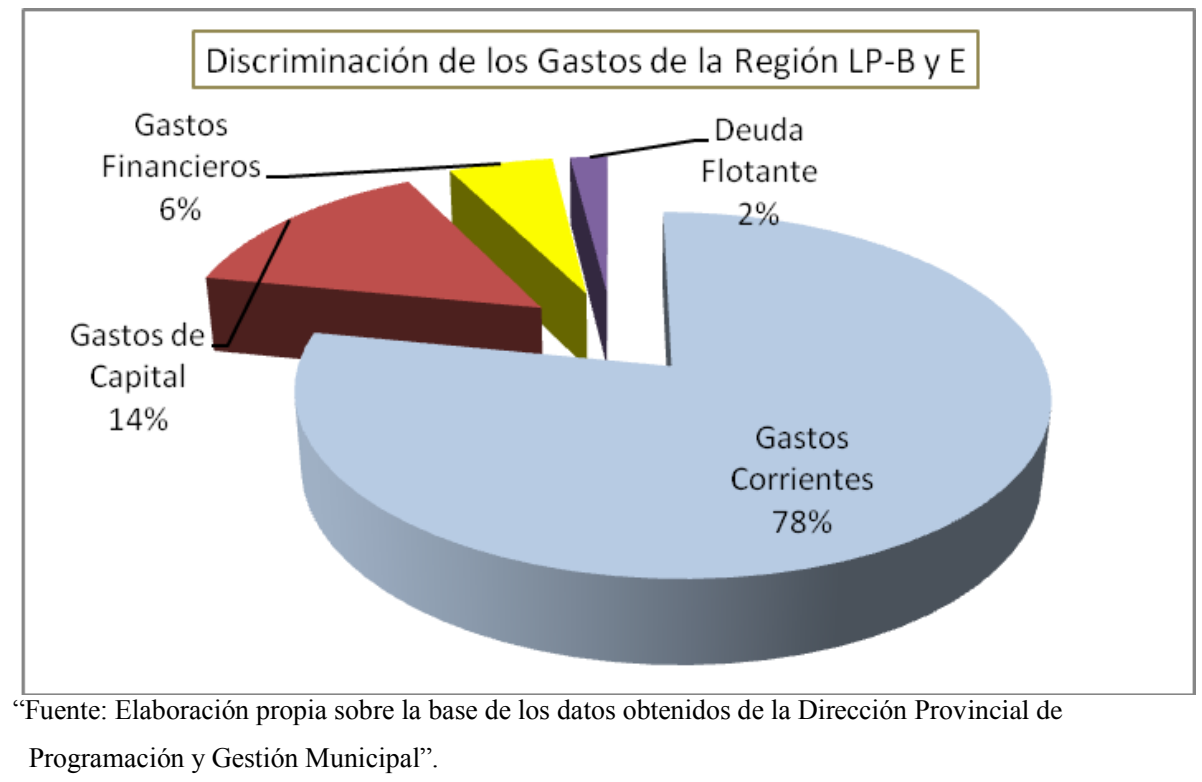

\begin{tabular}{|c|c|c|}
\hline Concepto & Región LP-B Y E & La Plata \\
\hline Gastos Corrientes & \$959.833.031 & $\$ 692.017 .893$ \\
\hline Gastos de Capital & $\$ 177.173 .756$ & $\$ 119.620 .225$ \\
\hline Gastos Financieros & $\$ 67.780 .552$ & \$ 39.949.489 \\
\hline Deuda Flotante & $\$ 24.180 .177$ & $\$ 20.795 .869$ \\
\hline
\end{tabular}

Del total de Gastos de la Región, los gastos corrientes son los que poseen mayor participación.

\subsubsection{Discriminación de los Gastos Corrientes consolidados para la Región y en comparación con el municipio La Plata}

\begin{tabular}{l|r|r|}
\hline \multicolumn{1}{|c|}{ Concepto } & Región LP-B Y E & \multicolumn{1}{|c|}{ La Plata } \\
\hline Gastos en Personal & $\$ 431.285 .300$ & $\$ 294.396 .162$ \\
\hline Bienes de Consumo & $\$ 118.378 .080$ & $\$ 62.082 .416$ \\
\hline $\begin{array}{l}\text { Servicios no Personales } \\
\text { "Fuente: Elaboración propia sobre la base de los datos obtenidos de la Dirección Provincial de } \\
\text { Programación y Gestión Municipal". }\end{array}$ & &
\end{tabular}




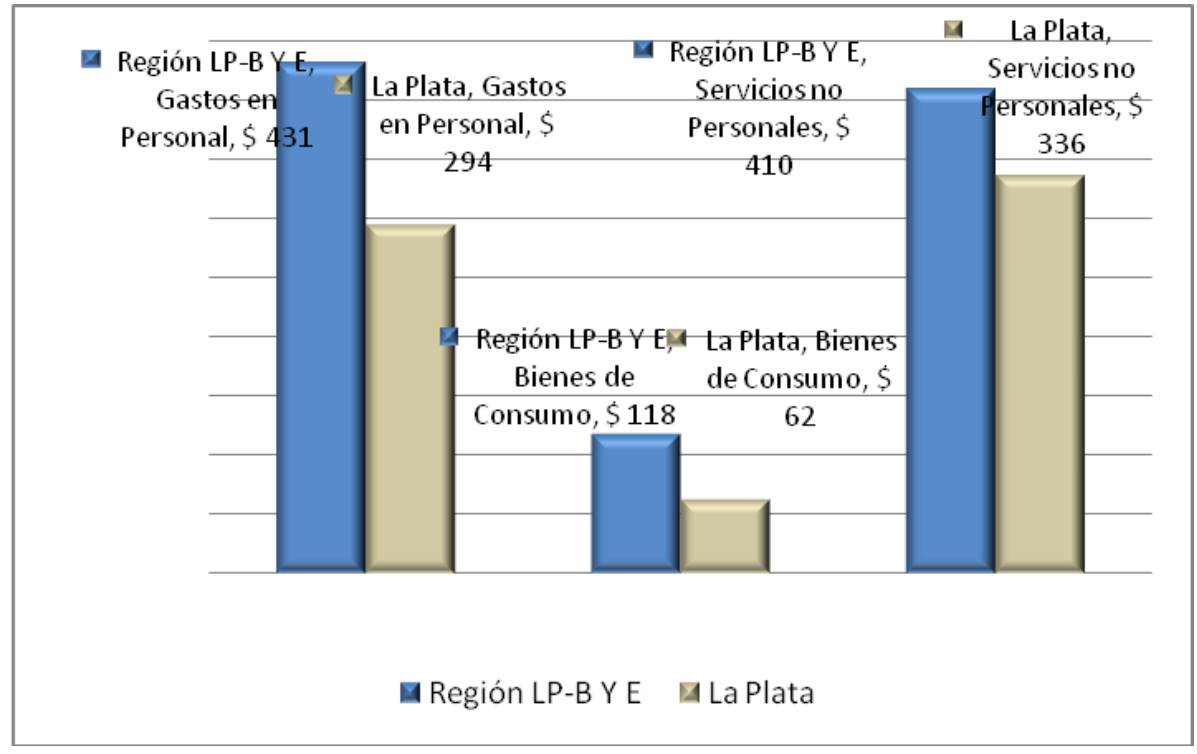

\section{Cifras en millones de pesos}

"Fuente: Elaboración propia sobre la base de los datos obtenidos de la Dirección Provincial de Programación y Gestión Municipal".

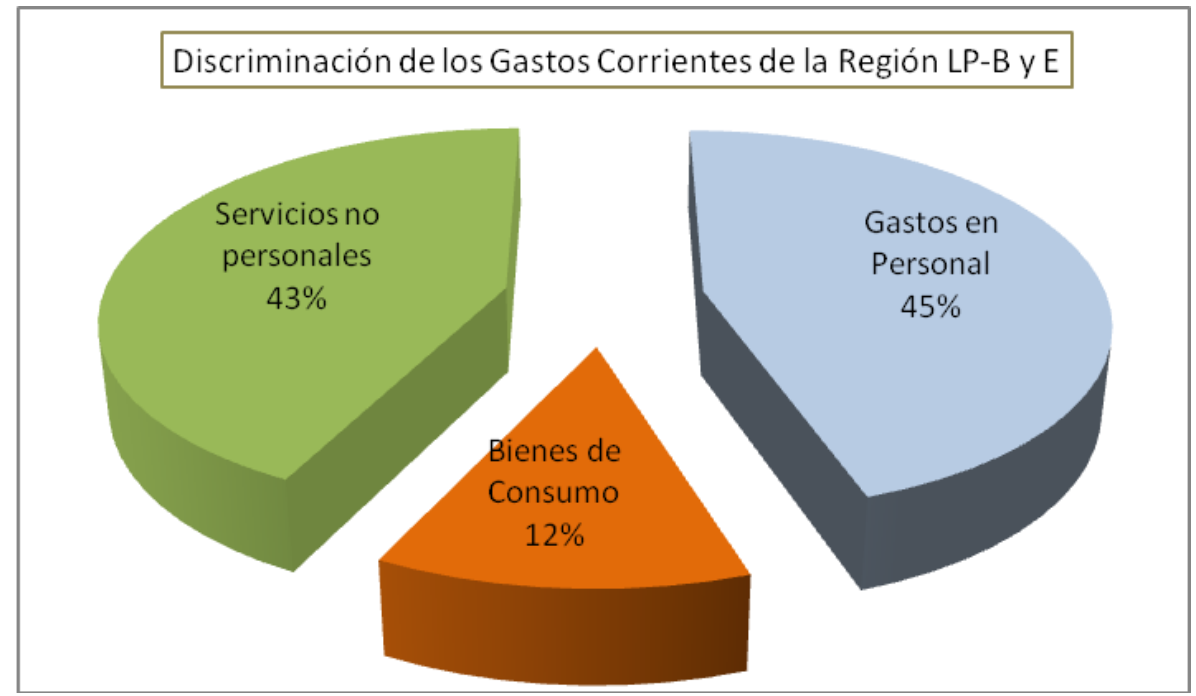

"Fuente: Elaboración propia sobre la base de los datos obtenidos de la Dirección Provincial de Programación y Gestión Municipal".

Se puede observar que el mayor gasto corriente en la región, es el gasto en personal con un $45 \%$, luego Servicios no personales con un $43 \%$ y por ùltimo Bienes de consumo un $12 \%$. 


\subsubsection{Consolidación de los Gastos totales de la Región discriminados por tipo de} gasto

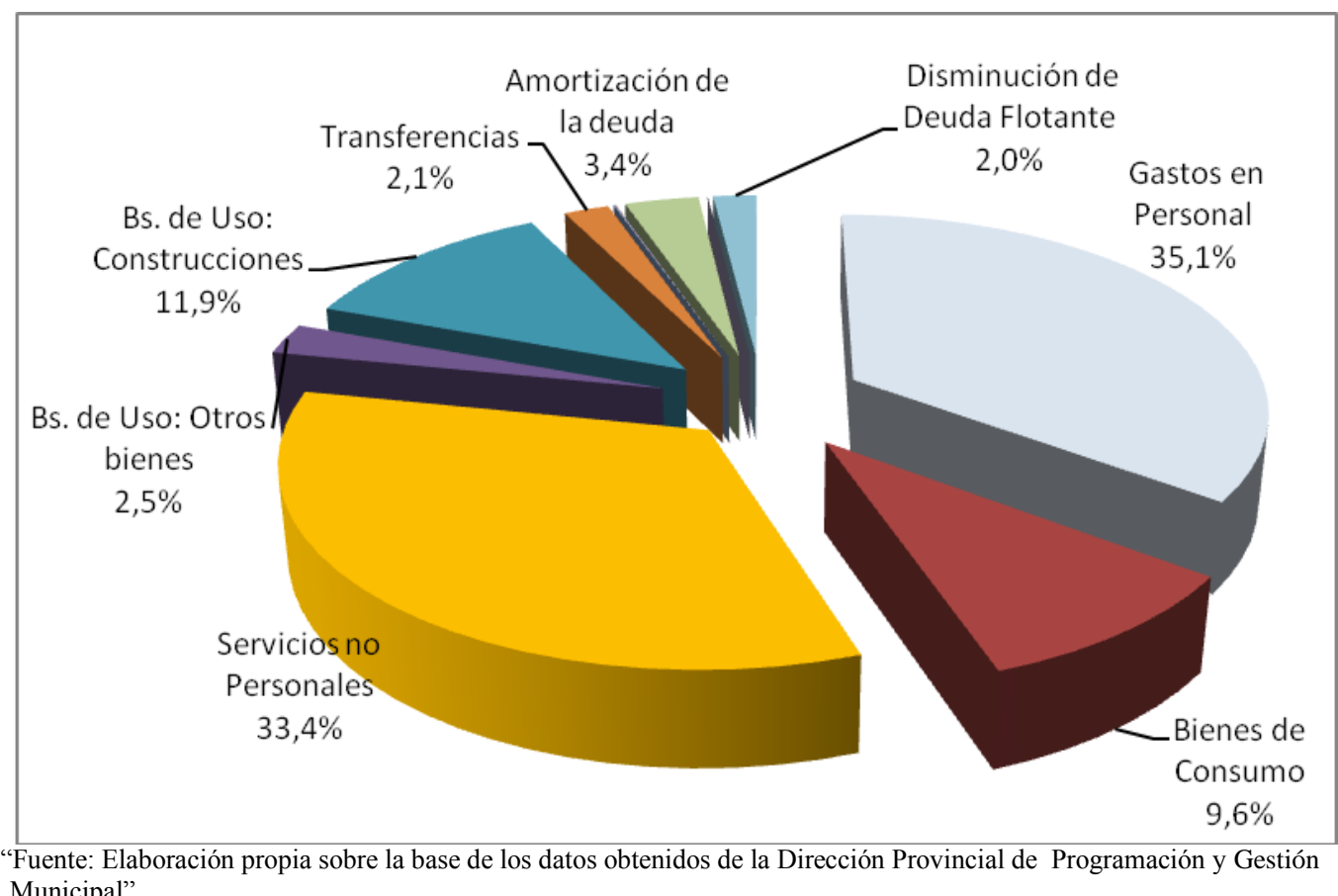

Nota: Otros gastos, Activos financieros e intereses y gastos de la Deuda dan un porcentaje de participación de prácticamente cero

\begin{tabular}{lr}
\multicolumn{1}{c}{ Concepto } & Región LP-B YE. \\
Gastos en Personal & $\$ 431.285 .300$ \\
Bienes de Consumo & $\$ 118.378 .080$ \\
Servicios no Personales & $\$ 410.169 .651$ \\
\hline Bs. de Uso: Otros bienes & $\$ 30.875 .945$ \\
\hline Bs. de Uso: Construcciones & $\$ 146.297 .811$ \\
Transferencias & $\$ 25.264 .025$ \\
\hline Activos Financieros & $\$ 871.597$ \\
\hline Intereses y Gastos de la deuda & $\$ 222.077$ \\
\hline Amortización de la deuda & $\$ 41.422 .854$ \\
Otros gastos & $\$ 9.068$ \\
\hline Disminución de Deuda Flotante & $\$ 24.180 .177$ \\
\hline Total de Gastos & $\$ 1.228 .976 .584$ \\
\hline "Fuente: Elaboración propia sobre la base de los datos obtenidos de la Dirección Provincial \\
de Programación y Gestion Municipal".
\end{tabular}

Respecto de la totalidad de los gastos, se destacan con su mayor porcentaje de participación, dentro de los Gastos Corrientes: Gasto en personal $35,1 \%$ y servicios no personales $33,4 \%$ y en tercer lugar Bienes de usoconstrucciones con un 11,9\%, correspondiente a Gastos de Capital. 


\subsubsection{Consolidación del Presupuesto de Ingresos Totales de la Región}

\begin{tabular}{c|ccc} 
Concepto & Región LP-B y E & La Plata \\
\hline Ingresos Totales & $\$ 1.184 .380 .876$ & $\$ 847.936 .736$
\end{tabular}
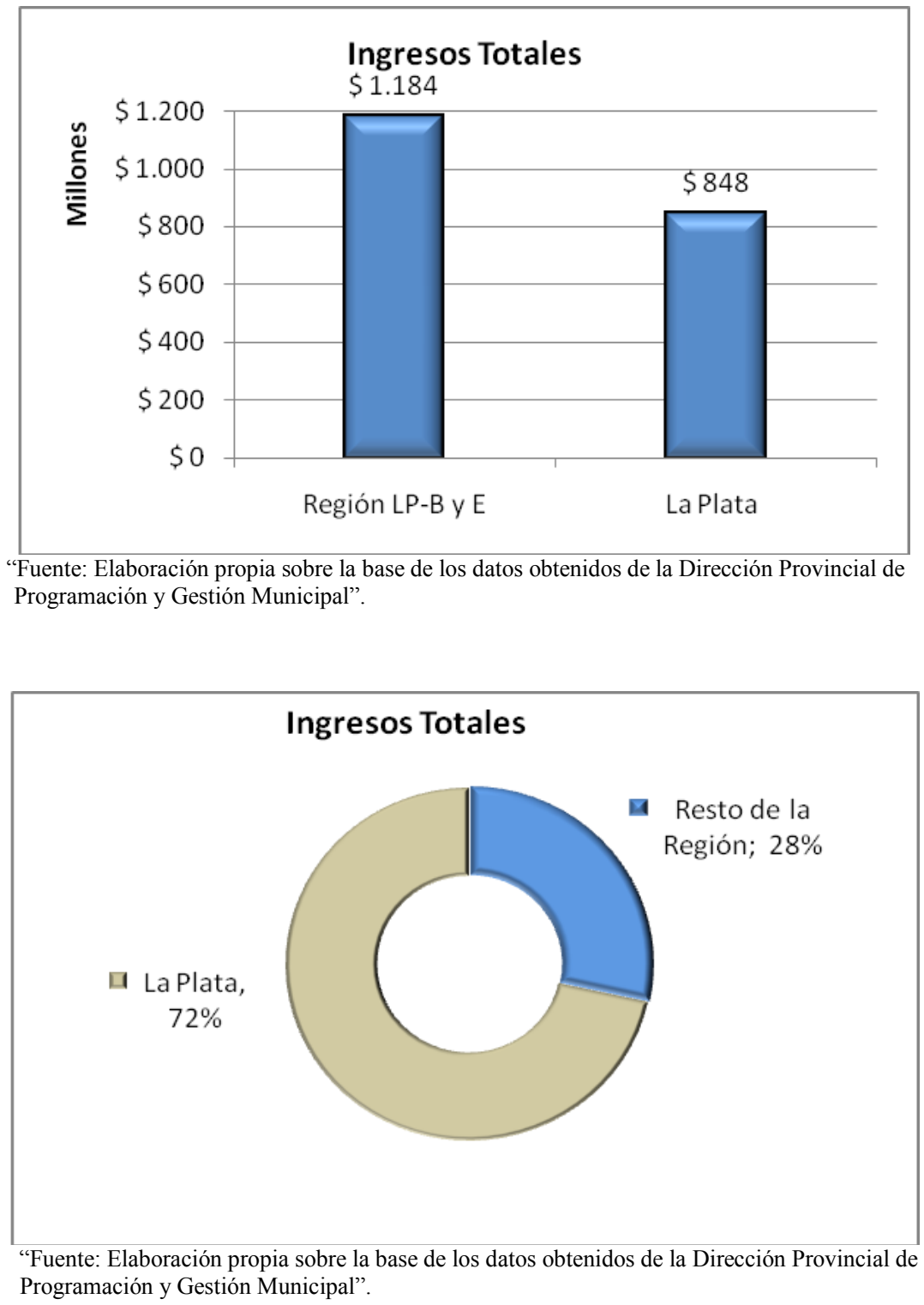

El porcentaje de participación del Municipio de La Plata en la totalidad de los Ingresos de la región es del $72 \%$.

7.3.2.1 Discriminación de los Ingresos totales consolidados para la Región y en comparación con el municipio de La Plata 


\begin{tabular}{|c|r|r|}
\hline Concepto & Región LP-B y E & \multicolumn{1}{c|}{ La Plata } \\
\hline Ingresos Corrientes & $\$ 1.074 .720 .276$ & $\$ 801.963 .331$ \\
\hline Ingresos de Capital & $\$ 109.660 .600$ & $\$ 45.973 .405$ \\
\hline $\begin{array}{l}\text { Inuente: Elaboración propia sobre la base de los datos obtenidos de la Dirección Provincial de } \\
\text { Programación y Gestión Municipal". }\end{array}$
\end{tabular}

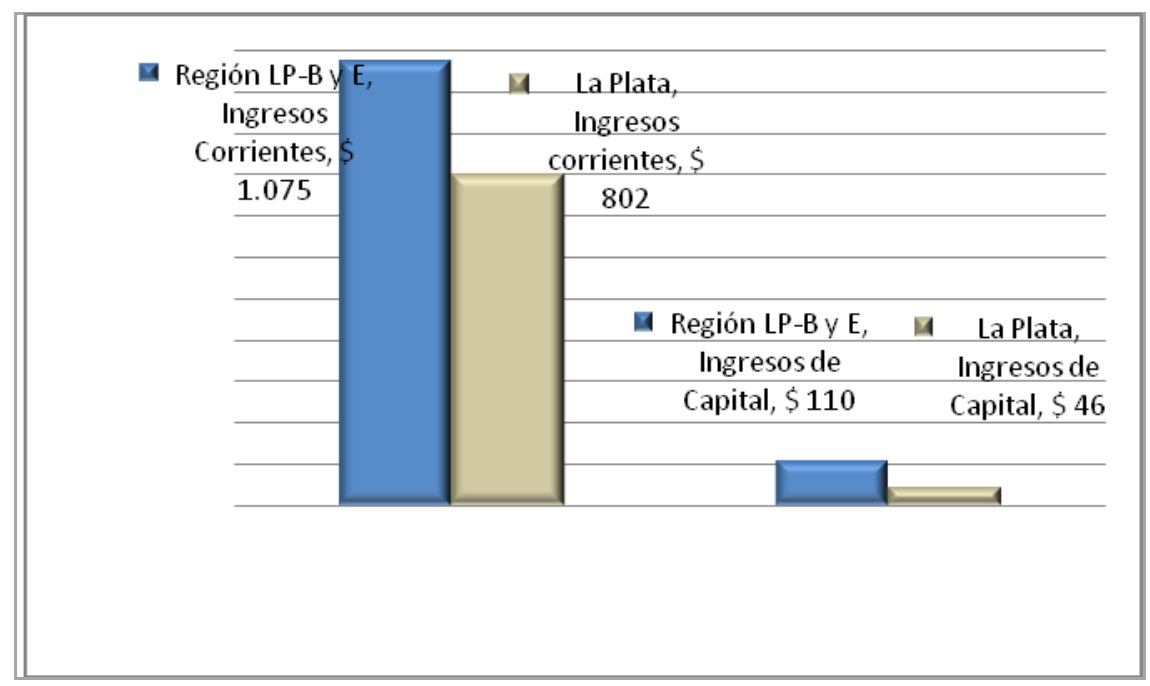

Cifras en millones de pesos

"Fuente: Elaboración propia sobre la base de los datos obtenidos de la Dirección Provincial de Programación y Gestión Municipal”.

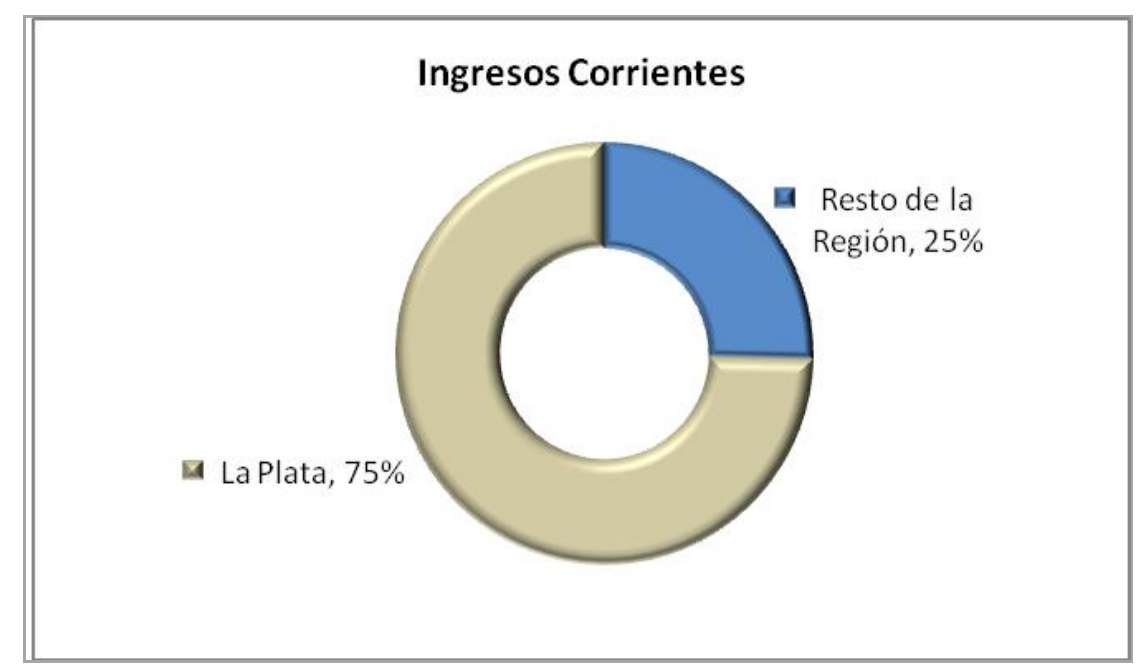

"Fuente: Elaboración propia sobre la base de los datos obtenidos de la Dirección Provincial de Programación y Gestión Municipal". 


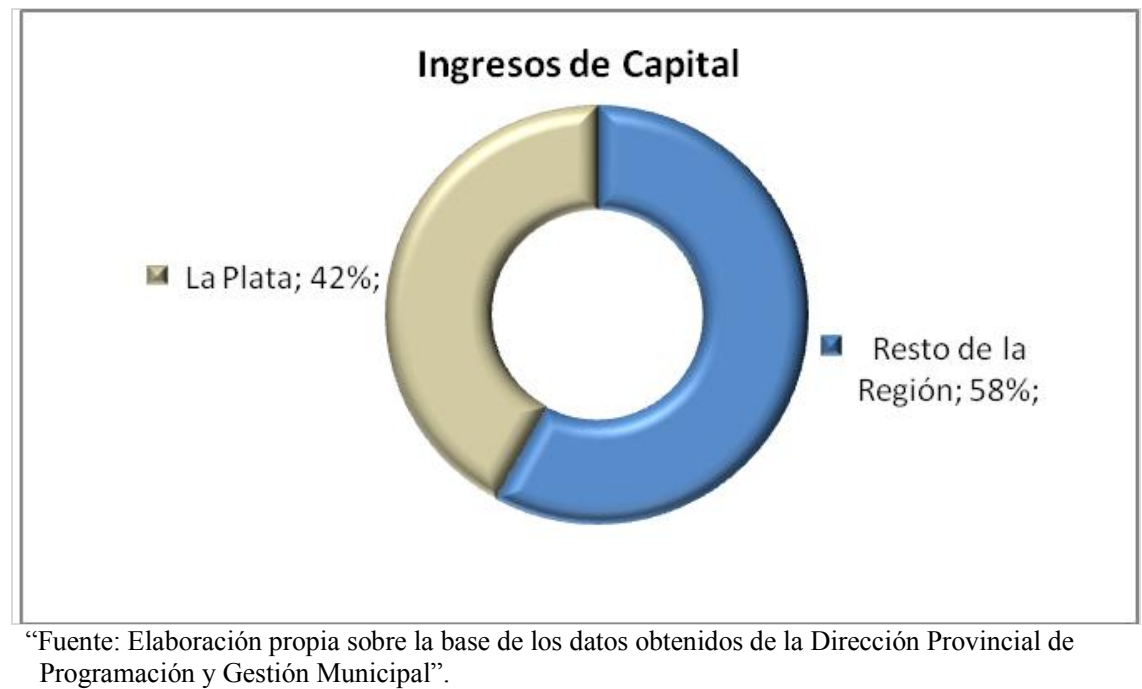

Del total de los Ingresos Corrientes de la Región, la municipalidad de La plata participa en un $75 \%$.

Del total de los Ingresos de Capital de la Región, la municipalidad de La Plata participa en un $42 \%$

\subsubsection{Discriminación de los Ingresos Corrientes consolidados para la Región y en} comparación con el Municipio de La Plata

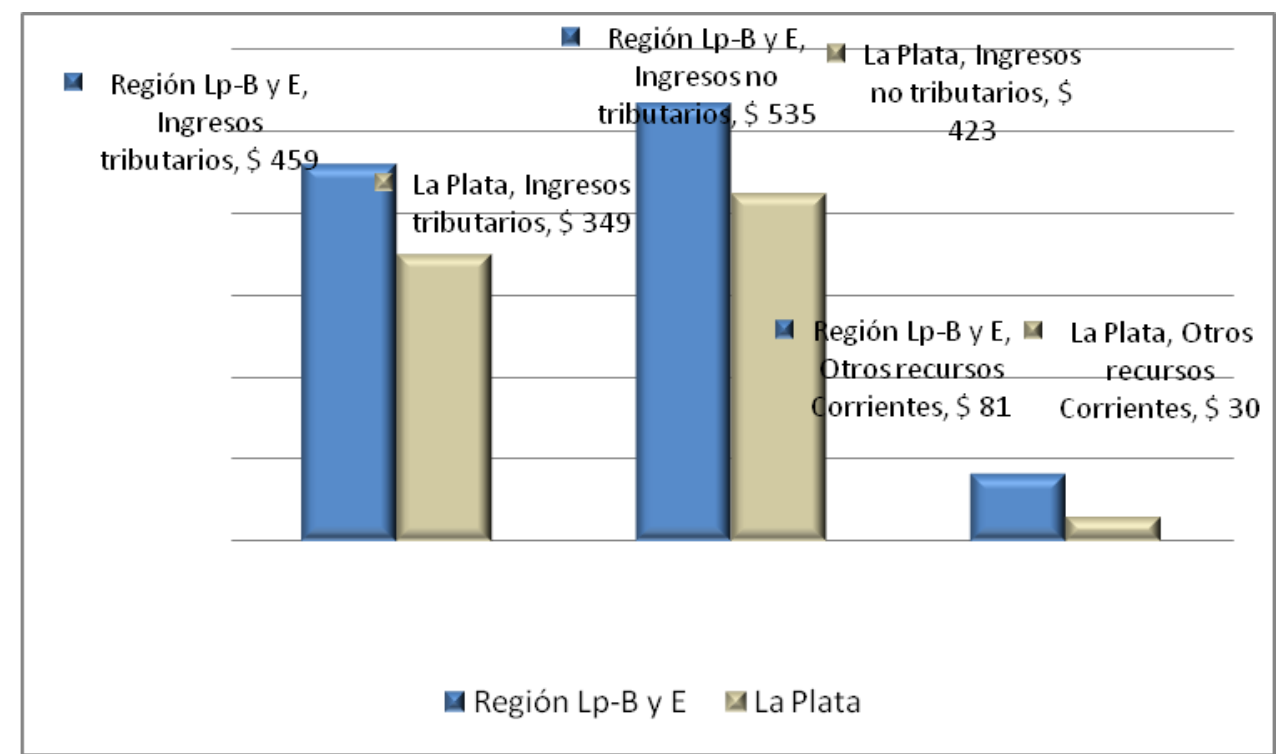

Cifras en millones de pesos

"Fuente: Elaboración propia sobre la base de los datos obtenidos de la Dirección Provincial de Programación y Gestión Municipal". 


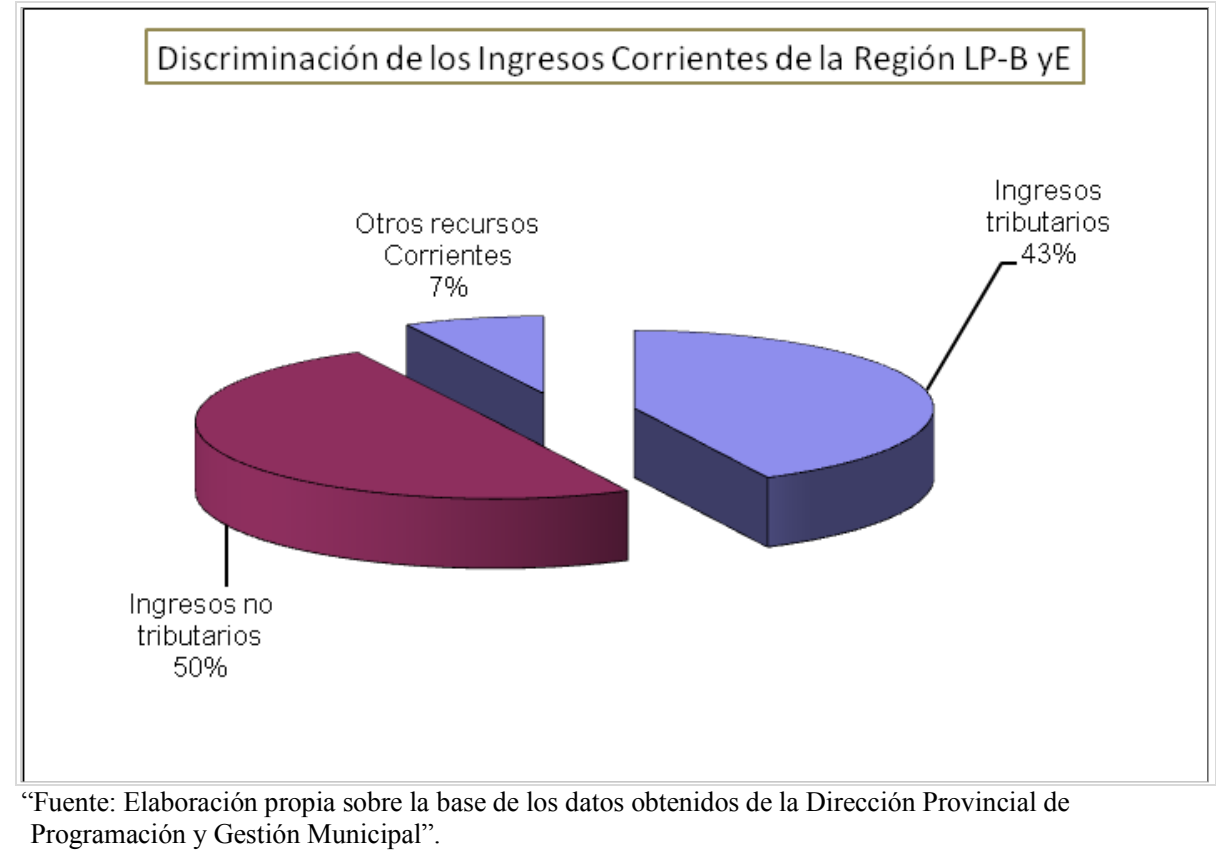

\begin{tabular}{|c|c|c|}
\hline Concepto & Región LP-B y E & La Plata \\
\hline Ingresos tributarios & $\$ 458.727 .428$ & $\$ 348.686 .537$ \\
\hline Ingresos no tributarios & $\$ 534.513 .542$ & $\$ 423.329 .688$ \\
\hline Otros recursos Corrientes & $\$ 81.479 .305$ & $\$ 29.947 .106$ \\
\hline Total de Ingresos Corriente & $\$ 1.074 .720 .276$ & $\$ 801.963 .331$ \\
\hline
\end{tabular}

Se puede observar que los Ingresos Corrientes de la región se componen en un $50 \%$ de Ingresos no tributarios, un $43 \%$ de Ingresos tributarios y un $7 \%$ de Otros Recursos corrientes.

7.3.2.3 Discriminación de los Ingresos de Capital para la Región y en comparación con el municipio de La Plata 


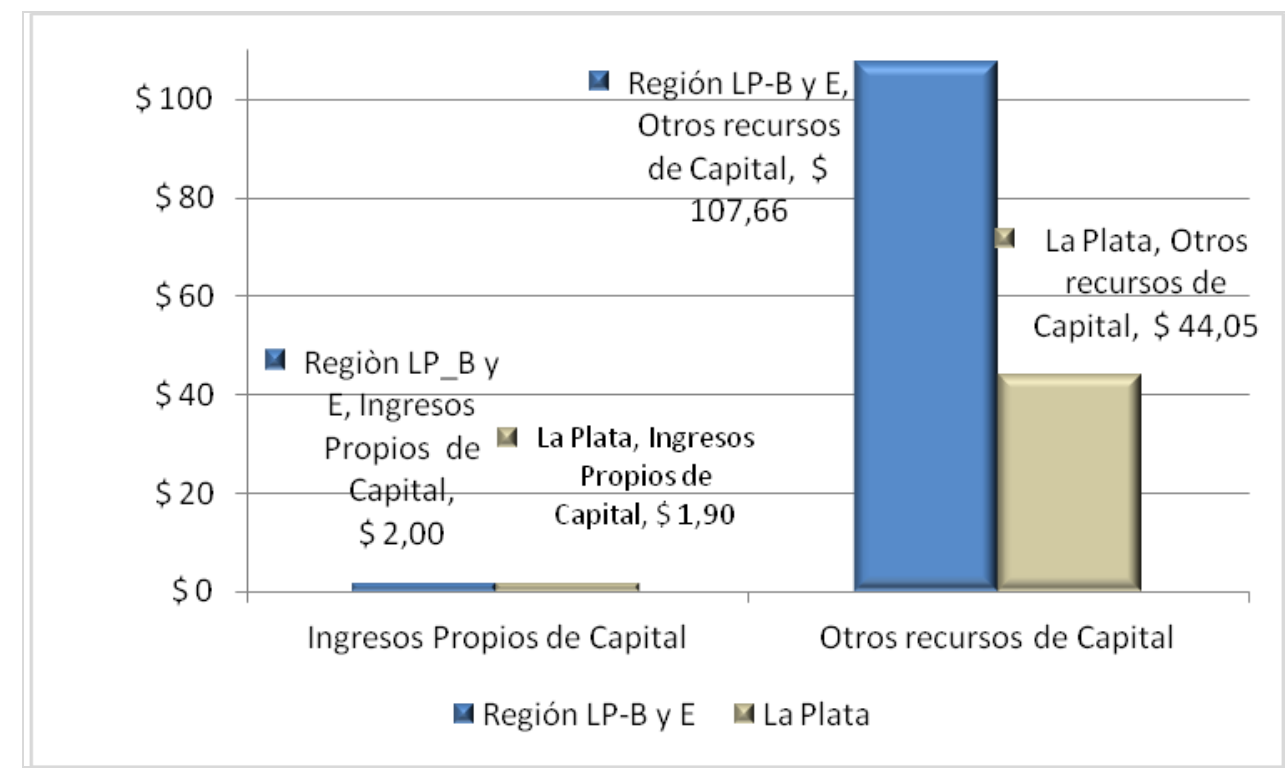

Cifras en millones de pesos

"Fuente: Elaboración propia sobre la base de los datos obtenidos de la Dirección Provincial de Programación y Gestión Municipal”.

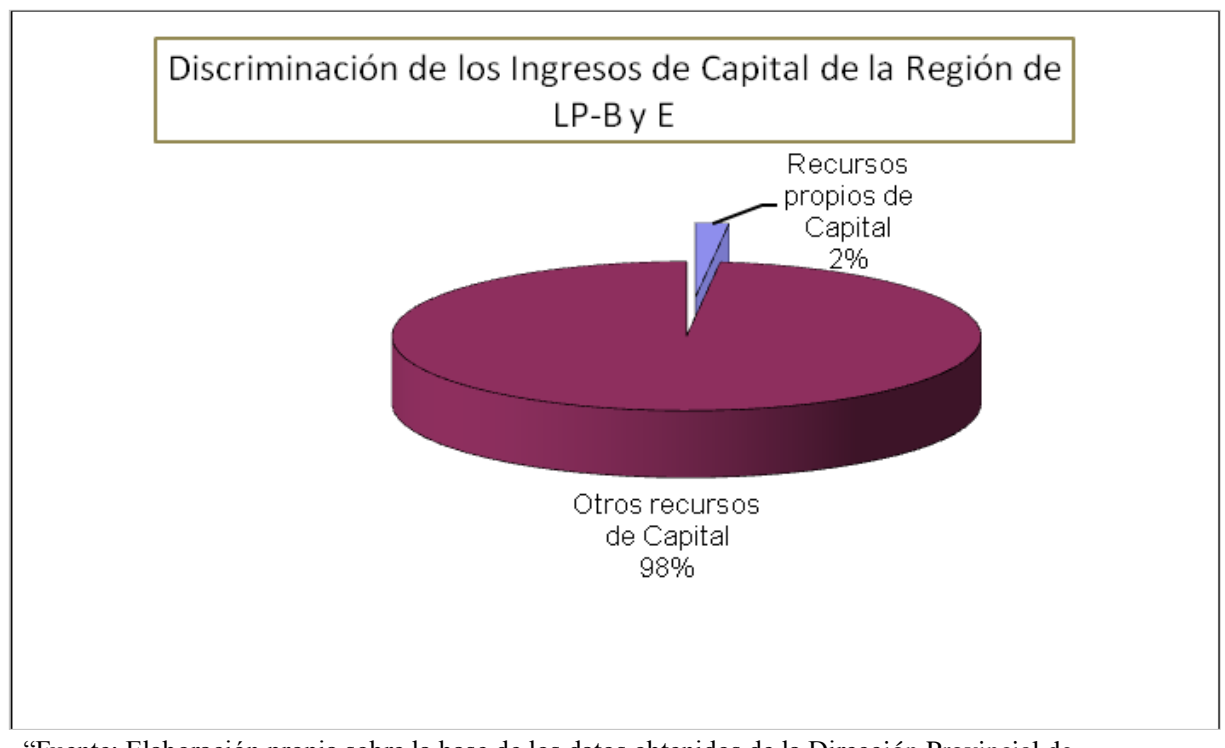

"Fuente: Elaboración propia sobre la base de los datos obtenidos de la Dirección Provincial de Programación y Gestión Municipal".

Nota: La partida otros recursos de capital se componen de Transferencia de capital, Recuperación de Préstamos y Disminución de otros activos financieros.

\begin{tabular}{|c|c|c|}
\hline Concepto & Región LP-B y E & La Plata \\
\hline Ingresos Propios de capital & $\$ 2.003 .469$ & $\$ 1.921 .022$ \\
\hline Otros recursos de Capital & $\$ 107.657 .131$ & $\$ 44.052 .383$ \\
\hline Total de Ingresos de Capital & $\$ 109.660 .600$ & $\$ 45.973 .405$ \\
\hline
\end{tabular}


7.3.3 Transferencias realizadas por el gobierno de la provincia de Buenos Aires a la Región

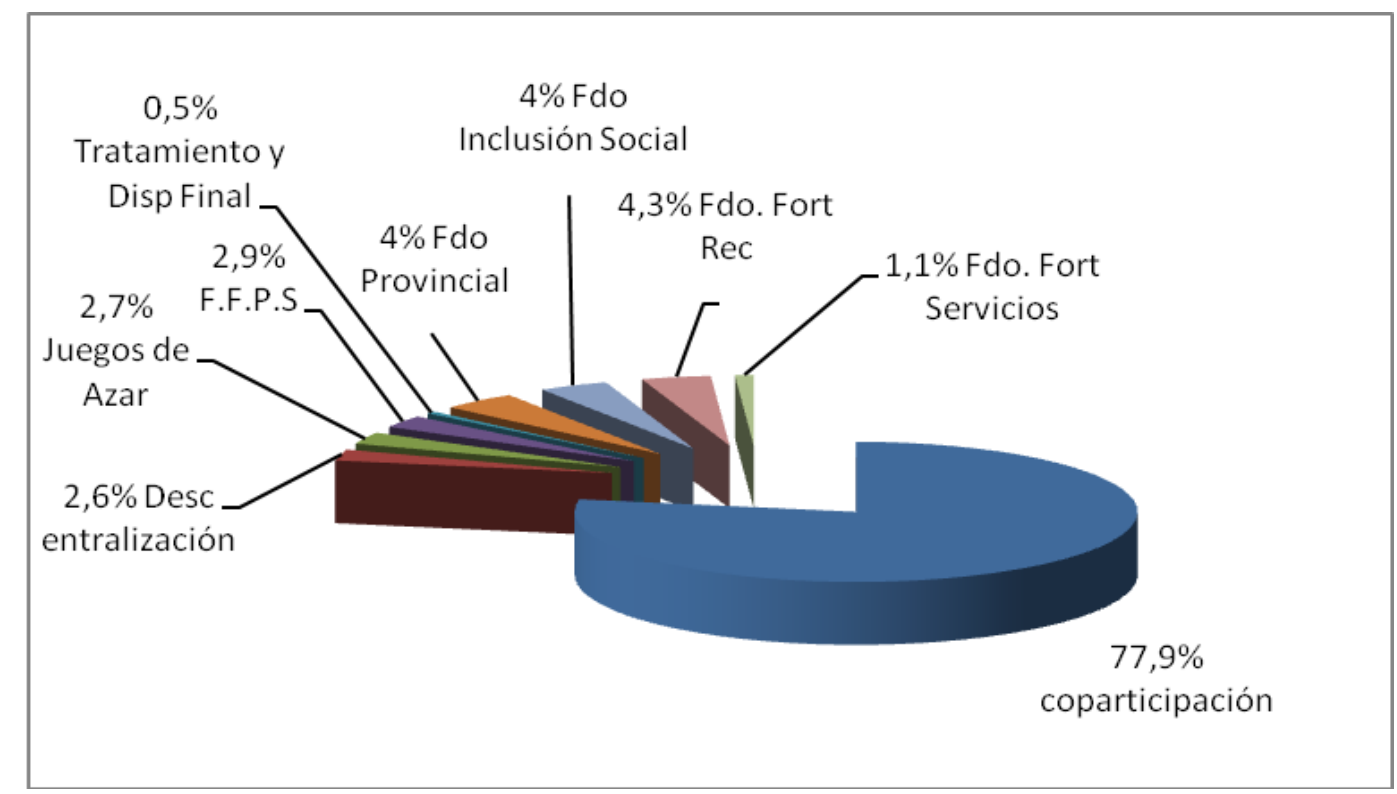

"Fuente: Elaboración propia sobre la base de los datos obtenidos a través de la página web: www.ec.gba.gov.ar/ areas/Sub_Politica_Coord_Eco/CoordMunicipal/municipios"

De las transferencias recibidas por los municipios de la Región, mayoritariamente provienen de fondos de coparticipación.

7.3.4 Detalle de la composición de la Transferencia por descentralización realizada por el gobierno de la provincia de Buenos Aires a la Región.

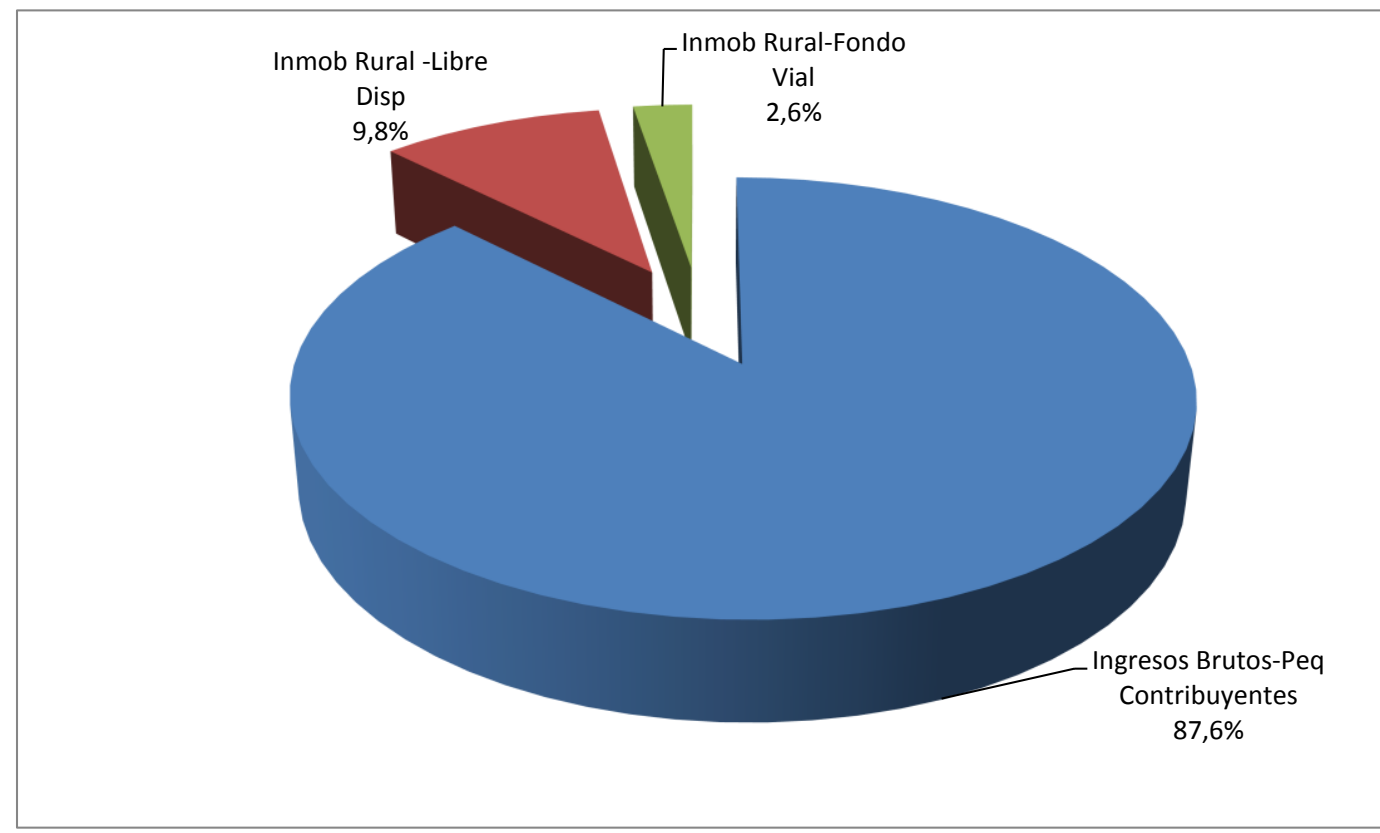

"Fuente: Elaboración propia sobre la base de los datos obtenidos a través de la página www.ec.gba.gov.ar/ areas/Sub_Politica_Coord_Eco/CoordMunicipal/municipios" 
De las transferencias por descentralización recibidas por los municipios de la Región, mayoritariamente provienen de Ingresos Brutos-pequeños contribuyentes.

7.3.5 Comparación de los Gastos en personal de la región con el municipio de La Plata

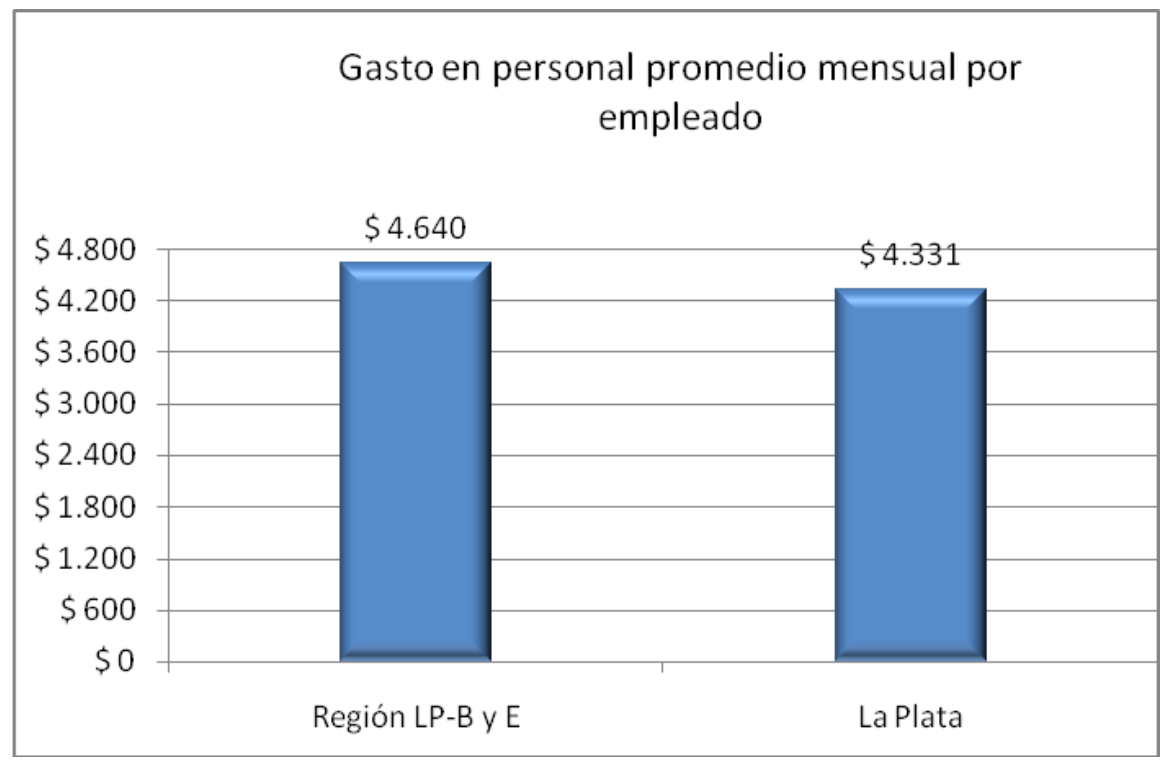

"Fuente: Elaboración propia sobre la base de los datos obtenidos de la Dirección Provincial de Programación y Gestión Municipal”.

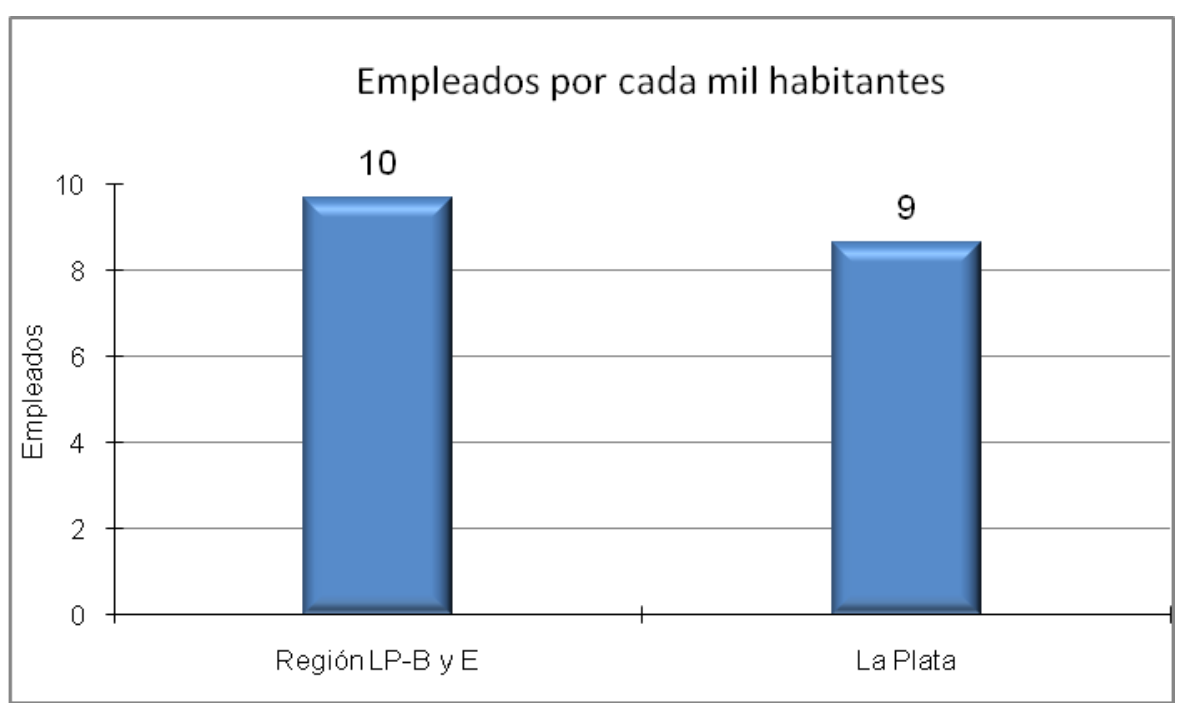

"Fuente: Elaboración propia sobre la base de los datos obtenidos de la Dirección Provincial de Programación y Gestión Municipal y censo 2010- indec". 


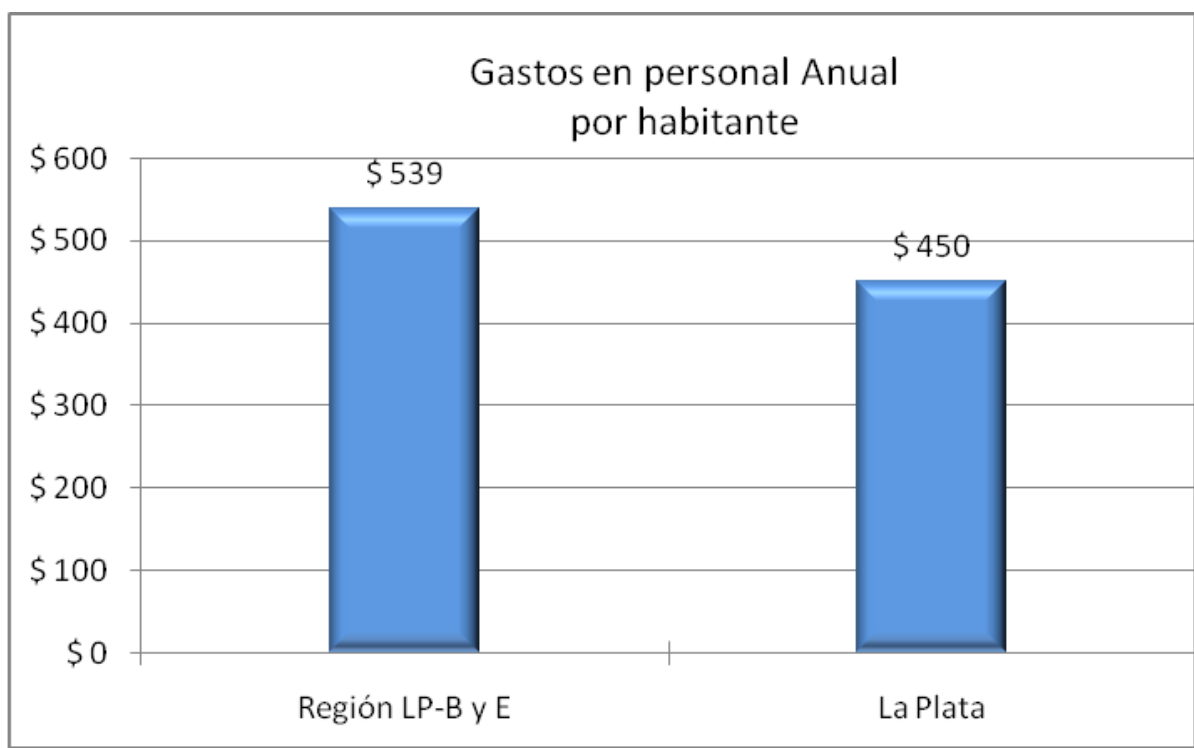

"Fuente: Elaboración propia sobre la base de los datos obtenidos de la Dirección Provincial de Programación y Gestión Municipal y censo 2010-indec".

La relación Gastos en Personal promedio mensual por empleado resultó menor para el municipio de La Plata respecto de la región, igual comportamiento ocurre para los parámetros cantidad de empleados municipales por cada mil habitantes y Gasto en personal anual por habitante.

\subsection{Comparación Internacional de Gastos Municipales}

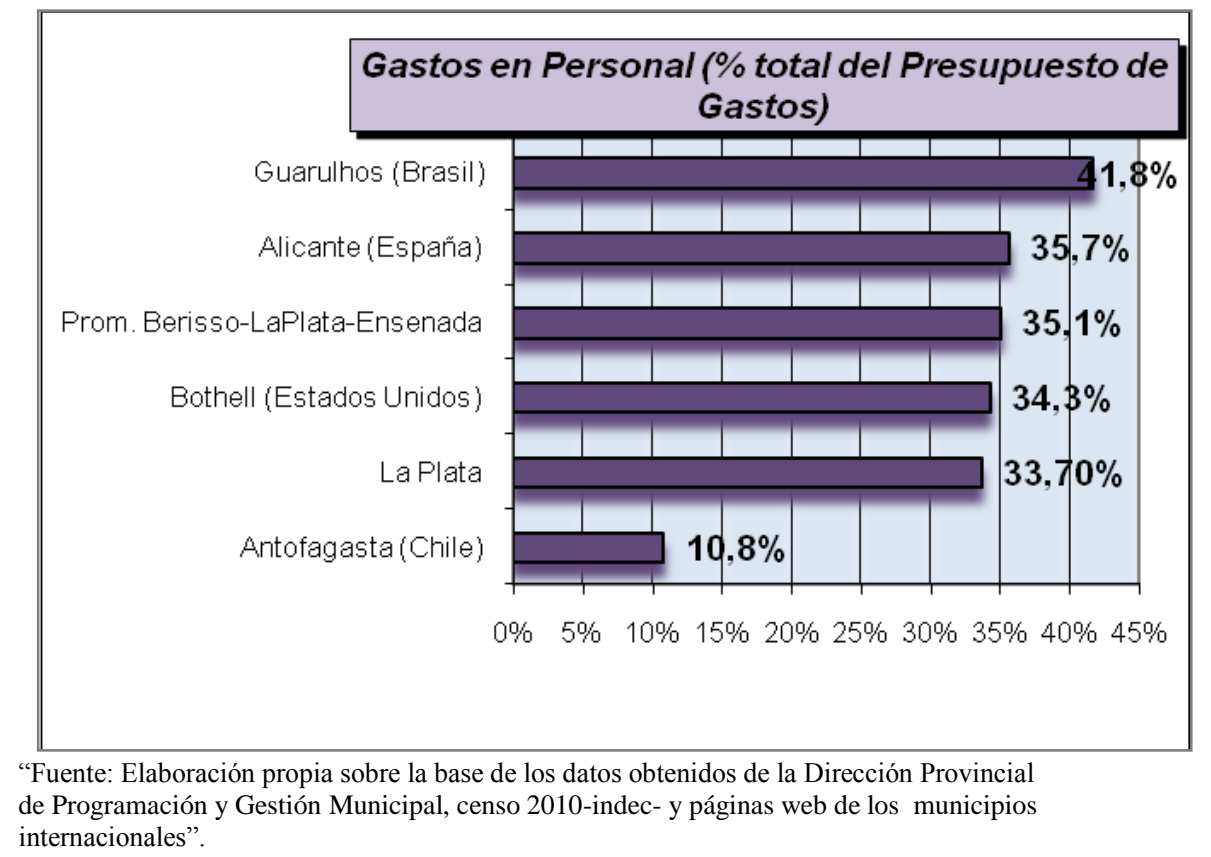


El gasto en personal del municipio de La Plata se encuentra en un nivel inferior respecto de la región, similar respecto de Bothell. Se destaca el bajo porcentaje de participación del municipio de Antofagasta (Chile).

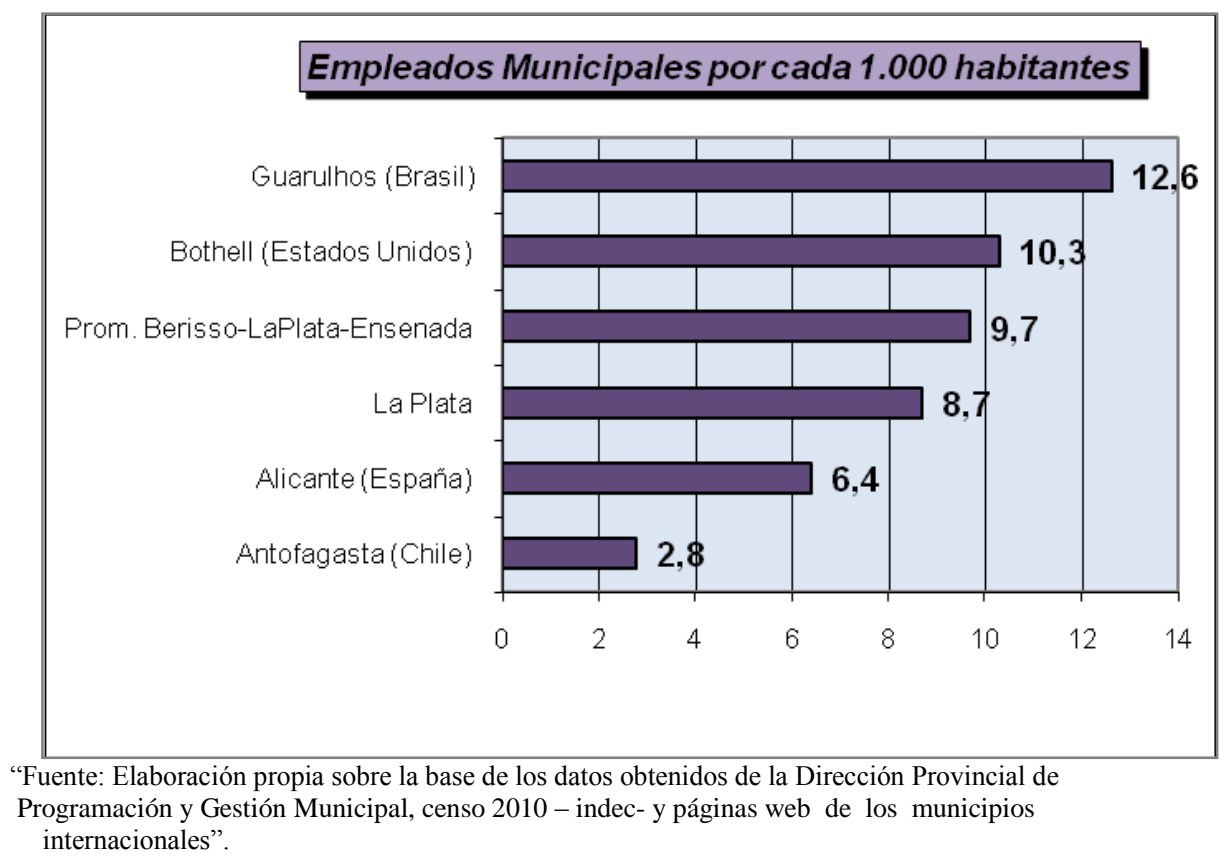

El Municipio de La Plata comparativamente con la Región y con la selección de municipios extranjeros presenta un número levemente inferior de empleados municipales cada 1000 habitantes. Presentando el número más bajo en dicha relación el municipio de Antofagasta (Chile).

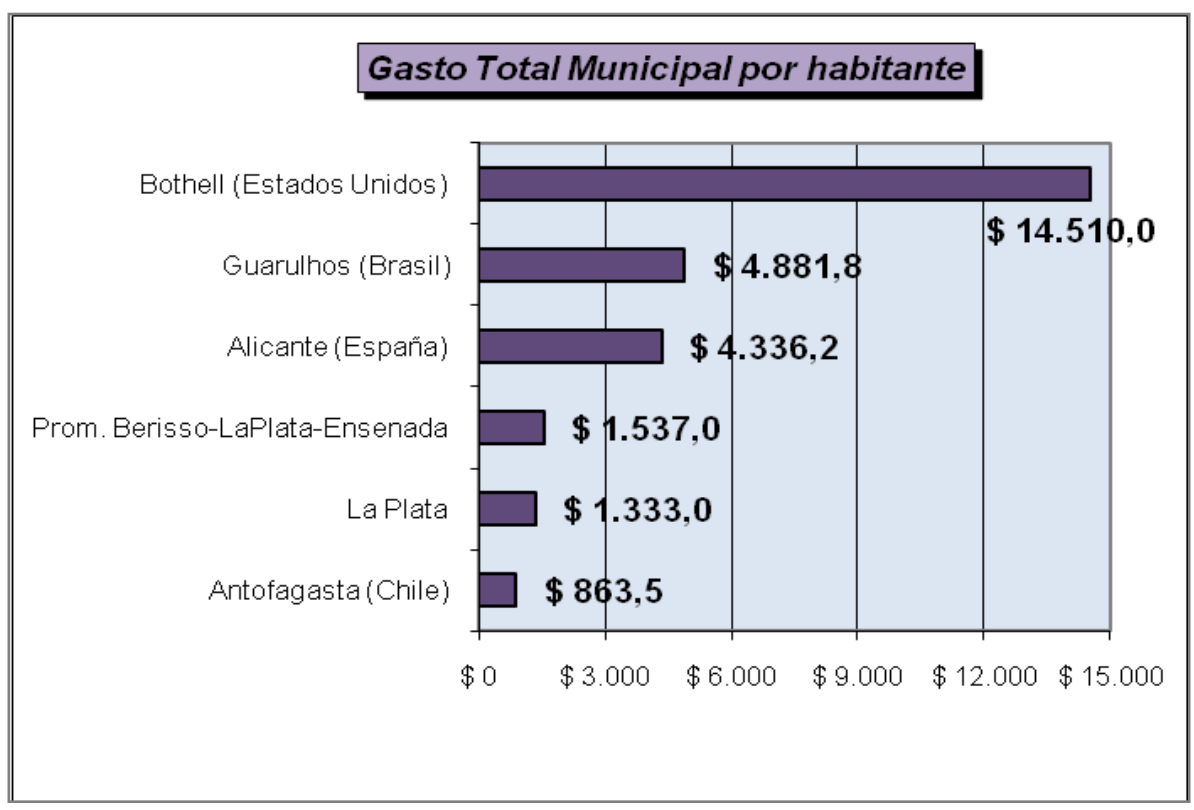

"Fuente: Elaboración propia sobre la base de los datos obtenidos de la Dirección Provincial de Programación y Gestión Municipal, censo 2010 - indec- y páginas web de los municipios internacionales". 


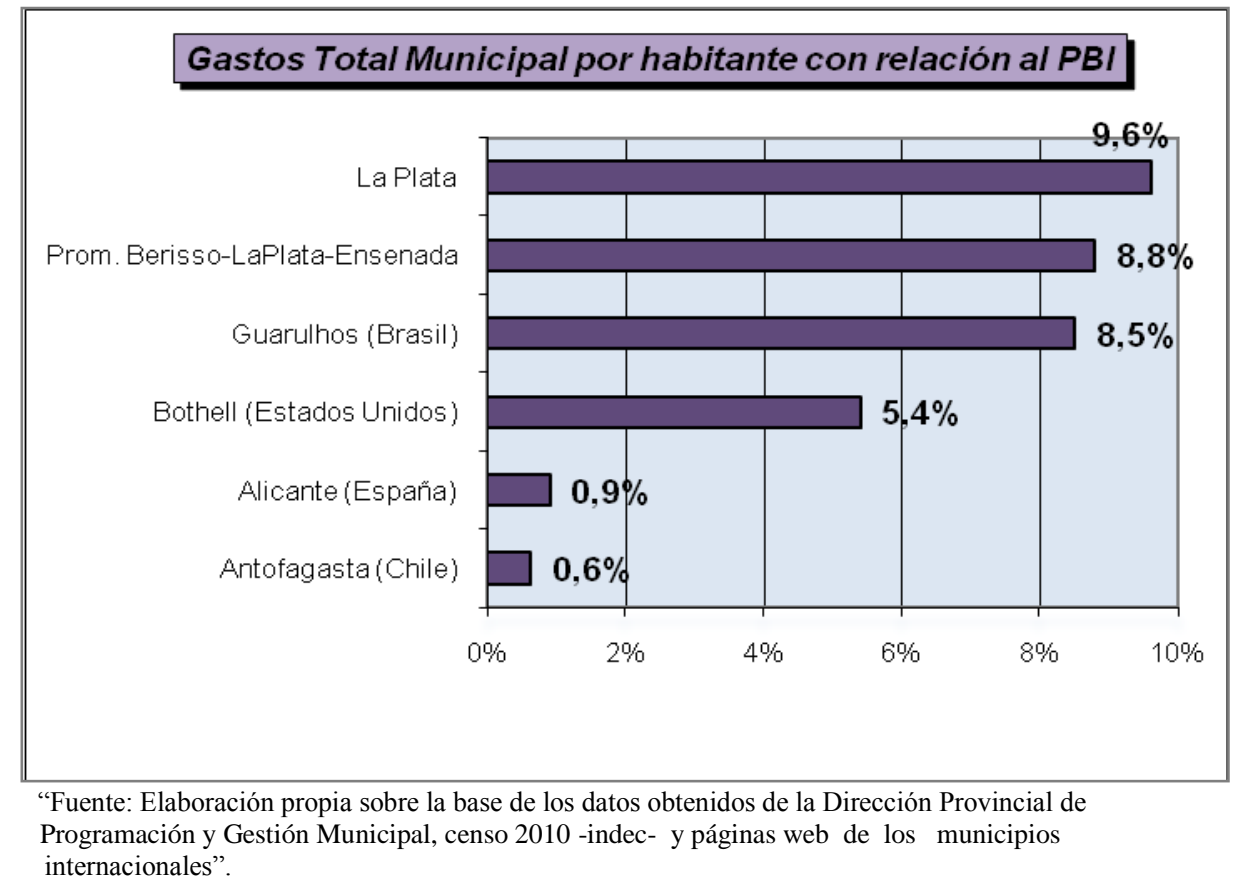

Comparativamente, en las ciudades de países extranjeros el Gasto total municipal por habitante es superior al de La Plata, a excepción de Antofagasta (Chile). Si se realiza el análisis en cuanto a la relación de dicho Gasto total municipal por habitante con relación al PBI, La Plata participa en un porcentaje mucho mayor que los municipios extranjeros y que la propia región de LP, B y E.

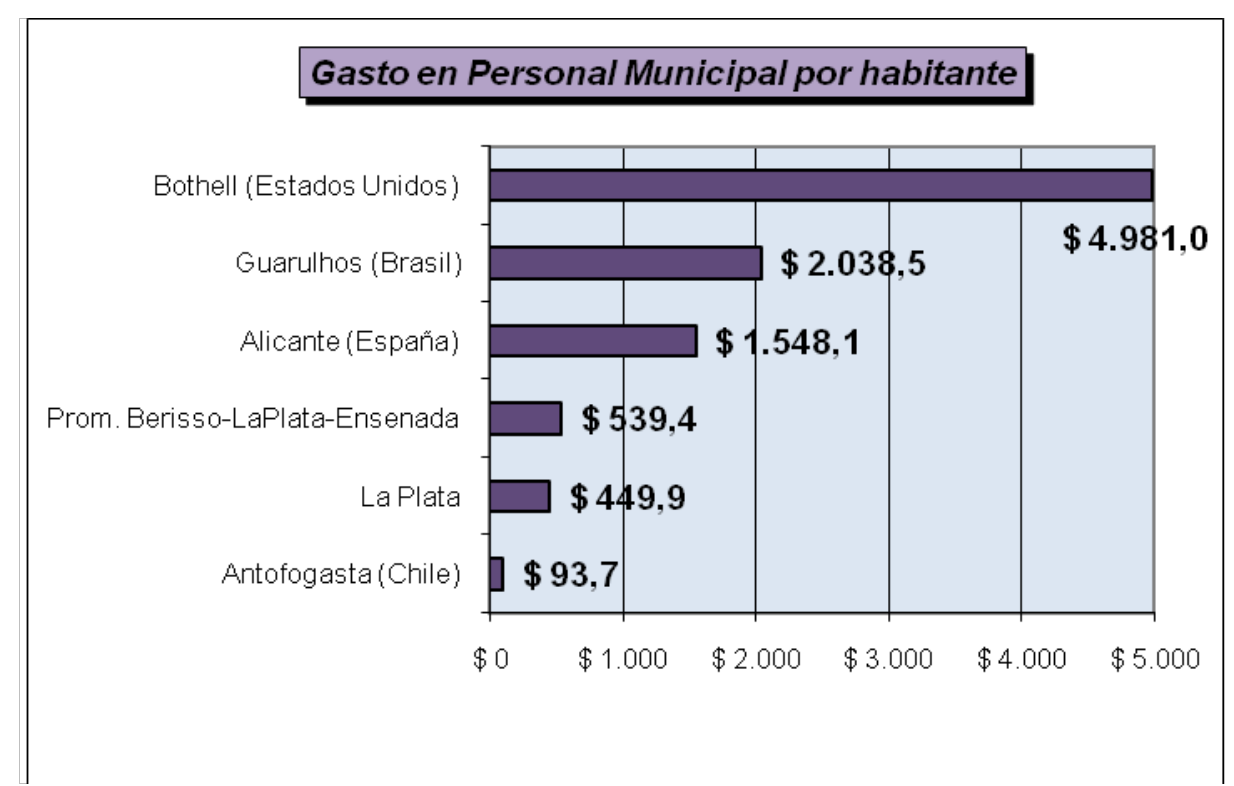

"Fuente: Elaboración propia sobre la base de los datos obtenidos de la Dirección Provincial de Programación y Gestión Municipal, censo 2010 indec- y páginas web de los municipios internacionales”. 


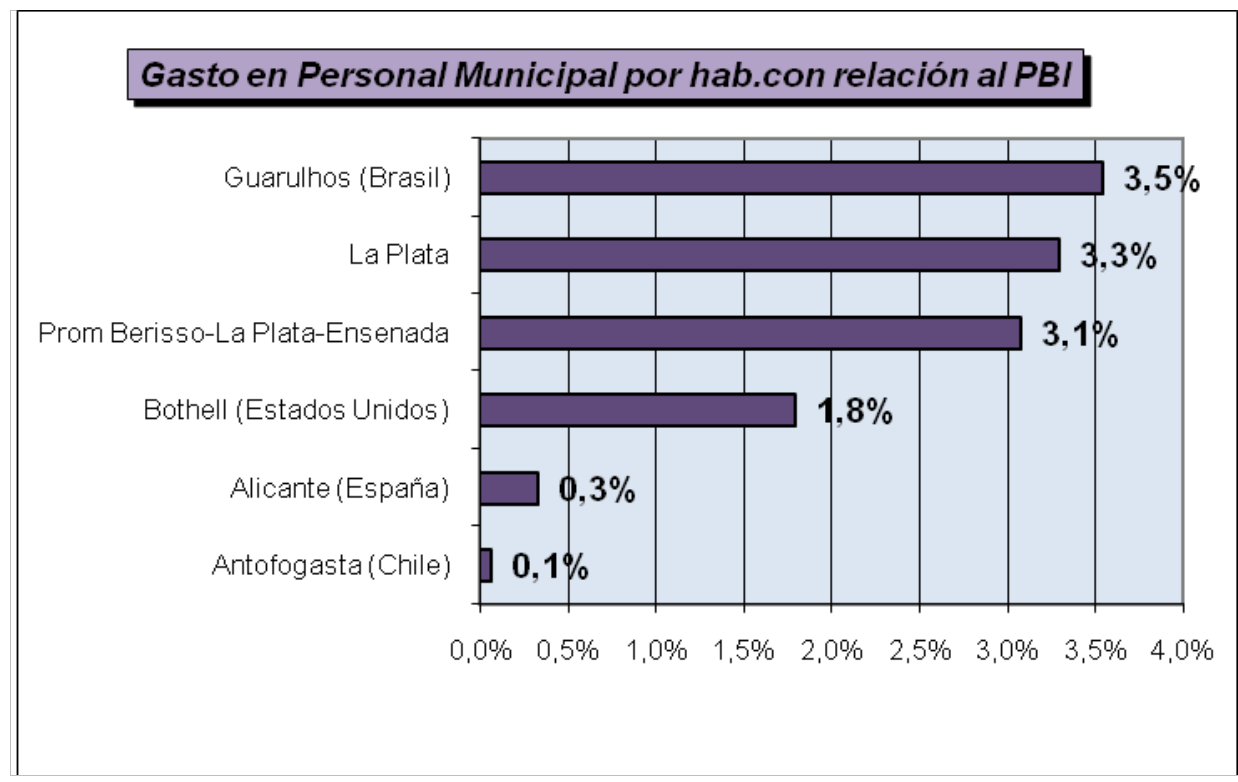

"Fuente: Elaboración propia sobre la base de los datos obtenidos de la Dirección Provincial de Programación y Gestión Municipal, censo 2010 indec- y páginas web de los municipios internacionales”.

Si bien comparativamente, en los municipios extranjeros analizados gastan mucho más presupuesto en sueldos al personal que en La Plata, a excepción de Antofagasta (Chile), si se relaciona dicho gasto en personal por habitante con relación al PBI, La Plata participa en un porcentaje mucho mayor que los municipios extranjeros y que la propia región de LP, B y E, a excepción de Guarulhos (Brasil).

\section{Conclusiones}

Se pudo observar particularmente que:

- De la información presupuestaria de Recursos y Gastos del Municipio de La Plata, surge que:

Respecto del total de Ingresos del municipio la mayor parte corresponden a Ingresos Corrientes, los que en promedio representan un 95.5\% y los Ingresos de Capital, representan, en promedio, un 4,5\%.

La composiciòn de los Recursos Corrientes para el período bajo análisis esta dada mayormente por los Ingresos no Tributarios que representan un $52 \%$, los Ingresos Tributarios un 39\% y $9 \%$ corresponden a Otros Recursos corrientes. 
Debe destacarse que los Ingresos No tributarios, dentro de la composición de los Recursos Corrientes, posiciona al municipio dentro de una escala de cierta autonomía por encima de otros municipios $15^{*}$, dado que sus mayores recursos son de Tasas, Derechos y Contribuciones.

En relación a los Recursos de Capital, se observa que en un gran porcentaje se compone de la fuente "Otros Recursos de Capital" (el que involucra los conceptos Transferencia de Capital, endeudamiento público, obtención de préstamos, etc.) y en menor porcentaje de Recursos Propios de capital.

Respecto de los Gastos, como rasgo principal, se observa en la estructura presupuestaria de gastos que la mayor proporción son corrientes, quedando muy poco margen de gastos de capital, siendo estos ùltimos gastos los que podrìan activar la economía productiva.

La composición de los Gastos Corrientes del municipio, esta dada casi en igual proporción entre los servicios no personales y los gastos en personal, destinándose muy poco a bienes de consumo.

Respecto de los Intereses y Gastos de la deuda se puede observar que la participación dentro de los Gastos Financieros ha ido disminuyendo en los períodos analizados.

La Relación Ingresos Corrientes/Gastos Corrientes, indica que los Ingresos Corrientes superan a los Gastos Corrientes, en los 5 años analizados, y dicho parámetro podría indicar que el municipio presenta cierta autonomía toda vez que no tendría que recurrir al endeudamiento o los ingresos de capital para la financiación de los mismos.

Respecto de la Relación Ingresos Corrientes-Ingresos No tributarios/ Gastos Corrientes, se observa que los recursos de origen municipal, resultan

15Según el estudio realizado por el Instituto de Análisis Fiscal (IARAF) en el año 2010, los Municipios Argentinos se financiaban en promedio con un $35 \%$ de recursos corrientes- no tributarios, es decir recursos propios. 
insuficientes para cubrir la totalidad de los gastos corrientes, lo que implica que el gobierno municipal no puede financiar la totalidad de gastos con recursos propios y que son necesarias transferencias compensatoria de los niveles superiores. Esto mostraría falta de independencia o autonomía.

Por otra parte, la Relación Ingresos corrientes-Ingresos No tributarios/ Gasto en Personal, muestra que los ingresos de origen municipal, cubren ampliamente los gastos en personal del municipio y, a su vez, dicha relación ha ido aumentando con el transcurso de los años analizados, posibilitándole al municipio, un margen de maniobra importante para la toma de decisiones de gestión pública estrictamente financiera.

Finalmente, se puede determinar que el municipio, cubre todos sus gastos, que si bien depende de la coparticipación de los organismos superiores, no es en un porcentaje excesivo, y que llega a cubrir ampliamente su gasto en personal, lo que implicaría un buen indicio, dado que no se encuentra ligado a presiones políticas de niveles superiores.

- Del análisis de la información presupuestaria de Recursos y Gastos de la Región LP-B y E y en comparación con el municipio de La Plata, se pudo observar que:

El municipio de la Plata, tiene un amplio porcentaje de participación en La Región, participando en un $72 \%$ de los ingresos de la región y respecto de los gastos en un $71 \%$.

Así se puede observar que en la composición de los Ingresos Corrientes la región sigue la misma tendencia que el Municipio de La Plata, dado que la mitad de los Ingresos Corrientes de la región son no tributarios, y los ingresos tributarios representan un $43 \%$, y en una menor proporción corresponden a Otros Recursos corrientes.

En relación a los gastos, La Región no sigue la misma tendencia que el municipio de La Plata, dado que su mayor gasto es en personal, luego servicios 
no personales y por ùltimo con una menor participación los Bienes de consumo.

Esto implicaría que, dado el amplio porcentaje de participación que tiene el municipio de La Plata, en cuanto a los gastos en la región, y siendo que La Región no sigue la misma tendencia, podria concluirse que los municipios de Berisso y Ensenada, gastan un amplio porcentaje de sus gastos en personal, lo que implica respecto de la región cierta ineficiencia.

Respecto del análisis efectuado del Gasto en personal a nivel regional se puede observar que:

El gasto en personal promedio mensual por empleado de La Plata es $\$$ 4.331,00 siendo levemente inferior al de la Región el cual es de \$4.640,00.

En cuanto a la relación empleados habitantes, La Plata tiene 9 empleados por cada 1.000 habitantes y la Región 10 empleados.

Cabe destacar que la cantidad de personal por habitante con la que cuenta un municipio, puede estar asociada con una mayor prestación de servicios a la comunidad o con una política ocupacional más activa por parte del municipio, lo cual, en este último caso, es una decisión política que poco tiene que ver con una administración eficiente.

- Comparación internacional:

Del análisis del Gasto en Personal en relación al Presupuesto de Gastos el municipio de La Plata, se encuentra entre los que menos gasta (33,7\%), a excepción de Antofagasta (chile).

Asimismo y en relación a la cantidad de empleados por cada 1.000 habitantes, La Plata se encuentra entre los tres de más baja cantidad de empleados junto con Antofagasta ( 3 empleados por cada 1.000 hab.) y Alicante (6 empleados por cada 1.000 hab.). 
El Gasto Total Municipal por habitante de La Plata se encuentra en uno de los escalones inferiores, $\$ 1.333,00$, siendo Bothell el de mayor gasto por habitante $\$ 14.510,00$. Ahora bien, si se realiza el mismo análisis en cuanto a la relación del Gasto Total por habitante con relación al PBI, La Plata es el que más gasta $(9,6 \%)$ y Bothell está entre los que menos gasta $(5,4 \%)$.

El mismo análisis puede realizarse respecto del gasto del personal por habitante; siendo el municipio de La Plata uno de los que menos gasta en personal en relación por habitante (\$449),en comparación con las demás ciudades seleccionadas para el análisis, (Alicante $\$ 1.548$, Guarulhos $\$$ 2.039 , Bothell \$ 4.981) sin embargo al comparar el gasto en personal por habitante con relación al $\mathrm{PBI}$, el municipio de La Plata, tiene el mayor porcentaje de gasto $(3,3 \%)$, a excepción de Guarulhos (3,5\%).

En lo atinente a los ratios de Gasto total y de Gasto en Personal respecto del PBI, el Municipio de La Plata se halla en los niveles más altos en la comparación internacional. Dado que se utilizó como estimador aproximado el Valor Bruto de Producción (VBP) y no el Producto Bruto Geográfico (PBG), la relación se tornaría aún más desventajosa si se usara el indicador pertinente, toda vez que el Producto Bruto Geográfico es menor que el Valor Bruto Producción. Esto muestra que la presión tributaria local impacta notoriamente en el contribuyente en una mayor medida que lo hace en relación a lo que se comparó internacionalmente.

Adicionalmente tampoco justificaría el mayor esfuerzo requerido a los contribuyentes, esta mayor presión tributaria en relación a la riqueza localmente generada, toda vez que las erogaciones son mayoritariamente destinadas a gastos corrientes.

Así, la presión tributaria, altera el comportamiento de los consumidores, productores o trabajadores, de tal forma que se reduce la eficiencia económica, desincentivando la actividad económica. 


\section{Bibliografía}

Amat Oriol y Soldevila Pilar (1998) "Contabilidad y gestión de costes" Ediciones Gestión 2000, Barcelona.

Asociación Española de Contabilidad y Administración de Empresas (AECA) (1997) "Indicadores de gestión para las entidades públicas" (Doc. 16 año 1997, ponentes: Ferrán Termes, Oriol Amat y Carlos Vivas).

Chiavenato Aldalberto (2004) "Introducción a la Teoría General de la Administración", Séptima Edición, de, McGraw-Hill Interamericana.

Dornbusch Rudiger, Fischer Stanley y StartzRichard (2004), "Macroeconomía" 9ํㅡㄹición, Mc Graw Hill, Colombia.

Duverger Maurice (1960), "Instituciones Financieras”, Edit. Bosch, Barcelona.

Ferrán Termes, Oriol Amat y Carlos Vivas (1997), “Indicadores de gestión para las entidades públicas" - Asociación Española de Contabilidad y Administración de Empresas (AECA).

Ferrucci Ricardo Jorge (2002), "Instrumental para el estudio de la economía argentina". 9 Edición, Ediciones Macchi, Buenos Aires.

Gelli María Angèlica (2006), Constitución de la Nación Argentina. Tercera edición ampliada y actualizada. La Ley, Buenos Aires.

Koontz Harold y Weihrich Heinz (2004), "Administración Una Perspectiva Global", 12a. Edición, McGraw-Hill Interamericana.

Legislación Municipal de la provincia de Buenos Aires y Leyes complementarias (2007), Editorial Lex, Buenos Aires.

Porter Michael E. (1991), "La Ventaja Competitiva de las Naciones", Vergara, Buenos Aires. 
Porto Alberto (2002) - Microeconomía y Federalismo Fiscal. Edulp. UNLP

Porto Alberto (2004) - Finanzas Públicas Locales en la Argentina. Documento de Trabajo Nro. 57. http://www.depeco.econo.unlp.edu.ar/doctrab/doc57.pdf

Rico Rubén Roberto (1998), "Calidad Estratégica Total: Diseño, implementación y gestión del cambio estratégico" $1^{\circ}$ Edición, Ediciones Macchi Buenos Aires.

Samuelson Paul y Nordhaus William (2002), "Economía", Decimo séptima Edición, McGraw Hill Interamericana de España.

Torga Pascual Alberto y Versino Elsa Irene (2012), "Información Contable de la Administración Pública para el usuario Ciudadano"- XXXIII jornadas universitarias nacionales de contabilidad.

Torga Pascual Alberto y Versino Elsa Irene (2013), "El mecanismo de seguimiento de implementación de la convención interamericana contra la corrupción" (MESESIC), 19ำ Encuentro Nacional de investigadores universitarios del área contable 9ำ Simposio regional de investigación contable.

\section{Páginas Web consultadas:}

http://www.depeco.econo.unlp.edu.ar/mfinpub/estufp12.pdf.

Trapé Alejandro, Botteón Claudia y Molina, Raúl, "Autonomía financiera municipal: Aspectos metodológicos y aplicación al caso de los municipios de la provincia de Mendoza".

www.depeco.econo.unlp.edu.ar/doctrab/doc57.pdf.

Porto Alberto (octubre 2004), "Finanzas Públicas Locales en la Argentina", Trabajo Nro. 57.

http://www.econo.unlp.edu.ar/articulo/2011/11/8/presentacion_del_informe_car acterizacion_productiva_regional_2010-

Trabajo "Caracterización Productiva Regional, La Plata - Berisso - Ensenada", año 2010, MBA - FCE - UNLP. 
http://www.ec.gba.gov.ar/areas/Sub_Politica_Coord_Eco/CoordMunicipal/munic ipios.

http://www.eumed.net/rev/cccss/0712/mar.htm

Mariano A. Ricciardi (2008) Artículo: El rol del estado y el dilema entre eficiencia y equidad.

http://www.gordillo.com/articulos/art.9

Gordillo Agustín (1998) Artículo: "Un corte transversal al derecho administrativo: la Convención Interamericana Contra la Corrupción”.

http://municipios.unq.edu.ar/modules/mislibros/archivos/gdfgd.pdf

García Delgado Daniel (1997), "Hacia un nuevo modelo de gestión local. Municipio y Sociedad civil argentina" FLACSO- Oficina de Publicaciones del Ciclo Básico Común de la Universidad de Buenos Aires y Universidad Católica de Córdoba.

http://www.iaraf.org.

Argañaráz Nadín, Devalle Sofía y D'Angelo Mariano, "Una constelación de tasas municipales en Argentina: Existen más de 130 tipos de tasas diferentes Informe Económico № 153.

www.alicante.es/

www.bcra.gov.ar

www.bilbao.net

www.ci.bothell.wa.us

www.censo2010.indec.gov.ar

www.ensenada.gov.ar

www.elnortero.cl/noticia/economia/infografia-revisa-la-deuda-municipal-de-las-

capitales-regionales-de-chile

www.gba.gov.ar

www.gob.gba.gov.ar/cdi/inicio.html

www.guarulhosweb.com.br/noticia.php?nr=44765 
www.htc.gba.gov.ar

www.ine.cl

www.infoleg.gov.ar

www.laplata.gov.ar

www.mecon.gov.ar

www.valencia.es/ayuntamiento/ayuntamiento

www2.berisso.gba.gov.ar 


\section{Referencias y Anexos}

\begin{tabular}{|c|c|}
\hline CALCULO DE RECURSOS & $\begin{array}{l}\text { La Plata } \\
2007\end{array}$ \\
\hline RECURSOS CORRIENTES & 311.325.213 \\
\hline 1.1. INGRESOS TRIBUTARIOS & 124.102.927 \\
\hline LEY 10.559 & 97.893 .914 \\
\hline OTROS TRIBUTARIOS & 26.209 .013 \\
\hline 1.2. INGRESOS NO TRIBUTARIOS & 165.308 .801 \\
\hline TASAS & 142.979 .151 \\
\hline DERECHOS & 12.684 .914 \\
\hline OTROS INGRESOS NO TRIBUTARIOS & 9.644 .736 \\
\hline OTROS RECURSOS CORRIENTES & 21.913 .484 \\
\hline 1.4. VENTA DE BIENES Y SERVICIOS & 0 \\
\hline 1.5. INGRESOS DE LA OPERACIÓN & 0 \\
\hline 1.6. RENTAS DE LA PROPIEDAD & 329.869 \\
\hline 1.7 TRANSFERENCIAS CORRIENTES & 21.583 .616 \\
\hline RECURSOS DE CAPITAL & 10.661.237 \\
\hline 2. RECURSOS PROPIOS DE CAPITAL & 2.417.206 \\
\hline VENTA DE ACTIVOS & 0 \\
\hline CONTRIBUCIÓN DE MEJORAS & 2.417 .206 \\
\hline 3. OTROS RECURSOS DE CAPITAL & 8.244 .031 \\
\hline TRANSFERENCIAS DE CAPITAL & 1.779 .139 \\
\hline VENTA DE TÍT. Y VAL., ACC Y PART. K & 0 \\
\hline RECUPERACIÓN DE PRÉSTAMOS & 6.464 .892 \\
\hline $\begin{array}{l}\text { DISMINUC. OTROS ACTIVOS } \\
\text { FINANCIEROS }\end{array}$ & 0 \\
\hline ENDEUDAMIENTO PÚBLICO & 0 \\
\hline OBTENCIÓN DE PRÉSTAMOS & 0 \\
\hline INCREMENTO DE OTROS PASIVOS & 0 \\
\hline INCREMENTO DEL PATRIMONIO & 0 \\
\hline 4. CONTRIBUCIONES FIGURATIVAS & \\
\hline CONTRIBUCIONES FIGURATIVAS & 3.012 .466 \\
\hline TOTAL GENERAL & 324.998 .916 \\
\hline
\end{tabular}




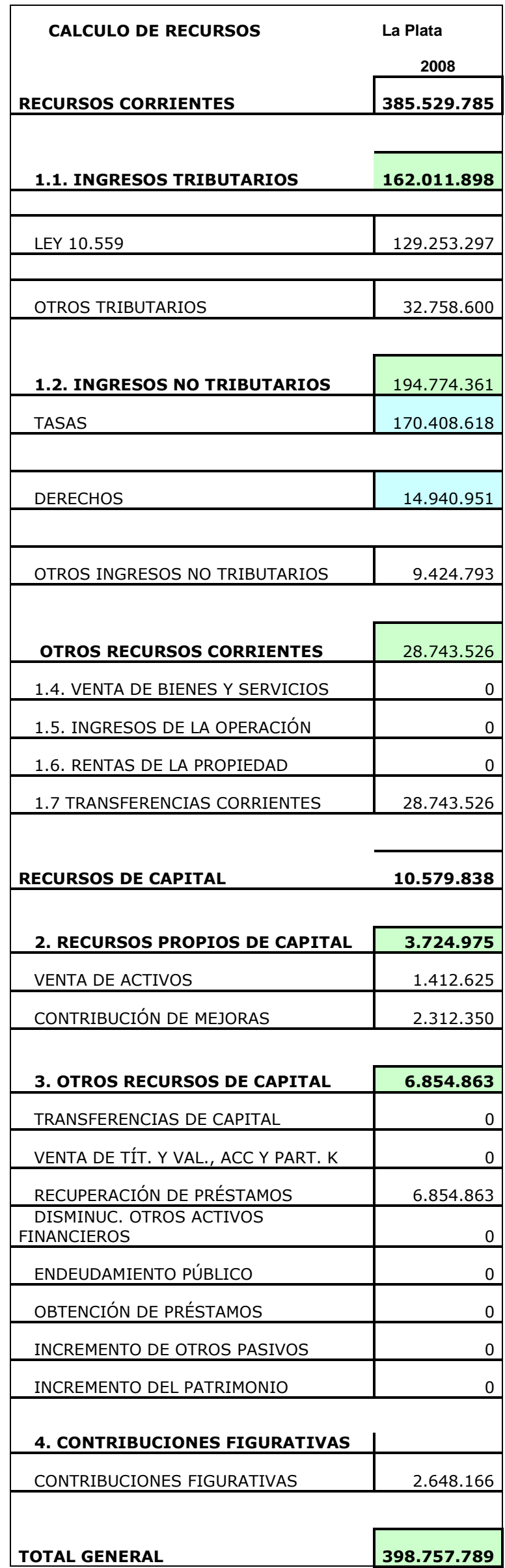




\begin{tabular}{|c|c|}
\hline CALCULO DE RECURSOS & $\begin{array}{l}\text { La Plata } \\
2009\end{array}$ \\
\hline RECURSOS CORRIENTES & 527.021 .863 \\
\hline 1.1. INGRESOS TRIBUTARIOS & 174.607 .714 \\
\hline LEY 10.559 & 144.496 .306 \\
\hline OTROS TRIBUTARIOS & 30.111 .408 \\
\hline 1.2. INGRESOS NO TRIBUTARIOS & 263.290 .038 \\
\hline TASAS & 185.357 .581 \\
\hline DERECHOS & 40.825 .098 \\
\hline OTROS INGRESOS NO TRIBUTARIOS & 37.107 .359 \\
\hline OTROS RECURSOS CORRIENTES & 89.124 .111 \\
\hline 1.4. VENTA DE BIENES Y SERVICIOS & 6.822 \\
\hline 1.5. INGRESOS DE LA OPERACIÓN & 0 \\
\hline 1.6. RENTAS DE LA PROPIEDAD & 243.438 \\
\hline 1.7 TRANSFERENCIAS CORRIENTES & 88.873 .851 \\
\hline RECURSOS DE CAPITAL & 38.299 .027 \\
\hline 2. RECURSOS PROPIOS DE CAPITAL & 2.670 .589 \\
\hline VENTA DE ACTIVOS & 39.037 \\
\hline CONTRIBUCIÓN DE MEJORAS & 2.631 .552 \\
\hline 3. OTROS RECURSOS DE CAPITAL & 35.628 .438 \\
\hline TRANSFERENCIAS DE CAPITAL & 24.988 .211 \\
\hline VENTA DE TÍT. Y VAL., ACC Y PART. K & 0 \\
\hline RECUPERACIÓN DE PRÉSTAMOS & 5.040 .227 \\
\hline $\begin{array}{l}\text { DISMINUC. OTROS ACTIVOS } \\
\text { FINANCIEROS }\end{array}$ & 5.600 .000 \\
\hline ENDEUDAMIENTO PÚBLICO & 0 \\
\hline OBTENCIÓN DE PRÉSTAMOS & 0 \\
\hline INCREMENTO DE OTROS PASIVOS & 0 \\
\hline INCREMENTO DEL PATRIMONIO & 0 \\
\hline 4. CONTRIBUCIONES FIGURATIVAS & \\
\hline CONTRIBUCIONES FIGURATIVAS & 3.735 .174 \\
\hline TOTAL GENERAL & 569.056 .064 \\
\hline
\end{tabular}




\begin{tabular}{|c|c|}
\hline CALCULO DE RECURSOS & $\begin{array}{l}\text { La Plata } \\
2010\end{array}$ \\
\hline RECURSOS CORRIENTES & 622.385 .755 \\
\hline 1.1. INGRESOS TRIBUTARIOS & 228.271.981 \\
\hline LEY 10.559 & 183.940 .879 \\
\hline OTROS TRIBUTARIOS & 44.331 .102 \\
\hline 1.2. INGRESOS NO TRIBUTARIOS & 322.696 .289 \\
\hline TASAS & 237.063 .616 \\
\hline DERECHOS & 51.659 .481 \\
\hline OTROS INGRESOS NO TRIBUTARIOS & 33.973 .192 \\
\hline OTROS RECURSOS CORRIENTES & 71.417 .486 \\
\hline 1.4. VENTA DE BIENES Y SERVICIOS & 37.555 \\
\hline 1.5. INGRESOS DE LA OPERACIÓN & 0 \\
\hline 1.6. RENTAS DE LA PROPIEDAD & 127.004 \\
\hline 1.7 TRANSFERENCIAS CORRIENTES & 71.252 .927 \\
\hline RECURSOS DE CAPITAL & 28.981 .168 \\
\hline 2. RECURSOS PROPIOS DE CAPITAL & 2.530 .941 \\
\hline VENTA DE ACTIVOS & 47.648 \\
\hline CONTRIBUCIÓN DE MEJORAS & 2.483 .293 \\
\hline 3. OTROS RECURSOS DE CAPITAL & 26.450 .227 \\
\hline TRANSFERENCIAS DE CAPITAL & 183.523 \\
\hline VENTA DE TÍT. Y VAL., ACC Y PART. K & 0 \\
\hline RECUPERACIÓN DE PRÉSTAMOS & 8.256 .704 \\
\hline $\begin{array}{l}\text { DISMINUC. OTROS ACTIVOS } \\
\text { FINANCIEROS }\end{array}$ & 18.010 .000 \\
\hline ENDEUDAMIENTO PÚBLICO & 0 \\
\hline OBTENCIÓN DE PRÉSTAMOS & 0 \\
\hline INCREMENTO DE OTROS PASIVOS & 0 \\
\hline INCREMENTO DEL PATRIMONIO & 0 \\
\hline 4. CONTRIBUCIONES FIGURATIVAS & \\
\hline CONTRIBUCIONES FIGURATIVAS & 5.320 .396 \\
\hline TOTAL GENERAL & 656.687 .319 \\
\hline
\end{tabular}




\begin{tabular}{|c|c|}
\hline CALCULO DE RECURSOS & $\begin{array}{l}\text { La Plata } \\
2011 \\
\end{array}$ \\
\hline RECURSOS CORRIENTES & 801.963 .331 \\
\hline 1.1. INGRESOS TRIBUTARIOS & 348.686.537 \\
\hline LEY 10.559 & 266.301 .971 \\
\hline OTROS TRIBUTARIOS & 82.384 .566 \\
\hline 1.2. INGRESOS NO TRIBUTARIOS & 423.329 .688 \\
\hline TASAS & 314.534 .817 \\
\hline DERECHOS & 63.757 .192 \\
\hline OTROS INGRESOS NO TRIBUTARIOS & 45.037 .679 \\
\hline OTROS RECURSOS CORRIENTES & 29.947 .106 \\
\hline 1.4. VENTA DE BIENES Y SERVICIOS & 58.364 \\
\hline 1.5. INGRESOS DE LA OPERACIÓN & 0 \\
\hline 1.6. RENTAS DE LA PROPIEDAD & $\underline{0}$ \\
\hline 1.7 TRANSFERENCIAS CORRIENTES & 29.888 .742 \\
\hline RECURSOS DE CAPITAL & 45.973 .405 \\
\hline 2. RECURSOS PROPIOS DE CAPITAL & 1.921 .022 \\
\hline VENTA DE ACTIVOS & 68.911 \\
\hline CONTRIBUCIÓN DE MEJORAS & 1.852 .111 \\
\hline 3. OTROS RECURSOS DE CAPITAL & 44.052.383 \\
\hline TRANSFERENCIAS DE CAPITAL & 16.320 .571 \\
\hline VENTA DE TÍT. Y VAL., ACC Y PART. K & 0 \\
\hline RECUPERACIÓN DE PRÉSTAMOS & 7.580 .137 \\
\hline $\begin{array}{l}\text { DISMINUC. OTROS ACTIVOS } \\
\text { FINANCIEROS }\end{array}$ & 20.151 .675 \\
\hline ENDEUDAMIENTO PÚBLICO & 0 \\
\hline OBTENCIÓN DE PRÉSTAMOS & 0 \\
\hline INCREMENTO DE OTROS PASIVOS & 0 \\
\hline INCREMENTO DEL PATRIMONIO & 0 \\
\hline 4. CONTRIBUCIONES FIGURATIVAS & \\
\hline CONTRIBUCIONES FIGURATIVAS & 4.293 .308 \\
\hline TOTAL GENERAL & 852.230 .044 \\
\hline
\end{tabular}




\begin{tabular}{ll} 
CALCULO DE GASTOS & \multicolumn{1}{c}{$\mathbf{2 0 0 7}$} \\
MUNICIPALIDAD DE LA PLATA & 125.644 .885 \\
Personal & 10.339 .004 \\
Bienes de Consumo & 127.643 .108 \\
Servicios no Personales & 263.626 .996 \\
\hline Total Gastos Corrientes & 6.870 .460 \\
\hline Bs. de Uso: Otros bienes & 24.059 .625 \\
Bs. de Uso: Construcciones & 30.930 .085 \\
\hline Total de Gastos de Capital & 4.138 .898 \\
Transferencias & 301.784 \\
Activos Financieros & 7.594 .385 \\
Intereses y Gastos de la deuda & 14.422 .049 \\
Amortización de la deuda & 26.457 .116 \\
Total de gastos Financieros & 48.835 \\
Otros gastos & - \\
\hline Disminución de Deuda Flotante & 321.063 .032 \\
\hline Total
\end{tabular}

\section{CALCULO DE GASTOS \\ MUNICIPALIDAD DE LA PLATA}

2008

Personal

148.795 .729

Bienes de Consumo

13.873.341

Servicios no Personales

158.678 .440

Total Gastos Corrientes

Bs. de Uso: Otros bienes

4.357 .983

Bs. de Uso: Construcciones

26.303 .744

Total de Gastos de Capital

30.661 .727

Transferencias

8.124 .548

Activos Financieros

3.520 .568

Intereses y Gastos de la deuda

5.556 .019

Amortización de la deuda

25.219 .593

Total de gastos Financieros

42.420 .728

Otros gastos 46.467

Disminución de Deuda Flotante

Total

394.476 .432

\section{CALCULO DE GASTOS MUNICIPALIDAD DE LA PLATA}

2009

Personal

Bienes de Consumo

26.477 .429

Servicios no Personales 198.382.359

Total Gastos Corrientes 410.282 .795

Bs. de Uso: Otros bienes

5.535 .105

Bs. de Uso: Construcciones

79.349 .572

Total de Gastos de Capital 84.884 .677

Transferencias

9.213 .179

Activos Financieros

34.087 .728

Intereses y Gastos de la deuda

6.930 .756

Amortización de la deuda

15.230 .643

Total de gastos Financieros

65.462 .306

Otros gastos

8.695

Disminución de Deuda Flotante 


\begin{tabular}{ll} 
CALCULO DE GASTOS & \multicolumn{1}{c}{$\mathbf{2 0 1 0}$} \\
MUNICIPALIDAD DE LA PLATA & \multicolumn{1}{c}{21.975 .674} \\
Personal & 44.651 .673 \\
Bienes de Consumo & 232.414 .054 \\
Servicios no Personales & 499.041 .401 \\
\hline Total Gastos Corrientes & 12.462 .040 \\
Bs. de Uso: Otros bienes & 58.373 .283 \\
Bs. de Uso: Construcciones & 70.835 .323 \\
\hline Total de Gastos de Capital & 10.862 .299 \\
\hline Transferencias & 20.167 .875 \\
Activos Financieros & 4.822 .721 \\
Intereses y Gastos de la deuda & 57.930 .300 \\
Amortización de la deuda & 93.783 .195 \\
Total de gastos Financieros & 50.572 \\
Otros gastos & 15.486 .625 \\
Disminución de Deuda Flotante & 679.197 .116 \\
\hline Total
\end{tabular}

\begin{tabular}{|c|c|}
\hline $\begin{array}{l}\text { CALCULO DE GASTOS } \\
\text { MUNICIPALIDAD DE LA PLATA }\end{array}$ & 2011 \\
\hline Personal & 221.975 .674 \\
\hline Bienes de Consumo & 44.651 .673 \\
\hline Servicios no Personales & 232.414 .054 \\
\hline Total Gastos Corrientes & 499.041 .401 \\
\hline Bs. de Uso: Otros bienes & 70.835 .323 \\
\hline Bs. de Uso: Construcciones & - \\
\hline Total de Gastos de Capital & 70.835 .323 \\
\hline Transferencias & 10.862 .299 \\
\hline Activos Financieros & 20.167 .875 \\
\hline Intereses y Gastos de la deuda & 78.239 .646 \\
\hline Amortización de la deuda & - \\
\hline Total de gastos Financieros & 109.269 .820 \\
\hline Otros gastos & 50.572 \\
\hline Disminución de Deuda Flotante & 20.791 .969 \\
\hline Total & 699.989 .085 \\
\hline
\end{tabular}

$\left(^{*}\right)$ Para su conversión en pesos se tuvieron en cuenta los siguientes tipos de cambio: 


\begin{tabular}{|c|c|}
\hline $\begin{array}{c}\text { Información: } \\
\text { www.bcra.gov.ar } \\
\mathbf{3 1 / 1 2 / 2 0 1 1}\end{array}$ & $\begin{array}{c}\text { Tipo de } \\
\text { Cambio en } \\
\mathbf{\$}\end{array}$ \\
\hline Dólar & 4,3 \\
\hline Euro & 6,00 \\
\hline Peso chileno & 0,008 \\
\hline Real & 2,3 \\
\hline
\end{tabular}

\begin{tabular}{|l|r|r|r|}
\hline $\begin{array}{c}\text { Datos } \\
\text { expresados } \\
\text { en pesos }\left(^{*}\right)\end{array}$ & $\begin{array}{c}\text { Gasto Total } \\
\text { Municipio pesos }\end{array}$ & $\begin{array}{r}\text { Gasto } \\
\text { en Personal pesos }\end{array}$ & $\begin{array}{r}\text { Cantidad } \\
\text { de Habitantes }\end{array}$ \\
\hline Chile (Antofogasta) & 327.206 .345 & 35.487 .290 & 378.923 \\
\hline Brasil (Guarulhos) & 6.342 .885 .863 & 2.648 .598 .224 & 1.299 .283 \\
\hline España (Alicante) & 1.450 .090 .447 & 517.728 .448 & 334.418 \\
\hline Bothell & 437.468 .945 & 150.187 .691 & 30.150 \\
\hline Región Argentina & 1.229 .017 .223 & 431.285 .300 & 799.523 \\
\hline La Plata & 872.422 .546 & 294.396 .162 & 654.324 \\
\hline Berisso & 214.130 .913 & 77.794 .386 & 88.470 \\
\hline Ensenada & 142.463 .764 & 59.094 .752 & 56.729 \\
\hline & & & \\
\hline
\end{tabular}

\begin{tabular}{|c|c|c|c|c|c|c|}
\hline \multirow[b]{2}{*}{ Municipio } & \multicolumn{5}{|c|}{ Descentralización Tributaria } & \multirow[b]{2}{*}{$\begin{array}{c}\text { Total } \\
\text { Descentralización } \\
\text { Tributaria }\end{array}$} \\
\hline & $\begin{array}{l}\text { Inmob.Rural } \\
\text { Libre Disp. }\end{array}$ & $\begin{array}{l}\text { Inmob.Rural } \\
\text { Fondo Vial }\end{array}$ & $\begin{array}{c}\text { Ingresos } \\
\text { Brutos } \\
\text { Peq. } \\
\text { Contrib. }\end{array}$ & $\begin{array}{c}\text { Embarcaciones } \\
\text { Deportivas }\end{array}$ & $\begin{array}{l}\text { Plan de } \\
\text { Recupero }\end{array}$ & \\
\hline BERISSO & 121.248 & 31.085 & 549.379 & - & - & 701.712 \\
\hline ENSENADA & 6.371 & 43.209 & 681.966 & - & - & 731.547 \\
\hline LA PLATA & 1.027 .430 & 232.734 & 9.117 .094 & - & - & 10.377 .257 \\
\hline TOTAL & 1.155 .049 & 307.027 & 10.348 .439 & - & - & 11.810 .516 \\
\hline Porcentaje & $10 \%$ & $3 \%$ & $88 \%$ & - & - & $100 \%$ \\
\hline
\end{tabular}




\begin{tabular}{|c|c|c|c|c|c|}
\hline Municipio & $\begin{array}{c}\text { Coparticipac. } \\
\text { Bruta }\end{array}$ & $\begin{array}{c}\text { Descentralización } \\
\text { Tributaria }\end{array}$ & $\begin{array}{l}\text { Juegos de } \\
\text { Azar }\end{array}$ & F.F.P.S. & $\begin{array}{c}\text { Tratamiento } \\
\text { y Disp. } \\
\text { Final de } \\
\text { Residuos }\end{array}$ \\
\hline BERISSO & 66.304 .526 & 701.712 & 2.796 .632 & 1.667 .656 & 311.033 \\
\hline ENSENADA & 25.901 .962 & 731.547 & 1.083 .077 & 1.129 .790 & \\
\hline LA PLATA & 266.301 .850 & 10.377 .257 & 8.807 .073 & 10.362 .712 & 2.229 .720 \\
\hline $\begin{array}{l}\text { TOTAL } \\
\text { Porcentaje }\end{array}$ & $\begin{array}{r}358.508 .339 \\
78 \%\end{array}$ & 11.810 .516 & $\begin{array}{r}12.686 .782 \\
3 \%\end{array}$ & $\begin{array}{r}13.160 .157 \\
3 \%\end{array}$ & $\begin{array}{r}2.540 .753 \\
1 \%\end{array}$ \\
\hline
\end{tabular}

\begin{tabular}{|l|r|r|r|r|r|}
\multicolumn{1}{|c|}{ Municipio } & $\begin{array}{c}\text { Fdo. Fort. } \\
\text { Rec. }\end{array}$ & $\begin{array}{c}\text { Fdo. Inclus. } \\
\text { Municip. }\end{array}$ & $\begin{array}{c}\text { Focial } \\
\text { Provincial } \\
\text { Solidario }\end{array}$ & $\begin{array}{c}\text { Fdo. Fort. } \\
\text { Servicios } \\
\text { Municipales }\end{array}$ & Total \\
\hline BERISSO & 3.705 .721 & 2.327 .696 & 3.400 .868 & 684.600 & $\mathbf{8 1 . 9 0 0 . 4 4 3}$ \\
\hline ENSENADA & 1.438 .689 & 1.576 .948 & 1.328 .553 & 416.920 & $\mathbf{3 3 . 6 0 7 . 4 8 6}$ \\
\hline LA PLATA & 14.880 .813 & 14.464 .159 & 13.659 .063 & 3.817 .240 & $\mathbf{3 4 4 . 8 9 9 . 8 8 7}$ \\
\hline TOTAL & 20.025 .222 & 18.368 .803 & 18.388 .484 & 4.918 .760 & 460.407 .816 \\
\hline Porcentaje & $4 \%$ & $4 \%$ & $4 \%$ & $1 \%$ & $100 \%$ \\
\hline
\end{tabular}

\section{Dirección Provincial de Estadística \\ Subsecretaria de Hacienda \\ Ministerio de \\ Economía \\ OBuenos Aires}

\section{Censo Nacional de Población, Hogares y Viviendas 2010}

Resultados definitivos de la provincia de Buenos Aires

Viviendas y población según sexo

\begin{tabular}{|l|r|r|r|r|}
\hline \multicolumn{1}{|c|}{ Partido } & Viviendas & $\begin{array}{c}\text { Población } \\
\text { total }\end{array}$ & Varones & Mujeres \\
\hline & & & & 45.458 \\
\hline Berisso & 29.531 & 88.470 & 43.012 & 28.939 \\
\hline Ensenada & 19.368 & 56.729 & 27.790 & 339.061 \\
\hline
\end{tabular}

Fuente: INDEC. Censo Nacional de Población, Hogares y Viviendas 2010 - Total país y provincias - Resultados Definitivos - Variables seleccionadas, Serie B № 1. 